\title{
On the Roots of the Intrinsic Value of Decision Rights: Experimental Evidence
}

\author{
João V. Ferreira* $\quad$ Nobuyuki Hanaki ${ }^{\dagger} \quad$ Benoît Tarroux ${ }^{\ddagger}$ \\ Published in Games and Economic Behavior, Volume 119, January 2020, \\ https://doi.org/10.1016/j.geb.2019.10.008
}

\begin{abstract}
This paper aims to investigate the motives behind an intrinsic value of decision rights. Based on a series of experimental treatments conducted in France and Japan, we measure how much of such potential value stems from (i) a desire for independence from others, (ii) a desire for power, or (iii) a desire for self-reliance. We find that both Japanese and French subjects attach a significant intrinsic value to hold control. Surprisingly, we find that self-reliance is the only significant motive behind it in both countries.
\end{abstract}

Keywords: Intrinsic value; Decision rights; Independence; Power; Self-reliance; Crosscultural experiment.

JEL classification: C91; D03; D23.

\section{Introduction}

Who holds the control over decisions is an important dimension of many social interactions. In organizations, markets, or civil society, individuals interact by keeping or delegating control over diverse decisions. In economics, the principal-agent dilemma over decision rights is the focus of a prolific literature (e.g. Simon 1951; Hart and Moore 1990; Aghion and Tirole 1997). While most authors have looked at decision rights as instrumental to achieve certain outcomes, holding the control over decisions may be valued for its own sake. Indeed, in a recent experimental study that separates the intrinsic and instrumental values of decision rights based on subjects' revealed preferences, Bartling et al. (2014) provide experimental evidence suggesting that Swiss subjects

\footnotetext{
*University of Southampton, SO17 1BJ Southampton, UK. E-mail: j.ferreira@soton.ac.uk

${ }^{\dagger}$ Institute of Social and Economic Research, Osaka University, Osaka, Japan. E-mail: nobuyuki.hanaki@iser.osaka-u.ac.jp (corresponding author)

¥Univ Lyon, Université Lumière Lyon 2, GATE L-SE UMR 5824, F-69130 Ecully, France. E-mail: tarroux@gate.cnrs.fr
} 
attach an economically meaningful intrinsic value to decide for themselves rather than delegating it to another person.

A natural question that follows — and that was left unanswered by Bartling et al. (2014) — is what are the motivating rationales behind such an intrinsic value of decision rights. One potential underlying reason is a preference for autonomy in the process of choice. If this is the case, decision rights carry an intrinsic value beyond their instrumental value either due to a desire to implement one's decision (a sense of self-reliance) or a desire for independence from the interference of another person. An alternative reason is a desire for power associated with holding the decision right. In this case, the intrinsic value of holding control stems from a desire to affect the payoffs and/or be able to decide on behalf of someone else. ${ }^{1}$

In this paper, we measure the weight of each of these rationales in the intrinsic value of decision rights. We extend the experimental design of Bartling et al. (2014) and implement, both in France and in Japan, a series of treatments that allow us to disentangle how much of the intrinsic value of decision rights stems from (i) the aversion to be affected by the decision made by someone else (independence), (ii) the desire to affect the payoffs and/or decide on behalf of someone else (power), or (iii) the desire to implement one's decision (self-reliance). ${ }^{2}$

All treatments maintain the experimental design of Bartling et al. (2014), which consists of two parts. In the first part of the experiment, a principal has the choice between keeping a decision right or delegating it to an agent. This part is constructed to elicit the principal's point of indifference between keeping and delegating the decision right. In the second part, the monetary values of keeping and delegating control are elicited with a pair of lotteries that are constructed based on the choices made by the principal in the first part.

The treatments vary with respect to the nature of the agent. In the first treatment, which is a replication of the experiment by Bartling et al. (2014), the agent is a human subject. In the second treatment, a bot plays the role of the agent. In this case, a principal who reveals an intrinsic value to hold control is neither motivated by a desire for independence nor a desire for power. The principal cannot be either affected by the decisions or exercise power over another person. This means that in the second treatment the potential intrinsic value of decision rights derives from self-regarding motives such as a desire for self-reliance. In the third treatment, a bot makes the decisions on behalf of a passive human agent. Here, an intrinsic value for holding control can be motivated by a desire for power or self-reliance but not by a desire for independence from the interference of another person. This holds since the principal cannot

\footnotetext{
${ }^{1}$ Independence, self-reliance, and power are related to the concepts of personal autonomy, authority, and control. In particular, independence and self-reliance are constitutive of personal autonomy (Christman 2011, Anderson 2013), and authority exercised over others includes power over and independence from others. Control, as here understood, is about being able to implement one's decisions, and can be motivated by a desire for independence, power, and/or self-reliance.

${ }^{2}$ Collecting data from two countries brings higher confidence in our results. The choice of these two countries also allows us to provide a first test on if the French (linked to Western) and Japanese (linked to Eastern) cultural backgrounds translate into different tastes for holding control.
} 
be affected by a decision made by a human agent, but the principal can hold control over the decisions that affect the passive human agent. The net effects of these treatments give us precise estimates to test the role of the different rationales in the potential intrinsic value of decision rights in this setting.

We find that subjects in both countries assign an economically and statistically significant intrinsic value to hold control over decisions. This result brings support, as a cross-cultural replication, to the main finding of Bartling et al. (2014). In terms of the motives for this preference, our main finding is that a desire for self-reliance is the only positive and statistically significant rationale behind the intrinsic value of decision rights in both France and Japan. This means that, somewhat surprisingly, independence and power are not motivations behind the intrinsic value of holding control in this setting. In other words, the source of the intrinsic value of decision rights in this setting seems not to be linked to the desire to affect or not being affected by another person, as we (Section 3) and Bartling et al. (2014, fn. 21) hypothesized.

By replicating and refining the analysis started by Bartling et al. (2014), we contribute to the literature on organizational behavior and the delegation of authority (e.g. Aghion and Tirole 1997). In particular, we add new evidence to the growing literature on experimental economics on the value of decision rights, autonomy, and power (e.g. Falk and Kosfeld 2006; Fehr et al. 2013; Owens et al. 2014; Burdin et al. 2015; Riener and Wiederhold 2016 Neri and Rommeswinkel 2017; Pikulina and Tergiman 2017; Buffat et al. 2018; Granic and Wagner in press). Bartling et al. (2014) show that underdelegation of decision rights from principals to agents, a result also found in previous experimentally controlled situations (e.g. Fehr et al. 2013; Owens et al. 2014), can be the result of an intrinsic value of holding control. Our results suggest that this underdelegation can be driven by a desire for self-reliance, rather than preferences for independence and power.

Understanding the roots of the intrinsic value of holding control may help the design of optimal allocations of decision rights in organizations. While independence and power are otherregarding motives that can only be present (and satisfied) in the presence of subordinate(s), self-reliance is a self-regarding motive that is present (and satisfied) as long as principals are able to implement their own decisions. This means that, ceteris paribus, an organization can adopt a more horizontal structure if self-reliance is the main root of the intrinsic value of holding control. This is relevant as horizontal-vertical structures and the right to implement decisions can impact the efficiency (and well-being) of principals, agents, and organizations. ${ }^{3}$

Disentangling these motives is also useful to interpret and predict other relevant economic behavior. For example, it sheds light into self-employment and career choices. In particular, our

\footnotetext{
${ }^{3}$ Previous studies suggest that principals' holding authority over agents may undermine the performance of the latter (Falk and Kosfeld 2006), and that the simple fact of choosing may increase satisfaction with one's decision (Botti and McGill 2006), increase cooperation at the group-level (Bó et al. 2010), increase well-being (Ryan and Deci 2006), and have a "pure motivation effect" on effort (Sjöström et al. 2017).
} 
decomposition allows recognizing that the "psychic value" that some individuals attribute to being in control is not necessarily driven by other-regarding motives. Finally, power as an end in itself is seen by many as an "antisocial" desire (see e.g. Skinner 1992). Therefore, a "planner" that is informed about the determinants of this desire is more likely to be able, if they wish so, to contravene it.

Our findings can be contrasted with the ones by Neri and Rommeswinkel (2017), who investigate our main research question with a different experimental design. In their experiment, they highlight independence, power, and "freedom of choice" as potential motives underlying the intrinsic value of holding control. ${ }^{4}$ Their findings suggest that, in their setting, independence is a rationale for the intrinsic value of holding control, while freedom of choice and power are not. Our results match in that a sense of power does not seem to be a strong determinant of the intrinsic value of decision rights (cf. Pikulina and Tergiman 2017). On the other hand, our results contrast with theirs in terms of the weight of independence. Note, however, that the two experiments differ significantly in terms of measurement and experimental methodology. ${ }^{5}$ One potential explanation for the different results is that while a desire for self-reliance - the desire to implement a decision already taken — crowds out independence, freedom of choice - the ability to make a choice - does not.

Care should be exercised in interpreting our main finding. It should not be interpreted as an indication that power and independence are not motives for a preference for holding control and sources of value in principal-agent interactions. For instance, power may be valuable by the amenities it brings, such as status and recognition. What our main result suggests is that without these additional instrumental sources of value, power and independence may be less valued than a desire for self-reliance as motivations for holding control.

The remaining of the paper is organized as follows. Section 2 is devoted to the experimental design. In Section 3 we describe the measurement of the rationales and our theoretical predictions, and we report our main findings in Section 4. Section 5 concludes.

\section{Experimental Design}

In what follows we summarize the experimental design of Bartling et al. (2014), explain our new treatments, and present the procedures followed in the experiment. ${ }^{6}$ We elicited participants' loss aversion, illusion of control, and cognitive ability through behavioral tasks that we describe

\footnotetext{
${ }^{4}$ In order to elicit freedom of choice they compare a treatment where a player with a default decision right can choose between two alternatives with another treatment where a player is faced with a choice set that contains only one alternative.

${ }^{5}$ In their main experimental setting, a principal (the player with the default decision right) and an agent face a choice between two alternatives. When making a choice, each player knows that one alternative gives a higher payoff than the other alternative for themselves, while the payoff for the other player can be either high or low (with equal probability for each of the two alternatives). The intrinsic value of holding control is measured by eliciting the price the principal is willing to pay to implement her own choice before she makes a decision.

${ }^{6}$ We refer the reader to Bartling et al. (2014) for the theoretical foundation of the experimental design and further details.
} 
in Appendix C.

\subsection{Part 1: The Delegation Game}

In the first part of the experiment, subjects play several 2-player one-shot delegation games. A principal (she) can either keep or delegate a decision right to an agent (him), which grants the right to implement a risky project. The outcome of the project determines the principal's and the agent's payoffs. There are two risky projects, $\mathcal{A}$ and $\mathcal{P}$, with the payoff ordering summarized in Table 1 where the subscripts refer to the projects, and 0 stands for the failure of the risky projects. The projects are risky since their success depends on the effort level (probability of success) chosen by the player that keeps/gets the decision right.

Table 1: Projects' Payoff Ordering

\begin{tabular}{|c|c|}
\hline Principal $(P)$ & Agent $(A)$ \\
\hline$P_{\mathcal{P}} \geq P_{\mathcal{A}}>P_{0}$ & $A_{\mathcal{A}} \geq A_{\mathcal{P}}>A_{0}$ \\
\hline
\end{tabular}

The principal and the agent choose simultaneously a project, $\mathcal{A}$ or $\mathcal{P}$, and an intended effort level, denoted by $E$ and $e$ respectively, that they would like to implement in case they have the decision right. Effort can be chosen from the set $[0,100]$ and corresponds to the probability (in percent) that the project will be successful. Effort is equally costly to the principal and the agent. The cost of effort is given by $C(E)=k E^{2}$ and $C(e)=k e^{2}$ respectively, where $k \in\{0.01,0.02\}$ is a cost parameter. ${ }^{7}$ Both subjects make their two choices simultaneously without knowing who is going to have the decision right, i.e., without knowing whose decision (of project and effort) will be implemented. Their choices are binding, and the choices made by the subject who ultimately holds the decision right determine the project to be implemented and its outcomes. Only this player pays the cost of effort.

In addition, and essential for the design, the principal also indicates a minimum effort requirement $\underline{e} \in[1,100]$ that the agent needs to choose for her to be willing to delegate the decision right. Hence, delegation takes place if and only if the agent's intended effort level is at least as high as the principal's minimum effort requirement, i.e., if and only if $e \geq \underline{e}$. The principal chooses this minimum requirement without knowing the $e$ chosen by the agent; similarly, the agent chooses his intended effort level without knowing the $\underline{e}$ chosen by the principal. It follows that the minimum effort requirement should represent the principal's point of indifference between keeping the decision right and delegating it to the agent.

In total, subjects play ten different delegation games (ten rounds) with stranger matching. The participants remain in the role of principal or agent throughout the experiment and receive no feedback until the end of the experiment. The rounds differ only concerning the projects' payoffs and cost of effort. These differences allow us to test for situational determinants of

\footnotetext{
${ }^{7}$ The cost parameter $k$ varies across rounds, but it is always common knowledge and identical for both players.
} 
a potential intrinsic value of decision rights such as the stake size and the conflict of interest between the principal and the agent. Table 2 summarizes the main parameters of the ten games. ${ }^{8}$

Table 2: Parameters of the Games

\begin{tabular}{|c|c|c|c|c|c|c|c|c|}
\hline & \multicolumn{4}{|c|}{ Project Successful } & \multirow{2}{*}{\multicolumn{2}{|c|}{$\begin{array}{c}\text { Project } \\
\text { Unsuccessful }\end{array}$}} & \multirow[b]{3}{*}{$C(E)$} & \multirow[b]{3}{*}{$C(e)$} \\
\hline & \multicolumn{2}{|c|}{ Project $\mathcal{P}$} & \multicolumn{2}{|c|}{ Project $\mathcal{A}$} & & & & \\
\hline & $P_{\mathcal{P}}$ & $A_{\mathcal{P}}$ & $P_{\mathcal{A}}$ & $A_{\mathcal{A}}$ & $P_{0}$ & $A_{0}$ & & \\
\hline Game 1 & 220 & 190 & 190 & 220 & 100 & 100 & $0.01 E^{2}$ & $0.01 e^{2}$ \\
\hline Game 2 & 280 & 235 & 235 & 280 & 100 & 100 & $0.01 E^{2}$ & $0.01 e^{2}$ \\
\hline Game 3 & 180 & 140 & 140 & 180 & 100 & 100 & $0.01 E^{2}$ & $0.01 e^{2}$ \\
\hline Game 4 & 220 & 160 & 160 & 220 & 100 & 100 & $0.01 E^{2}$ & $0.01 e^{2}$ \\
\hline Game 5 & 260 & 260 & 260 & 260 & 100 & 100 & $0.01 E^{2}$ & $0.01 e^{2}$ \\
\hline Game 6 & 440 & 380 & 380 & 440 & 200 & 200 & $0.02 E^{2}$ & $0.02 e^{2}$ \\
\hline Game 7 & 560 & 470 & 470 & 560 & 200 & 200 & $0.02 E^{2}$ & $0.02 e^{2}$ \\
\hline Game 8 & 360 & 280 & 280 & 360 & 200 & 200 & $0.02 E^{2}$ & $0.02 e^{2}$ \\
\hline Game 9 & 440 & 320 & 320 & 440 & 200 & 200 & $0.02 E^{2}$ & $0.02 e^{2}$ \\
\hline Game 10 & 520 & 520 & 520 & 520 & 200 & 200 & $0.02 E^{2}$ & $0.02 e^{2}$ \\
\hline
\end{tabular}

Subjects are paid at the end of the experiment according to the outcome of one randomly chosen round. Payments are based on the project chosen by the player that holds the decision right and the effort level chosen by that player, as well as a random number $r_{1} \in[1,100]$. If the principal keeps the decision right, the project she has chosen is successful if $r_{1} \leq E$; if instead the agent gets the decision right, the project he has chosen is successful if $r_{1} \leq e$. Otherwise, the chosen project fails.

\subsection{Part 2: The Lottery Task}

In the second part of the experiment, all subjects complete an individual decision task. Each subject states their certainty equivalent for 20 different lotteries, i.e., the smallest certain payoff they are willing to accept instead of each one of these lotteries. Each lottery determines probabilistically the subject's payoff and the payoff of another randomly paired participant.

Consider the subjects who played the role of principal in Part 1 of the experiment. These are the subjects for which we measure a potential intrinsic value of holding control. For each of these subjects, and without them being informed of that, the lotteries are constructed based on their own choices in the delegation game. ${ }^{9}$

Their choices of project, $E$, and $\underline{e}$ in each round of the delegation game determine a pair of lotteries: (i) A principal's intended effort and the chosen project fully determine a control lottery; and (ii) her minimum effort requirement fully determines a delegation lottery. ${ }^{10}$

\footnotetext{
${ }^{8}$ The order of the games was randomized across sessions.

${ }^{9}$ Withholding this information is essential to separate the elicitation of Part 2 from the decisions in Part 1. Since the order of the lotteries and rounds in Part 1 is random and their connection is not self-evident, it seems very unlikely that any subject has become aware of this fact.

${ }^{10}$ Condition (ii) is grounded on the assumption that the principal perceives delegation to lead to the choice of project $\mathcal{A}$. We discuss this assumption in the Online Supplementary Material VIII.
} 
For each lottery, we elicited the principals' certainty equivalent in an incentive compatible manner $\grave{a}$ la Becker et al. (1964). The lotteries consist of a low $(\underline{P})$ and a high $(\bar{P})$ payoff for the principal and a low $(\underline{p})$ and a high $(\bar{p})$ payoff for another randomly paired participant. ${ }^{11}$ The lotteries are presented in an individually randomized order, and principals are asked to state the smallest certain payoff - the certainty equivalent $(c e)$ - that they are willing to accept instead of each lottery.

At the end of the experiment, two of these 20 lotteries are randomly chosen for payment. These two lotteries are either played or not depending upon the ce that the principal has stated for each lottery and two randomly generated numbers $r_{i} \sim U[\underline{P}, \bar{P}]$ where $i=2,3$. For each lottery, if $r_{i} \geq c e$ the principal receives $r_{i}$ for sure and the randomly paired participant receives a certain payment equivalent to the projects' payoff in case of failure in Part 1. Otherwise (if $r_{i}<c e$ ), the lottery is played. Feedback is given to participants only at the end of the experiment.

\subsection{Example of Parts 1 and 2}

To summarize, take the following example. Suppose that instead of ten games, there was only Game 1 in Part 1 (see Table 2), and assume that a principal chooses project $\mathcal{P}, E=50$ (with a corresponding effort $\operatorname{cost} C(E)=25$ ), and $\underline{e}=40$ (with a corresponding effort $\operatorname{cost} C(\underline{e})=16$ for the agent). Assume that her randomly matched agent chooses project $\mathcal{A}$ and $e=30$. According to these choices, the principal keeps the decision right; but since feedback is not yet given to the participants, Part 2 starts without the subjects being aware of the outcomes of Part 1. Two lotteries - with payoffs for the principal and another randomly paired participant - are determined from the principal's decisions taken in Part 1 without them being informed of it:

- A control lottery such that $\bar{P}=P_{\mathcal{P}}-C(E)=220-25=195$ and $\bar{p}=A_{\mathcal{P}}=190$ with $50 \%$ probability, and $\underline{P}=P_{0}-C(E)=100-25=75$ and $\underline{p}=P_{0}=100$ with $50 \%$ probability.

- A delegation lottery such that $\bar{P}=P_{\mathcal{A}}=190$ and $\bar{p}=A_{\mathcal{A}}-C(\underline{e})=220-16=204$ with $40 \%$ probability, and $\underline{P}=P_{0}=100$ and $\underline{p}=A_{0}-C(\underline{e})=100-16=84$ with $60 \%$ probability.

The principal then states her certainty equivalents for these two lotteries. Assume that the principal states a certainty equivalent for the control lottery of 140 and a certainty equivalent for the delegation lottery of 160 . Final payments are then calculated according to three randomly generated numbers, $r_{1}, r_{2}$ and $r_{3} .{ }^{12}$ If $r_{1} \leq E$ the principal receives $220-25=195$ points and the

\footnotetext{
${ }^{11}$ This differs from a typical experimental certainty equivalent elicitation task since lotteries and certainty equivalents involve not only payoffs for the decision maker but instead for two players. This is done to ensure comparability with the "lotteries" in Part 1.

${ }^{12}$ The same holds for the full experiment, except that the game of Part 1 and the lotteries of Part 2 are chosen independently for payment.
} 
randomly matched agent receives 190 for Part 1 . If $r_{1}>E$, the principal and the agent receive 75 and 100 points respectively. For Part 2, if $r_{2} \geq 140$ for the control lottery then the principal receives $r_{2}$ for sure and the randomly paired participant receives 100 points. Otherwise, the control lottery is played and payments are determined according to its result. For the delegation lottery, if $r_{3} \geq 160$ then the principal receives $r_{3}$ for sure and the randomly paired participant receives 100 points. Otherwise, the delegation lottery is played and payments are determined according to its result. In addition, the principal receives a supplementary payment for her role as a "randomly paired participant" to another subject in Part 2. Feedback is finally given to all participants.

\subsection{Treatments}

To examine the motives behind a potential intrinsic value of decision rights, we implemented three treatments (T1, T2, and T3) that vary the nature of the agent. ${ }^{13}$ In $\mathrm{T} 1$, the agent is a human subject. In T2 a bot (computer program) plays the role of the agent. And in T3 a bot makes decisions on behalf of a passive human agent. Figure 1 summarizes the organization of these treatments.

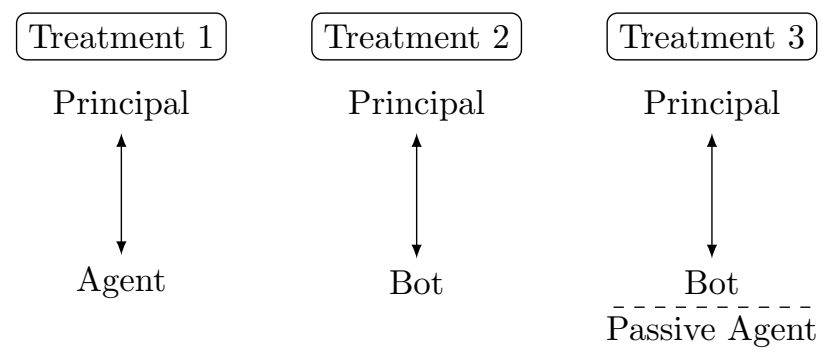

Figure 1: Treatments

In Part 1 of T2 and T3, the bot (i) always chooses the project alternative that provides it (or the passive human agent) the larger payoff (i.e., project $\mathcal{A}$ ), and it (ii) uniformly randomly determines its effort from $[0,100]$. The principal (and the passive human agent) are informed of this decision-making model of the bot. Condition (i) is consistent with the theoretical (selfinterested) prediction for the agents' choice in Part 1. Condition (ii) is an attempt to mimic nature, in the sense of a chance device. This is also the interpretation given to a random device by Bohnet et al. (2008), that use a similar strategy to disentangle different motives behind subjects' willingness to take risk. In Part 2, the bot randomly determines the certainty equivalents. This has no bearing to our design since Part 2 is an individual decision task in which an agent or a bot is only known to the principal in the position of a randomly matched "participant" that is affected by her decisions.

In $\mathrm{T} 3$, if the bot receives the decision right, it makes the decisions on behalf of the passive

\footnotetext{
${ }^{13}$ We use a between- instead of a within-subjects design since the latter would be infeasible in terms of duration.
} 
human agent. This means that passive human agents make no relevant decision themselves and their payoffs depend on the decisions taken by the principal and the bot, while the principals' payoffs depend on their own decisions and the ones taken by the bot. ${ }^{14}$

In the Online Supplementary Material (OSM hereinafter) VIII we discuss the robustness of the design to social and risk preferences, ambiguity aversion, beliefs about the agent's behavior, differences in beliefs regarding the agent's and bot's behavior, as well as other alternative explanations for our results.

\subsection{Procedures}

All subjects were students recruited at universities where we have conducted our experiment. Subjects were recruited via email sent to the students registered in the universities' lab databases in both France and Japan. The experiment was computerized using z-Tree (Fischbacher 2007). Payments were made according to one randomly drawn round of the delegation game (Part 1), and to four randomly drawn lotteries in Part 2 (two of them in the role of the "random other participant"). Subjects received an extra endowment for the loss aversion and illusion of control tasks and were paid according to their results on these tasks. The following exchange rate applied: 100 points $=2.5 €$ or 300 Yen. Subjects earned a $5 €$ or 600 Yen show-up fee and received on average an additional $29.6 €$ in France and 3450 Yens in Japan in experimental sessions that lasted on average 2.5 hours.

Participants were provided with paper-based instructions for all parts of the experiment (available in OSM IX). Instructions for Part 2 of the experiment were handed out only after Part 1 was finished. Participants knew that the experimental session would consist of several parts, but they did not know the precise content of the future parts before the respective instructions were provided. To ensure that subjects understood the experimental design and the impact of their decisions on their earnings, they had to answer a series of control questions after reading the instructions of Part 1 and after reading the instructions of Part 2. They were confronted with the different choices they would have to make during the experiment, and their answers were corrected and shown to them for revision. They were also provided with a sheet detailing all possible effort levels and their associated costs to aid the correct understanding of the quadratic cost function.

To ensure the equivalence of experimental procedures across countries, we followed (for the most part) the methodology first used and described in Roth et al. (1991). We aimed to control for (i) subject-pool, (ii) language, (iii) currency, and (iv) experimenter effects. We took several measures to control for subject-pool effects. First, we recruited only university students in both locations. This guarantees that our subject pool is mostly homogeneous in terms of length of

\footnotetext{
${ }^{14}$ In order to entertain these participants, we let them perform the same decisions as agents in T1 although they are aware that these decisions will not be taken into account for payoffs.
} 
educational background. Second, we gathered data on subjects' demographics and their cognitive ability in order to control for potential effects of non-cultural variables. Third, we ran the experiment in two locations in each country (Rennes and Nice in France and Osaka and Tsukuba in Japan). This allows us to test if our cross-cultural findings (reported in OSM II) are not the result of subject pool differences between two laboratories. To minimize language effects, instructions in English were translated into the local language by a French or Japanese native speaker, and back translated to English by another person. Translators were careful to write the instructions in neutral language, and the authors ensured compatibility with the German and English instructions of Bartling et al. (2014). In terms of currency effects, payoffs were expressed in "points" and the comparability of earnings was ensured by taking an average between standards of living, local hourly payments, and show-up fee practices of the laboratories. ${ }^{15}$ To minimize experimenter effects, all experimenters were native speakers and were present in the first session of each treatment ran in France. The sessions in Japan were conducted by the second author, and the sessions in France were conducted by the third. Further, most of the instructions were read individually, minimizing the subjects' interaction with the experimenter.

\section{Measurement and Hypotheses}

Regardless of the unobserved social and risk preferences of the principal, the experimental design ensures that it is optimal for the principal to choose a minimum effort requirement $\underline{e}$ such that she is indifferent between keeping and delegating the decision right at $\underline{e}$. The optimal choice of $\underline{e}$ should be independent of the principal's beliefs about the agent's/bot's effort choice. It follows that we can measure the intrinsic value of decision rights (IV hereinafter) by comparing the certainty equivalents (monetary values) of the control and delegation lotteries. The principal's utility of keeping control consists of the monetary value of the control lottery [ce(CL)] plus the potential IV. The principal's utility of delegating at $\underline{e}$ consists of the monetary value of the delegation lottery [ce(DL)]. As shown by Bartling et al. (2014), it is then possible to quantify the potential IV as the certain amount of points (money) that a principal demands as a compensation for the delegation of the decision right:

$$
\mathrm{IV}=c e(D L)-c e(C L)
$$

We distinguish three motives that can underlay a potential intrinsic value of holding control. The first potential motive is a desire for independence:

Motive 1 (IND) Aversion to be affected by the decision made by another person.

This motive is closely connected to the concept of negative freedom. In one of its most

\footnotetext{
${ }^{15}$ With the exception of the loss-aversion task where outcomes were expressed in the local currency (as in Bartling et al. 2014). The conversion rate was maintained.
} 
famous formulations, negative freedom is described as the opportunity of "not being prevented from choosing as I do by other men" (Berlin 1969, p. 8, italics added). The second potential motive is a desire for power:

Motive 2 (POW) Desire to affect the payoffs and/or be able to decide on behalf of another person.

Therefore power, as here defined, relates with the part of authority that is exercised over others' outcomes and/or behavior. It resonates with what has been called the love of domination, which Adam Smith saw as an important motivation of human behavior (Smith 1978, as cited in Bartling et al. 2014, fn. 2).

Finally, we highlight a desire for self-reliance (SELF) as a candidate motive for the intrinsic value of holding control:

Motive 3 (SELF) Desire to implement one's decision.

Self-reliance, as here understood, is a self-regarding motivation that is unrelated to the freedom from the interference of others (as in IND) or the desire to dominate others (as in POW). This means that a desire for self-reliance can motivate behavior even when there is not another person to delegate the decision to.

To measure the strength of these different motives, we compare the net effects of the three treatments. IND, POW, and SELF are potential motives for the IV in T1, SELF is the single potential motive behind the IV in T2, and POW and SELF are potential motives for the IV in T3. Taking the measured IV of our three treatments, we can construct precise estimates of the weight of each motive in the potential intrinsic value of holding control:

$$
\begin{aligned}
\text { IND } & =I V_{T 1}-I V_{T 3}=(I N D+P O W+S E L F)-(P O W+S E L F) . \\
\text { POW } & =I V_{T 3}-I V_{T 2}=(P O W+S E L F)-(S E L F) . \\
\text { SELF } & =I V_{T 2}=(S E L F) .
\end{aligned}
$$

We expected independence to be a motive for the intrinsic value of holding control given the long tradition on the value of negative freedom. For instance, freedom from the interference of others is endorsed as essential by most liberals, such as Hayek (1960), Nozick (1974), and Buchanan (1986). Power was also expected to be a rationale behind the IV since it is seen by many as a powerful motivation for human behavior. For instance, managers are believed to have goals such as the "pursuit of power" from which they derive private benefits of holding control (Hart and Moore 1995, p. 568). These two hypotheses are endorsed by Bartling et al. (2014, sec. 1 and fn. 21). Here, we also considered self-reliance as a potential motive underlying the IV, and 
expected it to be positive and significant as it is often associated with increased well-being and a sense of worth. For instance, Deci and Ryan (1985) hold that self-determination is essential for well-being, and the freedom of choice literature resonates with the idea that choosing has an intrinsic worth irrespective of constraints (see e.g. Sen 1988). These expectations can be resumed in the following hypotheses:

Hypothesis $1 I N D>0$.

Hypothesis $2 P O W>0$.

Hypothesis 3 SELF>0.

Before proceeding, it is worth noting that our measurement and hypotheses rely on the assumption that the willingness to keep control in T2 and T3 is not driven by motives linked to the chance device per se. Among these, the most prominent would be a desire for independence from randomness. In order to assess the weight of this motive in our setting, we have conducted additional treatments that are described in OSM IV. In a nutshell, the results from these additional treatments show that independence from randomness is not a significant motive behind the intrinsic value of holding control in our setting.

\section{Results}

The main study involved 521 subjects, from which 319 were in the position of principal. Since we link our results to two different cultural backgrounds, we drop from the analysis 45 principals that are neither of French or Japanese nationality nor born in France or in Japan. ${ }^{16}$ From the remaining 274 principals, 142 participated in France [94 in Rennes (28 in T1, 38 in T2, 28 in T3) and 48 participated in Nice (15 in T1, 20 in T2, 13 in T3)] and 132 participated in Japan [65 in Osaka (23 in T1, 18 in T2, 24 in T3) and 67 in Tsukuba (20 in T1, 25 in T2, 22 in T3)]. ${ }^{17}$

In the final part of the experiment, we collected social demographic and values measures that bring some insights into the similarities and differences of the samples of the two countries. We also collected behavioral data on cognitive ability (Raven's test score), loss aversion, and illusion of control. Table 5 in Appendix B summarizes subjects' characteristics.

These measures suggest that the two samples - principals in France and principals in Japan - are, except for gender, cognitive ability, and the main field of study, similar in terms of non-cultural dimensions. Accordingly, in our analysis we control for gender, cognitive ability, main field of study ${ }^{18}$, loss aversion, and illusion of control. This way we control for alternative

\footnotetext{
${ }^{16}$ See OSM VII for other restrictions based on "stronger" and "weaker" proxies for cultural background. Our results are robust to the different proxies.

${ }^{17}$ We ran a total of 33 sessions: 14 at Rennes, 8 at Nice, 5 at Osaka, and 6 at Tsukuba. The fewer observations in Nice are due to the nationality restriction.

${ }^{18}$ In our analysis we include a single dummy for "Economics \& management" because they are a majority in France and previous studies document differences in behavior between students in economics \& management and other fields (e.g. Fehr et al. 2006). Our results are robust with dummies for the other fields.
} 
explanations based on these characteristics. We address other alternative explanations in OSM VIII.

Since we have data from two locations in each country, we can check if the subjects' behavior is consistent within each country. If we observe no significant difference between two locations of the same country, we can be more confident that there is a certain degree of homogeneity within a country and that we are capturing its cultural background. We report the results of the within-country analysis in OSM I. In brief, we find that the IV is similar and not statistically significantly different for the two locations within each country. In addition, we find that the principals' decisions in Part 1 - project, effort, and minimum effort requirement - are similar and mostly not statistically significantly different as well. The values characteristics reported in Appendix B also suggest that the two samples are influenced by the French and Japanese cultural backgrounds. Taken together, these results indicate that the subject-pools within each country come from the same distribution. Therefore, in what follows we perform the analysis with pooled data by country.

\subsection{The Intrinsic Value of Decision Rights}

We start our main analysis by looking at the IV in the two countries. We analyze the intrinsic value of decision rights as measured by the difference in certainty equivalents of the delegation and the control lotteries as stated in Equation 1: IV $=c e(D L)-c e(C L) .{ }^{19}$ Figure 2 presents the values of the IV measure for the three treatments in each country.

Result 1 Decision rights have on average a positive intrinsic value for both French and Japanese subjects.

As can be seen in Figure 2, the certainty equivalents of the delegation lotteries are on average 19 to 42 points higher than those of the control lotteries depending on the treatment and country. This amounts to $13 \%$ to $25 \%$ in terms of percentage differences (see Table A13 in OSM V). Note that while subjects in France attach on average a higher intrinsic value to be in control in $\mathrm{T} 1$ and T3 than in T2, subjects in Japan attach the highest value in T2 and the lowest in T1. Table 4 in Appendix A shows that we reject the hypotheses that subjects value the delegation lotteries and the control lotteries equally for any treatment in both countries. ${ }^{20}$ This suggests that, on average, subjects in France and Japan assign a positive intrinsic value to hold control.

\footnotetext{
${ }^{19}$ In OSM V we report results using the percentage difference in ce that normalizes the IV for the monetary stakes of the lotteries. Note that, however, we cannot use this alternative measure to elicit the weight of each rationale on the IV because we cannot exclude that the corresponding measure of power is biased by the effect of social preferences. While IV $=c e(D L)-c e(C L)$ neutralizes the effect of social preferences for any treatment and comparisons between treatments, the percentage difference, given by $I V / C E=\frac{c e(D L)-c e(C L)}{(c e(D L)+c e(C L)) / 2}$, does not neutralize the effect when comparing treatments with and without the potential effect of social preferences, as $T 2$ and $T 3$ in our measure of power.

${ }^{20}$ Nonparametric Wilcoxon signed-rank tests and bootstrap tests also reject these hypotheses $(p<0.001$ for all cases).
} 


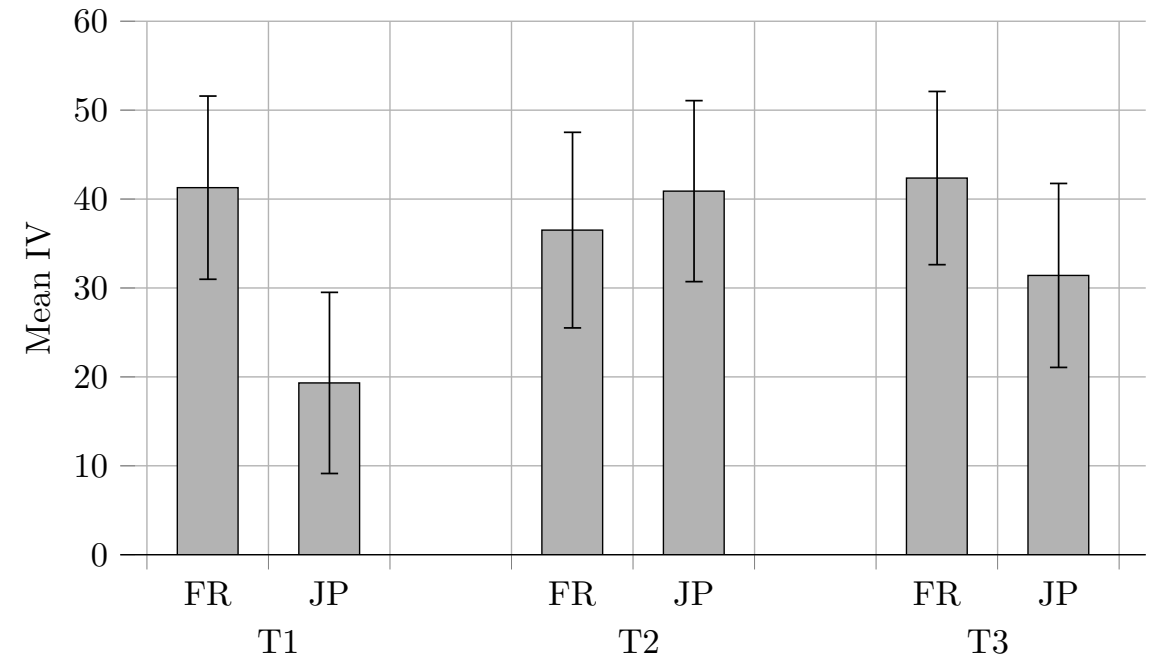

Figure 2: Mean IV, sorted by country and treatment.

Notes: The bars display one standard error of the mean. Values are based on an OLS regression with clustered standard errors per subject and individual controls reported in column (2) of Table 4 in Appendix A.

Several robustness tests bring support to Result 1. First, we observe that a large majority of subjects derive a positive intrinsic value of holding control in all treatments in both countries. In our total sample, $89 \%$ of subjects value (on average) the delegation lotteries strictly more than the corresponding control lotteries. Second, a bootstrap analysis suggests that a positive and significant IV holds for all separate games in France, and most games in Japan. ${ }^{21}$ This suggests that a positive intrinsic value of decision rights is a robust preference across different delegation games for all treatments. Finally, we test whether the intrinsic value of decision rights is measured consistently across subjects in the ten delegation games. ${ }^{22}$ To test for consistency, we follow Bartling et al. (2014) and measure the correlation of the IV across games by computing Cronbach's alpha (Cronbach 1951), in our case per treatment and country. The measure reports the correlation between games and varies between zero and one. Cronbach's alphas per treatment are between 0.49 (in T1) and 0.75 (in T3) in France and between 0.47 (in T2) and 0.60 (in T1) in Japan. This suggests a moderate and positive correlation of our IV measure across subjects in France and Japan in the ten delegation games and all treatments.

Taken together, these results suggest that our first finding is robust for both countries and all treatments. This finding brings further support, as a cross-cultural replication, to the main finding of Bartling et al. (2014) on the positive and statistically significant intrinsic value of holding control in this setting. ${ }^{23}$

\footnotetext{
${ }^{21}$ For principals in France, bootstrap tests reject the hypothesis that the IV is equal to zero for the 10 games in $\mathrm{T} 1(p<0.01$ for $7, p<0.05$ for 2 , and $p<0.1$ for 1$)$, for the 10 games in T2 $(p<0.01$ for all games $)$, and for the 10 games in T3 $(p<0.01$ for 9 and $p<0.05$ for 1$)$. For principals in Japan, bootstrap tests reject this hypothesis for 7 games in T1 $(p<0.01$ for 2 and $p<0.05$ for 5$)$, for 9 games in T2 $(p<0.01$ for 8 and $p<0.05$ for 1$)$, and for 8 games in T3 $(p<0.01$ for 7 and $p<0.1$ for 1$)$.

${ }^{22}$ Consistency means that if a principal assigns a higher intrinsic value to decision rights than another principal in one game, then the former also assigns a higher value in the other games.

${ }^{23}$ Using the data from Bartling et al.'s (2014), we observe that the IV for Swiss subjects — worth 27 points - lies in between the IV in France and the IV in Japan. See OSM II for cross-cultural results.
} 


\subsection{The Roots of the Intrinsic Value of Decision Rights}

The measured IV in our three treatments and their differences provide estimates of our three main variables of interest: INDependence, POWer, and SELF-reliance. We present the measured values of these motives in Table 3. For instance, consider independence for subjects in France. On average, subjects attach 1.1 points less to the delegation lottery compared to the control lottery when they interact with a human agent (T1) than when they interact with a bot that decides on behalf of a passive human agent (T3).

Table 3: The Roots of the Intrinsic Value of Decision Rights

\begin{tabular}{cccc}
\hline \hline & $\begin{array}{c}\text { INDependence } \\
\left(I V_{T 1}-I V_{T 3}\right)\end{array}$ & $\begin{array}{c}\text { POWer } \\
\left(I V_{T 3}-I V_{T 2}\right)\end{array}$ & $\begin{array}{c}\text { SELF-reliance } \\
\left(I V_{T 2}\right)\end{array}$ \\
\hline France & -1.079 & 5.854 & $36.509^{* * *}$ \\
Japan & $-12.090^{*}$ & $-9.483^{*}$ & $40.894^{* * *}$ \\
\hline$H_{0}: \mathrm{FR}=\mathrm{JP}$ & $p=0.221$ & $p=0.066$ & $p=0.481$ \\
\hline \hline & Notes: ${ }^{*}$ Significant at 10\% level, **Significant at 5\% level, ${ }^{* * *}$ Significant at 1\% level, \\
based on two-tailed Wald tests from OLS regression with clustered standard errors per \\
subject and individual controls reported in column (2) of Table 4 in Appendix A.
\end{tabular}

Result 2 Self-reliance is the only significant rationale for the intrinsic value of decision rights for both French and Japanese subjects.

As shown in the table, self-reliance is a significant and positive motive behind the IV in both countries. On average, the delegation lotteries are valued 36.5 (in France) to 40.9 (in Japan) points more than the control lotteries due to a desire for self-reliance. As Table 3 highlights, we reject the hypothesis that subjects in $\mathrm{T} 2$ value the delegation lotteries and the control lotteries equally, both in France and Japan.

Table 3 also shows that self-reliance is the only motive for the IV in both countries. As it can be seen from the table, French subjects tend to value holding control in T1 similarly than in T3, and we do not reject the null hypothesis of equality. This suggests that French subjects might be indifferent to independence in this setting. In Japan, independence has on average a negative impact on the IV. But as it can be seen from Table 3, we only reject the hypothesis that independence has no effect on the IV at $10 \%$ significance level. This thus brings only mild evidence that independence might be negatively valued in Japan in our setting. As for power, we do not reject the hypothesis that its weight is equal to zero for French subjects. As it is the case with independence, this suggests that subjects in France may be indifferent to power as a rationale for the IV in our setting. As for subjects in Japan, power is negatively valued but we only reject the null hypothesis at $10 \%$ significance level. This brings again only mild evidence that, in our setting, subjects in Japan may be averse to power per $s e .{ }^{24}$

\footnotetext{
${ }^{24}$ Note that the plain effect of replacing a human agent by a bot $(T 1-T 2)$ is large and statistically significant
} 
Several robustness tests bring support to Result 2. First, this result holds when using nonparametric tests (see Table A14 in OSM V). Second, using matching estimator techniques we find similar results for independence and power, and, bringing indirect support to Result 2, we do not reject the hypothesis that self-reliance is equally valued in both countries (see Tables A15 and A16 in OSM V). Third, these results also hold for both male and female subjects separately, as self-reliance is the only significant motive behind the IV and similarly valued in both France and Japan when we divide the sample by gender (see Table A19 in OSM VI). Fourth, alternative motives like independence from randomness are not significant in our setting (see OSM IV). Finally, these results are also robust to different stake sizes (see OSM VI), different proxies of cultural background (see OSM VII), and several alternative explanations based, for instance, on reciprocity, preference reversals, or corner solutions (see OSM VIII).

\section{Concluding Remarks}

Several recent experimental analyses have provided us with new insights on the incentive effects of decision rights and the preference for holding control. For example, while principals often use control to reduce agents' self-seeking actions, experimental results suggest that holding control may carry "hidden costs" in terms of agents' performance and principals' payoffs (Falk and Kosfeld 2006). In a context of participative decision making, Corgnet and Hernán-González (2014) show that consulting agents is beneficial for principals only if they follow the agents' choice. However, we have few insights into the motivations that lie behind the value of holding control when there is no instrumental reason to pursue it. This paper is an attempt to shed some light about the motives that lie behind the non-delegation of decision rights when that holds.

We find that, somewhat surprisingly, independence and power are not motives that lie behind an intrinsic value to hold control in our setting. Instead, the desire to implement one's decision seems to be the main motivation behind this preference. We find that these preferences are shared by French and Japanese subjects. So in general, while our results support the main finding of Bartling et al. (2014) concerning the positive and statistically significant intrinsic value of decision rights in this setting, they suggest that this value is not dependent upon another person being the potential holder of control.

Finally, we find worth pointing out that the experimental setting is fairly abstract and demanding in terms of rationality requirements. Future research resorting to more "ecological" designs - either lab or field - may help to understand the contextual and incentive determinants of the roots of the intrinsic value of holding control and how they operate in "real-world"

in Japan $(-21.572, p<0.01$ based on a two-tailed Wald test from the OLS regression reported in column (2) of Table 4 in Appendix A). While this difference could be explained by a desire for independence from randomness, the results of the additional treatments reported in OSM IV do not lend support to this hypothesis. An alternative explanation is that the observed difference is due to the fact that independence and power, when taken together, are negatively valued in Japan. 
settings.

Acknowledgements. We are grateful to two anonymous referees, Giuseppe Attanasi, Salvador Barberà, Björn Bartling, Brice Corgnet, Fabio Galeotti, Nicolas Gravel, Fabrice Le Lec, Stephane Luchini, Arthur Schram, Robert Sugden, and Alain Trannoy for their valuable comments. We have also benefited from comments and suggestions from seminar participants at Aix-Marseille School of Economics, Paris School of Economics, ISER, GREDEG, and Kansai University, and participants at the Workshop on Experimental Advances in Organizational Behavior, 2017 ASFEE Meeting, and at the 2017 ESA European Meeting. We wish to thank Kazuhito Ogawa and staff at the Center for Experimental Economics at Kansai University, Eizo Akiyama and staff at the Experimental Economics Laboratory at University of Tsukuba, and staff at the Experimental Economics Laboratory of Nice and of Rennes for their kind support in carrying out the experiment. We also thank Elven Priour for his programming of the software, and Haruko Tanaka, Jeremy Mercer and Ruth Bachmann for their translations of the instructions. This paper forms part of the research project "ValFree" (The Value of Choice, grant No. ANR-16-CE41-000201) of the French National Agency for Research whose financial support is gratefully acknowledged. Financial supports from Aix-Marseille School of Economics, L'institut Universitaire de France, Murata Science Foundation, and $U C A^{J E D I}$ (ANR-15-IDEX-01) are also gratefully acknowledged.

\section{References}

Abdellaoui, M., A. Baillon, L. Placido, and P. P. Wakker (2011) The Rich Domain of Uncertainty: Source Functions and Their Experimental Implementation. The American Economic Review 101(2): 695-723.

Aghion, P. and J. Tirole (1997) Formal and Real Authority in Organizations. Journal of Political Economy 105(1): 1-29.

Anderson, J. (2013) Autonomy. In: H. LaFollette (ed) The International Encyclopedia of Ethics. Blackwell Publishing Ltd., first edition edition.

Bartling, B., E. Fehr, and H. Herz (2014) The Intrinsic Value of Decision Rights. Econometrica 82(6): 2005-39

Becker, G. M., M. H. DeGroot, and J. Marschak (1964) Measuring Utility by a Single-Response Sequential Method. Behavioral Science 9: 226-32.

Berg, J. E., J. W. Dickhaut, and T. A. Rietz (2010) Preference reversals: The impact of truthrevealing monetary incentives. Games and Economic Behavior 68: 443-468.

Berlin, I. (1969) Four Essays on Liberty. Oxford University Press., Oxford.

Bó, P. Dal, A. Foster, and L. Putterman (2010) Institutions and Behavior: Experimental Evidence on the Effects of Democracy. The American Economic Review 100: 2205-29.

Bohnet, I., F. Greig, B. Herrmann, and R. Zeckhauser (2008) Betrayal Aversion: Evidence from Brazil, China, Oman, Switzerland, Turkey, and the United States. The American Economic Review 98(1): 294-310.

Botti, S. and A. L. McGill (2006) When Choosing Is Not Deciding: The Effect of Perceived Responsibility on Satisfaction. Journal of Consumer Research 33(2): 211-19.

Buchanan, J. M. (1986) Liberty, Market and the State. Wheatsheaf Books, Brighton.

Buffat, J., M. Praxmarer, and M. Sutter (2018) Teams versus individuals: The intrinsic value of decision rights. , Mimeo. 
Burdin, G., S. Halliday, and F. Landini (2015) Third-Party vs. Second-Party Control: Disentangling the Role of Autonomy and Reciprocity., IZA Working Paper 9251.

Burks, S. V., J. P. Carpenter, L. Goette, and A. Rustichini (2009) Cognitive skills affect economic preferences, strategic behavior, and job attachment. Proceedings of the National Academy of Science, U.S.A. 106(19): 7745-7750.

Carpenter, J., M. Graham, and J. Wolf (2013) Cognitive ability and strategic sophistication. Games and Economic Behavior 80: 115-130.

Charness, G. and U. Gneezy (2010) Portfolio Choice and Risk Attitudes: An Experiment. Economic Inquiry 48(1): 133-46.

Christman, J. (2011) Autonomy in Moral and Political Philosophy. http://plato.stanford.edu/archives/spr2011/ entries/autonomy-moral/.

Corgnet, B. and R. Hernán-González (2014) Don't ask me if you will not listen: The dilemma of participative decision making. Management Science 60(3): 560-585.

Cronbach, L. J. (1951) Coefficient Alpha and the Internal Structure of the Tests. Psychometrika 16: $297-334$.

Deci, E. L. and R. M. Ryan (1985) Intrinsic Motivation and Self-Determination in Human Behavior. Plenum, New York.

Falk, A. and M. Kosfeld (2006) The Hidden Costs of Control. The American Economic Review 96: 1611-30.

Fehr, E. and L. Goette (2007) Do Workers Work More if Wages Are High? Evidence From a Randomized Field Experiment. The American Economic Review 97(1): 298-317.

Fehr, E., H. Herz, and T. Wilkening (2013) The Lure of Authority: Motivation and Incentive Effects of Power. The American Economic Review 103(4): 1325-59.

Fehr, E., M. Naef, and K. M. Schmidt (2006) Inequality Aversion, Efficiency, and Maximin Preferences in Simple Distribution Experiments: Comment. The American Economic Review 96(5): 1912-17.

Fischbacher, U. (2007) z-Tree: Zurich Toolbox for Ready-Made Economic Experiments. Experimental Economics 10(2): 171-8.

Gaechter, S., B. Herrmann, and C. Thoni (2010) Culture and Cooperation. Philosophical Transactions of the Royal Society B 265: 2651-61.

Gill, D. and V. Prowse (2016) Cognitive Ability, Character Skills, and Learning to Play Equilibrium: A Level-k Analysis. Journal of Political Economy 124(6): 1619-1676.

Granic, G. D. and A. K. Wagner (in press) Where Power Resides in Committees. Leadership Quarterly.

Grether, D. M. and C. R. Plott (1979) Economic Theory of Choice and the Preference Reversal Phenomenon. American Economic Review 69(4): 623-638.

Hanaki, N., N. Jacquemet, S. Luchini, and A. Zylbersztejn (2016a) Cognitive ability and the effect of strategic uncertainty. Theory and Decision 81(1): 101-121.

- (2016b) Fluid intelligence and cognitive reflection in a strategic environment: evidence from dominance-solvable games. Frontiers in Psychology: Personality and Social Psychology 10(http://dx.doi.org/10.3389/fpsyg.2016.01188).

Hart, O. and J. Moore (1990) Property Rights and the Nature of the Firm. Journal of Political Economy 98(6): 1119-58. 
(1995) Debt and Seniority: An Analysis of the Role of Hard Claims in Constraining Management. The American Economic Review 85(3): 567-85.

Hayek, F. A. (1960) The Constitution of Liberty. Routledge., London.

Henrich, J., R. Boyd, S. Bowles, C. Camerer, E. Fehr, and H. Gintis (2004) Foundations of Human Sociality: Economic Experiments and Ethnographic Evidence From Fifteen Smallscale Societies. Oxford University Press, Oxford.

Hofstede, G., G. J. Hofstede, and M. Minkov (2010) Cultures and organizations: Software of the mind. McGraw-Hill, New Yorkexpanded 3rd edition edition.

Holt, C. R. and S. K. Laury (2002) Risk aversion and Incentive Effects. The American Economic Review 92(5): 1644-55.

Inglehart, R. and W. E. Baker (2000) Modernization, Cultural Change, and the Persistence of Traditional Values. American Sociological Review 65(1): 19-51.

LeBoeuf, R. A., E. Shafir, and J. B. Bayuk (2010) The Conflicting Choices of Alternating Selves. Organizational Behavior and Human Decision Processes 111(1): 48-61.

L'Haridon, O. and F. M. Vieider (2016) All over the map: A Worldwide Comparison of Prospect Theory Parameters. , Working Paper.

Lichtenstein, S. and P. Slovic (1971) Reversals of preference between bids and choices in gambling decisions. Journal of Experimental Psychology 89(1): 46-55.

Markus, H. R. and S. Kitayama (1991) Culture and the Self: Implications for Cognition, Emotion, and Motivation. Psychological Review 98: 224-53.

Neri, C. and H. Rommeswinkel (2017) Freedom, Power and Interference., Mimeo.

Nisbett, R. E. (2003) The Geography of Thought: How Asians and Westerners Think Differently...and Why. The Free Press, New York.

Nisbett, R. E. and T. Masuda (2003) Culture and Point of View. Proceedings of the National Academy of Sciences of the United States of America 100: 11163-75.

Nozick, R. (1974) Anarchy, State, and Utopia. Basic Books.

Owens, D., Z. Grossman, and R. Fackler (2014) The Control Premium: A Preference for Payoff Autonomuy. American Economic Journal: Microeconomics 6(4): 138-61.

Parks, C. D. and A. D. Vu (1994) Social Dilemma Behavior of Individuals From Highly Individualist and Collectivist Cultures. Journal of Conflict Resolution 38: 708-18.

Pikulina, E. and C. Tergiman (2017) Preferences for Power., Mimeo.

Prelec, D. (1998) The Probability Weighting Function. Econometrica 66: 497-527.

Raven, J. C. (1998) Raven's Advanced Progressive Matrices (APM). Pearson, San Antonio, TX2003rd edition.

Riener, G. and S. Wiederhold (2016) Team Building and Hidden Costs of Control. Journal of Economic Behavior and Organization 123: 1-18.

Roth, A. E., V. Prasnikar, M. Okuno-Fujiwara, and S. Zamir (1991) Bargaining and Market Behavior in Jerusalem, Ljubljana, Pittsburgh, and Tokyo: An Experimental Study. The American Economic Review 81(5): 1068-95.

Ryan, R. M. and E. L. Deci (2006) Self-Regulation and the Problem of Human Autonomy: Does Psychology Need Choice, Self-Determination, and Will?. Journal of Personality 74(6): $1557-86$. 
Sen, A. K. (1988) Freedom of Choice: Concept and Content. European Economic Review 32: 269-94.

Simon, H. A. (1951) A Formal Theory of the Employment Relation. Econometrica 19(3): 293-05.

Sjöström, T., L. Ülkü, and R. Vadovic (2017) Free to Choose: Testing the Pure Motivation Effect of Autonomous Choice. , Mimeo.

Skinner, Q. (1992) On Justice, the Common Good and the Priority of Liberty. In: C. Mouffe (ed) Dimensions of Radical Democracy: Pluralism, Citizenship, Community. Verso, London.

Smith, A. (1978) Lectures on Jurisprudence (1762/63). Oxford University Press [2006], Oxford.

Welzel, C. and R. Inglehart (2005) Liberalism, Postmaterialism, and the Growth of Freedom. International Review of Sociology 15(1): 81-108.

Wong, R. Y.-M. and Y.-Y. Hong (2005) Dynamic Influences of Culture on Cooperation in the Prisoner's Dilemma. Psychological Science 16: 429-34. 


\section{Appendix \& Online Supplementary Material (OSM)}

The main appendix is organized as follows:
A. Main Regression
B. Characteristics of Subjects
C. Additional Experimental Measures

The supplementary material, available online here (HYPERLINK), is organized as follows:

I. Within-country Differences

II. Cross-cultural Comparison

III. Decisions Part 1

IV. Independence from Randomness

V. Additional Robustness Tests

VI. Situational Determinants

VII. Other Proxies of Cultural Background

VIII. Alternative Explanations

IX. Instructions 


\section{A. Main Regression}

Table 4: The Intrinsic Value of Decision Rights, $I V$

\begin{tabular}{ccc}
\hline \hline & $(1)$ & $(2)$ \\
T1 France & $42.270^{* * *}$ & $41.284^{* * *}$ \\
& $(4.469)$ & $(10.304)$ \\
T1 Japan & $18.933^{* * *}$ & $19.321^{*}$ \\
& $(4.808)$ & $(10.187)$ \\
T2 France & $36.709^{* * *}$ & $36.509^{* * *}$ \\
& $(4.236)$ & $(11.000)$ \\
T2 Japan & $39.967^{* * *}$ & $40.893^{* * *}$ \\
& $(3.197)$ & $(10.179)$ \\
T3 France & $42.663^{* * *}$ & $42.363^{* * *}$ \\
& $(4.690)$ & $(9.742)$ \\
T3 Japan & $31.320^{* * *}$ & $31.411^{* * *}$ \\
& $(4.165)$ & $(10.346)$ \\
Female & & 0.711 \\
& & $(4.041)$ \\
Raven's Score & & -0.053 \\
& & $(0.678)$ \\
Economics & & -0.049 \\
\& Management & & $(4.024)$ \\
Loss Aversion & & -0.255 \\
Illusion of Control & & $(1.159)$ \\
& & 0.268 \\
$R^{2}$ & 0.225 & $0.225)$ \\
N & 2740 & 2700 \\
\hline \hline Notes: * Significant at $10 \%$ level, **Significant at $5 \%$ \\
sions with clustered at $1 \%$ level, based on OLS regres- \\
& &
\end{tabular}




\section{B. Characteristics of Subjects}

Table 5: Characteristics of Subjects

\begin{tabular}{|c|c|c|c|}
\hline & France & Japan & $\overline{\text { Test }(p \text {-value })}$ \\
\hline \multicolumn{4}{|c|}{ Social Demographics } \\
\hline Age & 20.1 & 21.1 & $<0.001$ \\
\hline Female (Fraction) & $66.9 \%$ & $37.1 \%$ & $<0.001$ \\
\hline Social class (1 Upper, 5 Lower) & 2.7 & 2.7 & 0.679 \\
\hline \multicolumn{4}{|l|}{ Field of study: } \\
\hline Economics \& management & $57.8 \%$ & $18.2 \%$ & $<0.001$ \\
\hline Law & $14.1 \%$ & $7.6 \%$ & 0.085 \\
\hline Humanities & $6.3 \%$ & $27.3 \%$ & $<0.001$ \\
\hline Math & $4.2 \%$ & $2.3 \%$ & 0.365 \\
\hline Sciences & $2.1 \%$ & $18.2 \%$ & $<0.001$ \\
\hline Other & $15.5 \%$ & $26.5 \%$ & 0.025 \\
\hline $\begin{array}{lll}\text { Values } & \text { Valu }\end{array}$ & & & \\
\hline Political scale (0 Ext. left, 10 Ext. right) & 4.8 & 5.6 & $<0.001$ \\
\hline Liberty aspirations (0 Low, 5 High) & 2.2 & 1.5 & $<0.001$ \\
\hline Not religious (Fraction) & $56.3 \%$ & $81.1 \%$ & $<0.001$ \\
\hline \multicolumn{4}{|l|}{ Religion or religious denomination (Fraction): } \\
\hline Roman Catholic & $22.3 \%$ & $0.8 \%$ & $<0.001$ \\
\hline Muslim & $15.1 \%$ & $0.0 \%$ & $<0.001$ \\
\hline Buddhist & $2.2 \%$ & $12.1 \%$ & 0.001 \\
\hline Other & $0.0 \%$ & $5.3 \%$ & 0.005 \\
\hline \multicolumn{4}{|c|}{ Behavioral Data } \\
\hline Raven's test score (Max. 16) & 9.7 & 11.5 & $<0.001$ \\
\hline Loss aversion (1 High, 6 Low) & 3 & 3.2 & 0.523 \\
\hline \multicolumn{4}{|l|}{ Illusion of control: } \\
\hline Fraction no illusion (W.T.P. = 0) & $64.9 \%$ & $72 \%$ & 0.162 \\
\hline Mean W.T.P. if W.T.P. $>0$ (Max. 30 points) & 10.6 & 13.2 & 0.140 \\
\hline
\end{tabular}

Notes: Mean values for Age, Social class, Political scale, Liberty aspirations, Raven's test score, and Loss aversion. W.T.P. refers to "willingness to pay". Two-tailed Student test for Age, Social class, Political scale, Liberty aspirations, Raven's test score, Loss aversion, and Mean W.T.P. $\chi^{2}$ homogeneity test for Female, Fields of study, Not religious, Religions, and Fraction no illusion.

Note that according to the World Values Survey (WVS) data ${ }^{25}$ of two representative samples of Japanese and French individuals, $58 \%$ of Japanese declared not to belong to any religion or religious denomination and 31\% declared to be Buddhist, while in France $49 \%$ declared not to belong to any religion or religious denomination, $42 \%$ declared to be Catholic and $5 \%$ Muslim. These results are different (which is expected since our sample consists of university students) but generally aligned with ours. The WVS results on political orientation are very similar to ours, with the mean position of 4.8 in France and 5.5 in Japan. In terms of liberty aspirations, Welzel and Inglehart (2005) report, based on the WVS of 1989-91 data, and as in our sample, higher liberty aspirations in France (around 2.6) than in Japan (around 2.15). ${ }^{26}$

\footnotetext{
${ }^{25}$ The data reported is from the Wave 5 of the WVS (1096 Japanese individuals in 2005 and 1001 French individuals in 2006).

${ }^{26}$ A subject is said to have high liberty aspirations if he or she mentions the following (national) goals -
} 


\section{Additional Experimental Measures}

After Part 2 of the experiment, we ask subjects to complete a series of short tasks. As in Bartling et al. (2014), we elicit participants' loss aversion and illusion of control. In our experiment, we also elicit participants' cognitive ability. These measures allow us to control for alternative explanations for a potential IV.

We follow Bartling et al. (2014) and elicit the subjects' degree of loss aversion using a lottery task (as first in Fehr and Goette 2007). Subjects accept or reject a series of lotteries involving possible losses of different sizes $X$. For example, in France participants either accepted or rejected lotteries with a $50 \%$ probability of winning $5 €$ and $50 \%$ probability of losing $X €$, with $X$ going from 1 up to $6 €$. The amount $X$ at which a participant starts rejecting the lotteries is an indicator of his or her loss aversion. For instance, a participant who rejects all lotteries with a potential loss of $X>2$ is classified as more loss averse than a participant who only rejects lotteries with a potential loss of $X>4 .^{27}$

To elicit subjects' illusion of control, we adopt a modified version of the incentive compatible elicitation method used by Charness and Gneezy (2010). We measure illusion of control as the principal's willingness to pay for the right to personally stop the roll of two ten-sided electronic dice (that determine the random outcomes in Part 1 and 2 of the experiment). ${ }^{28}$ If they opt not to personally stop the rolling dice, the dice stop automatically.

To ensure the comparability between sites and for an additional control on the potential effects of bounded rationality, we elicit the subjects' cognitive ability through a Raven's Progressive Matrices test (RPM test). Recent experimental studies show that the scores of RPM tests are correlated with subjects' behavior in strategic games (e.g. Burks et al. 2009; Carpenter et al. 2013; Gill and Prowse 2016; Hanaki et al. 2016a; Hanaki et al. 2016b). This test is widely used worldwide, and is especially suited for cross-cultural studies since it is independent of language, reading, and writing skills. The test consists of choosing, among a given number of patterns, the one that best fits the "blank space" of a visual geometric design. The number and difficulty of the visual geometric designs vary from one version of the test to the other. In our experiment, subjects were asked to choose among 8 patterns ( 8 options) and there were 16 different visual geometric designs of different difficulties, taken from the advanced version of the RPM test (Raven, 1998), to be answered in 10 minutes. Our measure of cognitive ability is the score of

among others such as economic growth and maintaining order — as most important: (i) "Seeing that people have more say about how things are done at their jobs and in their communities", (ii) "Giving people more say in important government decisions", and (iii) "Protecting freedom of speech" (see Welzel and Inglehart 2005).

${ }^{27}$ Once all decisions were taken, one of the six lotteries was randomly selected for payment. If they accepted, the lottery was played, otherwise they received $0 €$. Remark that we might be unable to ascertain a participant's loss aversion if they have not a unique switching point. In our sample, there were 4 "non-consistent" subjects.

${ }^{28}$ We modify the task by substituting the two physical dice by two electronic dice that appear on the participants' screen. Subjects are asked if they are willing to pay to personally stop the rolling dice, and are informed that the numbers change too quickly for them to be able to choose which numbers to stop on. This avoids the time consuming activity (involving the participants and the experimenter) of rolling physical dice. 
this task computed as the number of correct answers. 


\section{Online Supplementary Material}

The supplementary material is organized as follows:

I. Within-country Differences

II. Cross-cultural Comparison

III. Decisions Part 1

IV. Independence from Randomness

V. Additional Robustness Tests

VI. Situational Determinants

VII. Other Proxies of Cultural Background

VIII. Alternative Explanations

IX. Instructions 


\section{Within-country Differences}

Figure A1 presents the IV measure for the three treatments in the two locations in France. As it can be seen from the figure, the values per treatment are similar for the two locations within France. Regression analyses reported in Table A1, either controlling or not for individual characteristics, do not reject the null hypotheses that the measured IVs in the two locations are the same for both T1 and T3. As for T2, we reject this hypothesis at 10\% level when using the average IV and controlling for individual characteristics. However, either using nonparametric tests (see Table A5) or controlling for the stake size using the percentage difference (see Table A4) we do not reject the null hypothesis that the measured IVs in the two locations are the same for all treatments.

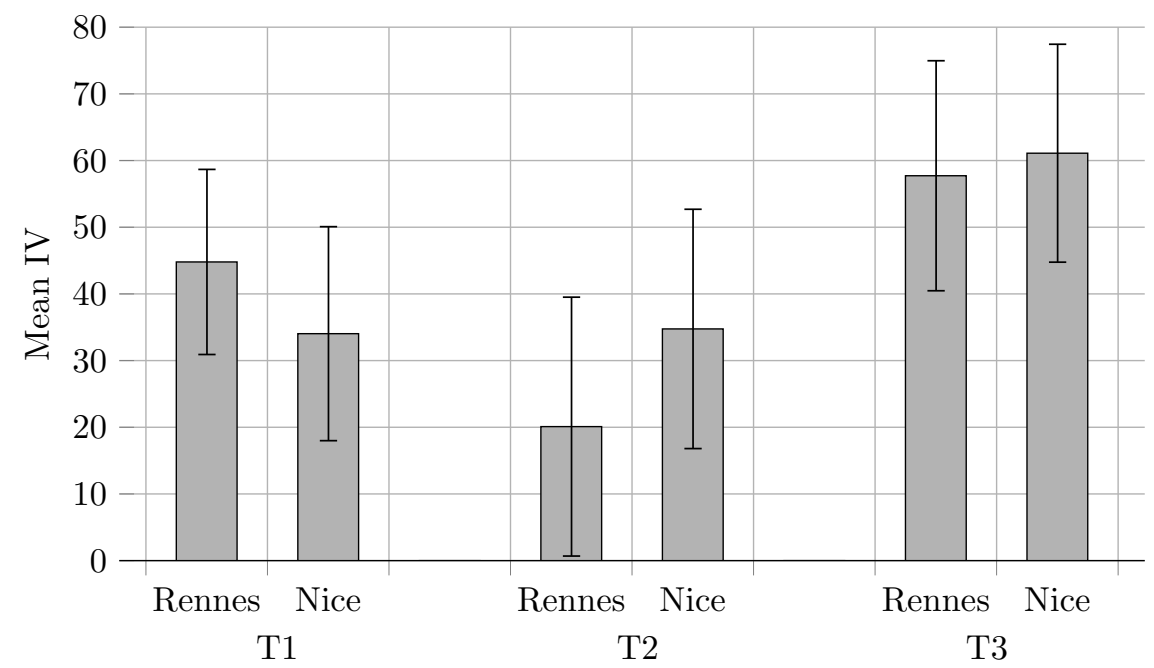

Figure A1: Mean IV, sorted by French location and treatment.

Notes: The bars display one standard error of the mean. Values are based on an OLS regression with clustered standard errors per subject and individual controls reported in columns (2), (4), and (6) of Table A1.

When looking to the three decisions that principals made in Part 1, we find that the chosen minimum effort requirement $\underline{e}$ is very similar (especially in T1 and T2) and not statistically significantly different for any treatment between the two locations (see Table A2), that effort choices are very similar and not significantly different for T2 and T3 but different and significantly different for T1 (see Table A3), and that principals chose the project that gave them the higher profit (project $\mathcal{P}$ ) in $87 \%$ of games in Rennes and $79 \%$ of games in Nice.

Figure A2 presents the IV measure for the three treatments in the two locations in Japan. As it can be seen from the figure, the values per treatment are very similar for the two locations within Japan. Regression analyses reported in Table A1, either controlling or not for individual characteristics, do not reject the null hypothesis that the measured IVs in the two locations are the same for all treatments. This result is robust either using nonparametric tests (see Table A5) or controlling for the stake size using the percentage difference (see Table A4). 


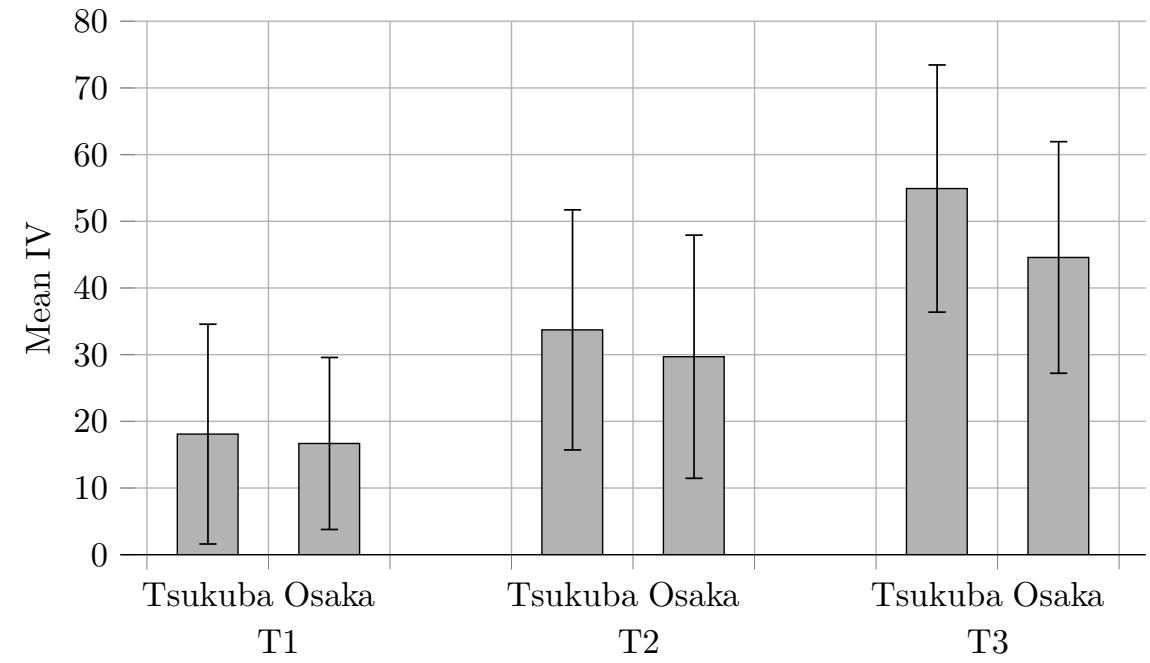

Figure A2: Mean IV, sorted by Japanese location and treatment.

Notes: The bars display one standard error of the mean. Values are based on an OLS regression with clustered standard errors per subject and individual controls reported in columns (2), (4), and (6) of Table A1.

In terms of the three decisions that principals made in Part 1, we find that the chosen minimum effort requirement $\underline{e}$ is very similar (especially in $\mathrm{T} 1$ and $\mathrm{T} 2$ ) and not statistically significantly different for any treatment between the two locations (see Table A2), that effort choices are not significantly different for $\mathrm{T} 1$ and $\mathrm{T} 2$ but different and significantly different for $\mathrm{T} 3$ (see Table A3), and that principals chose the project that gave them the higher profit (project $\mathcal{P}$ ) in $89 \%$ of games in Tsukuba and $87 \%$ of games in Osaka. 
Table A1: Within Country Differences, $I V$

\begin{tabular}{ccccccc}
\hline \hline & \multicolumn{2}{c}{ Treatment 1} & \multicolumn{2}{c}{ Treatment 2} & \multicolumn{2}{c}{ Treatment 3 } \\
& $(1)$ & $(2)$ & $(3)$ & $(4)$ & $(5)$ & $(6)$ \\
Rennes & $46.454^{* * *}$ & $44.792^{* * *}$ & $32.279^{* * *}$ & 20.098 & $41.221^{* * *}$ & $57.721^{* * *}$ \\
& $(5.488)$ & $(13.880)$ & $(5.648)$ & $(19.413)$ & $(5.395)$ & $(17.248)$ \\
Nice & $34.460^{* * *}$ & $34.036^{* *}$ & $45.125^{* * *}$ & $34.749^{*}$ & $45.769^{* * *}$ & $61.101^{* * *}$ \\
& $(7.376)$ & $(16.047)$ & $(5.603)$ & $(17.946)$ & $(9.205)$ & $(16.341)$ \\
Tsukuba & $20.660^{* * *}$ & 18.086 & $40.440^{* * *}$ & $33.716^{*}$ & $33.018^{* * *}$ & $54.912^{* * *}$ \\
& $(7.686)$ & $(16.482)$ & $(4.222)$ & $(18.001)$ & $(5.318)$ & $(18.535)$ \\
Osaka & $17.430^{* * *}$ & 16.679 & $39.311^{* * *}$ & 29.689 & $29.762^{* * *}$ & $44.577^{* *}$ \\
& $(6.058)$ & $(12.899)$ & $(4.935)$ & $(18.233)$ & $(6.353)$ & $(17.364)$ \\
Female & & -1.128 & & 1.521 & & 1.142 \\
& & $(7.142)$ & & $(6.902)$ & & $(6.807)$ \\
Raven's Score & & -0.082 & & 0.068 & & -0.772 \\
& & $(0.973)$ & & $(1.129)$ & & $(1.384)$ \\
Economics \& Management & & -3.331 & & 4.340 & & -3.566 \\
& & $(6.902)$ & & $(6.641)$ & & $-3.252)$ \\
Loss Aversion & & 0.757 & & 1.826 & & $(1.820)$ \\
& & $(1.680)$ & & $(2.499)$ & & 0.219 \\
Illusion of control & & 0.313 & & 0.389 & & $(0.405)$ \\
\hline$R^{2}$ & & $(0.424)$ & & $(0.440)$ & & 0.271 \\
N & 0.174 & 0.169 & 0.250 & 0.254 & 0.260 & 860 \\
\hline$H_{0}$ : Rennes = Nice & 0.196 & 850 & 1010 & 990 & 870 & 0.759 \\
$H_{0}$ : Tsukuba = Osaka & 0.742 & 0.236 & 0.110 & 0.074 & 0.671 & 0.205 \\
\hline \hline
\end{tabular}

Notes: *Significant at $10 \%$ level, ${ }^{* *}$ Significant at $5 \%$ level, $* * *$ Significant at $1 \%$ level, based on OLS regressions with clustered standard errors per subject. 
Table A2: Within Country Differences, $\underline{e}$

\begin{tabular}{|c|c|c|c|c|c|c|}
\hline & Treat & nent 1 & Treat & nent 2 & Treat & nent 3 \\
\hline & (1) & (2) & (3) & (4) & $(5)$ & (6) \\
\hline Rennes & $60.575^{* * *}$ & $55.650^{* * *}$ & $63.842^{* * *}$ & $66.229^{* * *}$ & $61.629^{* * *}$ & $70.919^{* * *}$ \\
\hline & $(2.829)$ & $(9.809)$ & $(2.078)$ & $(6.166)$ & $(2.612)$ & $(9.572)$ \\
\hline Nice & $62.733^{* * *}$ & $58.604^{* * *}$ & $65.660^{* * *}$ & $67.775^{* * *}$ & $70.046^{* * *}$ & $77.194^{* * *}$ \\
\hline & $(5.204)$ & $(11.036)$ & $(2.186)$ & $(6.347)$ & $(5.394)$ & $(9.456)$ \\
\hline Tsukuba & $54.025^{* * *}$ & $46.453^{* * *}$ & $61.108^{* * *}$ & $67.532^{* * *}$ & $56.882^{* * *}$ & $71.325^{* * *}$ \\
\hline & $(3.968)$ & $(10.948)$ & $(2.766)$ & $(6.871)$ & $(2.774)$ & $(11.166)$ \\
\hline Osaka & $49.791^{* * *}$ & $43.735^{* * *}$ & $60.667^{* * *}$ & $65.893^{* * *}$ & $52.862^{* * *}$ & $62.664^{* * *}$ \\
\hline & $(3.709)$ & $(10.538)$ & $(3.034)$ & $(7.651)$ & $(4.574)$ & $(10.230)$ \\
\hline Female & & -4.095 & & -1.653 & & 0.880 \\
\hline & & $(4.114)$ & & $(2.875)$ & & $(3.902)$ \\
\hline Raven's Score & & 0.650 & & -0.322 & & -0.821 \\
\hline & & $(0.727)$ & & $(0.466)$ & & $(0.748)$ \\
\hline Economics \& Management & & -0.152 & & $4.934^{*}$ & & 4.705 \\
\hline & & $(4.335)$ & & $(2.759)$ & & $(3.820)$ \\
\hline Loss Aversion & & 0.111 & & -0.597 & & -1.727 \\
\hline & & $(0.989)$ & & $(0.803)$ & & $(1.309)$ \\
\hline Illusion of Control & & 0.059 & & 0.175 & & 0.143 \\
\hline & & $(0.280)$ & & $(0.186)$ & & $(0.274)$ \\
\hline$R^{2}$ & 0.797 & 0.800 & 0.889 & 0.894 & 0.836 & 0.840 \\
\hline $\mathrm{N}$ & 860 & 850 & 1010 & 990 & 870 & 860 \\
\hline$H_{0}:$ Rennes $=$ Nice & 0.717 & 0.598 & 0.548 & 0.608 & 0.164 & 0.315 \\
\hline$H_{0}:$ Tsukuba $=$ Osaka & 0.438 & 0.644 & 0.915 & 0.689 & 0.455 & 0.147 \\
\hline
\end{tabular}

Notes: *Significant at $10 \%$ level, **Significant at $5 \%$ level, ***Significant at $1 \%$ level, based on OLS regressions with clustered standard errors per subject. 
Table A3: Within Country Differences, $E$

\begin{tabular}{ccccccc}
\hline \hline & \multicolumn{2}{c}{ Treatment 1 } & \multicolumn{2}{c}{ Treatment 2 } & \multicolumn{2}{c}{ Treatment 3 } \\
& $(1)$ & $(2)$ & $(3)$ & $(4)$ & $(5)$ & $(6)$ \\
Rennes & $70.682^{* * *}$ & $68.304^{* * *}$ & $63.926^{* * *}$ & $60.512^{* * *}$ & $68.950^{* * *}$ & $75.596^{* * *}$ \\
& $(2.350)$ & $(9.500)$ & $(2.538)$ & $(6.570)$ & $(2.662)$ & $(9.485)$ \\
Nice & $54.213^{* * *}$ & $52.821^{* * *}$ & $64.455^{* * *}$ & $61.629^{* * *}$ & $67.646^{* * *}$ & $73.220^{* * *}$ \\
& $(4.988)$ & $(10.589)$ & $(2.809)$ & $(6.820)$ & $(5.008)$ & $(9.450)$ \\
Tsukuba & $63.710^{* * *}$ & $60.485^{* * *}$ & $63.000^{* * *}$ & $62.812^{* * *}$ & $65.318^{* * *}$ & $77.271^{* * *}$ \\
& $(3.621)$ & $(9.985)$ & $(2.541)$ & $(7.793)$ & $(2.054)$ & $(11.276)$ \\
Osaka & $55.400^{* * *}$ & $52.22^{* * *}$ & $62.111^{* * *}$ & $60.757^{* * *}$ & $59.367^{* * *}$ & $67.306^{* * *}$ \\
& $(2.825)$ & $(9.344)$ & $(3.171)$ & $(7.883)$ & $(3.856)$ & $(9.969)$ \\
Female & & -0.570 & & -1.200 & & $6.120^{*}$ \\
& & $(3.913)$ & & $(3.329)$ & & $(3.282)$ \\
Raven's Score & & 0.314 & & -0.056 & & -0.814 \\
& & $(0.618)$ & & $(0.538)$ & & $(0.745)$ \\
Economics \& Management & & -2.946 & & 3.999 & & 0.271 \\
& & $(3.692)$ & & $(3.395)$ & & $(3.430)$ \\
Loss Aversion & & 0.123 & & 0.688 & & $(1.018$ \\
& & $(0.851)$ & & $(1.092)$ & & -0.008 \\
Illusion of Control & & -0.062 & & -0.016 & & $(0.227)$ \\
\hline$R^{2}$ & & $(0.234)$ & & $(0.248)$ & & 0.892 \\
$\mathrm{~N}$ & 0.875 & 0.875 & 0.896 & 0.900 & 0.888 & 860 \\
\hline$H_{0}$ : Rennes = Nice & 860 & 850 & 1010 & 990 & 870 & 0.668 \\
$H_{0}$ : Tsukuba = Osaka & 0.004 & 0.003 & 0.889 & 0.775 & 0.819 & 0.043 \\
\hline \hline
\end{tabular}

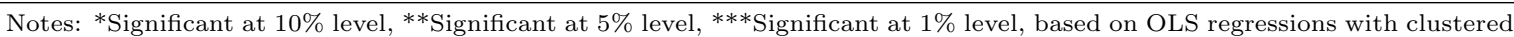
standard errors per subject. 
Table A4: Within Country Differences, $I V / C E$

\begin{tabular}{|c|c|c|c|c|c|c|}
\hline & \multicolumn{2}{|c|}{ Treatment 1} & \multicolumn{2}{|c|}{ Treatment 2} & \multicolumn{2}{|c|}{ Treatment 3} \\
\hline & $(1)$ & $(2)$ & $(3)$ & (4) & $(5)$ & (6) \\
\hline \multirow[t]{2}{*}{ Rennes } & $0.246^{* * *}$ & $0.267^{* * *}$ & $0.187^{* * *}$ & $0.185^{*}$ & $0.187^{* * *}$ & $0.239^{* * *}$ \\
\hline & $(0.035)$ & $(0.082)$ & $(0.034)$ & $(0.097)$ & $(0.025)$ & $(0.073)$ \\
\hline \multirow[t]{2}{*}{ Nice } & $0.190^{* * *}$ & $0.215^{* *}$ & $0.239^{* * *}$ & $0.248^{* *}$ & $0.231^{* * *}$ & $0.280^{* * *}$ \\
\hline & $(0.034)$ & $(0.087)$ & $(0.034)$ & $(0.099)$ & $(0.040)$ & $(0.069)$ \\
\hline \multirow[t]{2}{*}{ Tsukuba } & $0.100^{* *}$ & 0.131 & $0.177^{* * *}$ & $0.205^{* *}$ & $0.138^{* * *}$ & $0.217^{* * *}$ \\
\hline & $(0.041)$ & $(0.093)$ & $(0.018)$ & $(0.095)$ & $(0.022)$ & $(0.078)$ \\
\hline \multirow[t]{2}{*}{ Osaka } & $0.090^{* * *}$ & 0.121 & $0.191^{* * *}$ & $0.201^{* *}$ & $0.138^{* * *}$ & $0.192^{* * *}$ \\
\hline & $(0.028)$ & $(0.073)$ & $(0.029)$ & $(0.094)$ & $(0.026)$ & $(0.070)$ \\
\hline \multirow[t]{2}{*}{ Female } & & 0.020 & & 0.022 & & 0.021 \\
\hline & & $(0.040)$ & & $(0.039)$ & & $(0.029)$ \\
\hline \multirow[t]{2}{*}{ Raven's Score } & & -0.005 & & -0.005 & & -0.004 \\
\hline & & $(0.005)$ & & $(0.007)$ & & $(0.006)$ \\
\hline \multirow[t]{2}{*}{ Economics \& Management } & & -0.031 & & -0.008 & & -0.010 \\
\hline & & $(0.039)$ & & $(0.043)$ & & $(0.031)$ \\
\hline \multirow[t]{2}{*}{ Loss Aversion } & & 0.006 & & 0.012 & & -0.010 \\
\hline & & $(0.011)$ & & $(0.015)$ & & $(0.008)$ \\
\hline \multirow[t]{2}{*}{ Illusion of Control } & & 0.001 & & 0.000 & & 0.001 \\
\hline & & $(0.002)$ & & $(0.003)$ & & $(0.002)$ \\
\hline$R^{2}$ & 0.225 & 0.223 & 0.270 & 0.276 & 0.292 & 0.306 \\
\hline $\mathrm{N}$ & 860 & 850 & 1010 & 990 & 870 & 860 \\
\hline$H_{0}:$ Rennes $=$ Nice & 0.252 & 0.303 & 0.282 & 0.172 & 0.355 & 0.412 \\
\hline$H_{0}:$ Tsukuba $=$ Osaka & 0.834 & 0.867 & 0.664 & 0.918 & 0.991 & 0.480 \\
\hline
\end{tabular}

Notes: *Significant at $10 \%$ level, $* *$ Significant at $5 \%$ level, ${ }^{* * *}$ Significant at $1 \%$ level, based on OLS regressions with clustered standard errors per subject.

Table A5: Within Country Differences:

Parametric and non parametric tests

\begin{tabular}{|c|c|c|c|}
\hline & Treatment 1 & Treatment 2 & Treatment 3 \\
\hline \multicolumn{4}{|l|}{$H_{0}:$ Rennes $=$ Nice } \\
\hline Wilcoxon-Mann-Whitney test & 0.302 & 0.432 & 0.867 \\
\hline Student test & 0.209 & 0.154 & 0.661 \\
\hline \multicolumn{4}{|l|}{$H_{0}:$ Tsukuba $=$ Osaka } \\
\hline Wilcoxon-Mann-Whitney test & 0.609 & 0.844 & 0.482 \\
\hline Student test & 0.744 & 0.865 & 0.703 \\
\hline
\end{tabular}




\section{Cross-cultural Comparison}

Empirical evidence and casual observation suggest that cultural backgrounds may have a strong influence on core values like autonomy and power. There is by now a long list of cross-cultural experimental studies that document significant differences in preferences and behavior across societies (e.g. Roth et al. 1991; Henrich et al. 2004; Gaechter et al. 2010). An important and well-documented distinction is the one between Eastern and Western cultural backgrounds (e.g. Markus and Kitayama 1991; Nisbett 2003; Nisbett and Masuda 2003). In particular, several studies suggest that an East Asian cultural background emphasizes collectivism and cooperation more than a Western cultural background that promotes more individualistic values (e.g. Parks and $\mathrm{Vu}$ 1994; Wong and Hong 2005; LeBoeuf et al. 2010).

Here we explore if the French (linked to Western) and Japanese (linked to Eastern) cultural backgrounds translate into different tastes for holding control in our setting. We expected principals in France to attach a higher intrinsic value to hold control than principals in Japan. Our hypothesis was that this would be mainly driven by a higher value of independence and self-reliance in France. This is consistent with the experimental evidence just described. It is also supported by the WVS 2015 data that suggests that French give considerably more weight to self-expression values than Japanese ${ }^{29}$, and survey-evidence that suggests that the ties between individuals within the workplace are looser in France than in Japan (see Hofstede et al. 2010). Finally, we also expected power to be higher valued in France than in Japan. This seems to be consistent with the evidence that the extent to which the less powerful members of institutions and organizations expect and accept that power is distributed unequally is higher in France than in Japan (see Hofstede et al. 2010), which suggests that French may more easily exhibit a preference for power than Japanese. These expectations can be summarized in the following hypotheses:

Hypothesis 4 IND(France $)>I N D($ Japan $)$.

Hypothesis 5 POW (France $)>P O W($ Japan $)$.

Hypothesis $6 \operatorname{SELF}($ France $)>S E L F($ Japan $)$.

Looking at the measured IV in T1 (i.e., taking all rationales into account), we find that subjects in France attach a higher intrinsic value to hold control than those in Japan. On average, the IV in T1 is worth 22 points more in France than in Japan (see column (2) of Table 4 in Appendix A). We reject the hypothesis that subjects in France and subjects in Japan attach the same difference of value between the delegation lotteries and the control lotteries in T1 $(p<0.001$, Wald test based on the regression reported in column (2) of Table 4 in Appendix A). When taking the mean IV per subject, a Mann-Whitney U test and a bootstrap test also

\footnotetext{
${ }^{29}$ See Inglehart and Baker (2000) for the theoretical background of the WVS data and the "self-expression versus survival" measure.
} 
reject this hypothesis ( $p<0.001$ and $p<0.01$ respectively), and matching estimator techniques also support this result (see Table A15 in OSM V). Thus:

Result 3 Decision rights have on average a higher intrinsic value for French than for Japanese subjects.

Using the data from Bartling et al.'s (2014), we observe that the IV for Swiss subjects worth 27 points - lies in between the IV in France and the IV in Japan. Though on average this result is consistent with a higher IV for subjects with a Western cultural background than an Eastern one, we cannot reject the hypothesis that the value in Switzerland is equal to the one in Japan. This highlights the need for more evidence in order to extend (or reject) Result 3 for Western and Eastern subjects in general.

In terms of the roots of the intrinsic value of decision rights, subjects are surprisingly similar in the two countries. First, we do not reject the hypothesis that $S E L F($ France $)=S E L F($ Japan $)$ neither the hypothesis that $I N D($ France $)=I N D($ Japan $)$. Second, although we reject the hypothesis that $P O W($ France $)=P O W($ Japan $)$, we do so only at $10 \%$ significance level (see Table 3 in Section 4 for these results).

This means that, contrary to our hypotheses, we find no significant difference in terms of the value of independence and self-reliance between the two countries. This suggests that the more individualistic cultural background of France and/or the more collective oriented cultural background of Japan do not translate to a higher (lower) value of autonomy as a motive for the intrinsic value of holding control in our setting. At the same time, Japanese subjects give on average a lower value to both independence and power than subjects in France. This difference is only mildly statistically significant for power, but seems to explain the lower intrinsic value that Japanese subjects attach to hold control (as measured in T1).

As with our previous results, care should be taken in the interpretation of these results. Besides the abstract nature of our setting, we note that casual observation and introspection suggest that university students of non-western countries are among the most "westernized" individuals in these countries. Our results should, as such, be interpreted as a lower bound in terms of the potential effects arising from cultural differences. 


\section{Decisions Part 1}

Table A6: Minimum Effort Requirement, $\underline{e}$

\begin{tabular}{ccc}
\hline \hline & $(1)$ & $(2)$ \\
T1 France & $61.328^{* * *}$ & $62.155^{* * *}$ \\
& $(2.579)$ & $(5.855)$ \\
T1 Japan & $51.760^{* * *}$ & $53.663^{* * *}$ \\
& $(2.716)$ & $(5.816)$ \\
T2 France & $64.469^{* * *}$ & $65.171^{* * *}$ \\
& $(1.555)$ & $(4.874)$ \\
T2 Japan & $60.923^{* * *}$ & $63.606^{* * *}$ \\
& $(2.042)$ & $(5.522)$ \\
T3 France & $64.298^{* * *}$ & $64.878^{* * *}$ \\
& $(2.535)$ & $(5.040)$ \\
T3 Japan & $54.785^{* * *}$ & $56.103^{* * *}$ \\
& $(2.734)$ & $(5.912)$ \\
Female & & -1.979 \\
& & $(2.062)$ \\
Raven's Score & & -0.003 \\
& & $(0.379)$ \\
Economics \& Management & & $3.698^{*}$ \\
& & $(2.028)$ \\
Loss Aversion & & -0.649 \\
& & $(0.595)$ \\
Illusion of Control & & 0.096 \\
& & $(0.157)$ \\
\hline$R^{2}$ & & 0.846 \\
& & 2700 \\
\hline
\end{tabular}

Notes: *Significant at $10 \%$ level, ${ }^{* *}$ Significant at $5 \%$ level, ${ }^{* * *}$ Significant at $1 \%$ level, based on OLS regression with clustered standard errors per subject. 
Table A7: Minimum Effort Requirement, $\underline{e}$, Between Treatement Differences

\begin{tabular}{lc}
\hline \hline France & Wald Tests \\
$H_{0}: \mathrm{T} 1=\mathrm{T} 2$ & 0.328 \\
$H_{0}: \mathrm{T} 1=\mathrm{T} 3$ & 0.453 \\
$H_{0}: \mathrm{T} 2=\mathrm{T} 3$ & 0.921 \\
\hline Japan & \\
$H_{0}: \mathrm{T} 1=\mathrm{T} 2$ & 0.004 \\
$H_{0}: \mathrm{T} 1=\mathrm{T} 3$ & 0.529 \\
$H_{0}: \mathrm{T} 2=\mathrm{T} 3$ & 0.030 \\
\hline \hline
\end{tabular}

Notes: This table displays $p$-values for two-tailed Wald tests applied on the minimum effort requirement $\underline{e}$ per subject and game with individual controls and clustered standard errors per subject.

Table A8: Effort, $E$

\begin{tabular}{|c|c|c|}
\hline & (1) & $(2)$ \\
\hline T1 France & $\begin{array}{c}64.937^{* * *} \\
(2.599)\end{array}$ & $\begin{array}{c}61.006^{* * *} \\
(6.060)\end{array}$ \\
\hline T1 Japan & $\begin{array}{c}59.265^{* * *} \\
(2.339)\end{array}$ & $\begin{array}{c}56.804^{* * *} \\
(5.479)\end{array}$ \\
\hline T2 France & $\begin{array}{c}64.109^{* * *} \\
(1.917)\end{array}$ & $\begin{array}{c}60.984^{* * *} \\
(5.025)\end{array}$ \\
\hline T2 Japan & $\begin{array}{c}62.628^{* * *} \\
(1.980)\end{array}$ & $\begin{array}{c}60.986^{* * *} \\
(5.484)\end{array}$ \\
\hline T3 France & $\begin{array}{c}68.537^{* * *} \\
(2.404)\end{array}$ & $\begin{array}{c}65.608^{* * *} \\
(5.071)\end{array}$ \\
\hline T3 Japan & $\begin{array}{c}62.213^{* * *} \\
(2.271)\end{array}$ & $\begin{array}{c}59.941^{* * *} \\
(5.777)\end{array}$ \\
\hline Female & & $\begin{array}{l}1.4957 \\
(2.045)\end{array}$ \\
\hline Raven's Score & & $\begin{array}{l}-0.085 \\
(0.369)\end{array}$ \\
\hline Economics \& Management & & $\begin{array}{c}0.811 \\
(2.047)\end{array}$ \\
\hline Loss Aversion & & $\begin{array}{c}0.263 \\
(0.579)\end{array}$ \\
\hline Illusion of Control & & $\begin{array}{l}-0.003 \\
(0.150) \\
\end{array}$ \\
\hline$R^{2}$ & 0.884 & 0.885 \\
\hline $\mathrm{N}$ & 2740 & 2700 \\
\hline
\end{tabular}


Table A9: Effort, $E$, Between Treatement Differences

\begin{tabular}{lc}
\hline \hline France & Wald Tests \\
$H_{0}: \mathrm{T} 1=\mathrm{T} 2$ & 0.995 \\
$H_{0}: \mathrm{T} 1=\mathrm{T} 3$ & 0.203 \\
$H_{0}: \mathrm{T} 2=\mathrm{T} 3$ & 0.132 \\
\hline Japan & \\
$H_{0}: \mathrm{T} 1=\mathrm{T} 2$ & 0.177 \\
$H_{0}: \mathrm{T} 1=\mathrm{T} 3$ & 0.333 \\
$H_{0}: \mathrm{T} 2=\mathrm{T} 3$ & 0.731 \\
\hline \hline
\end{tabular}

Notes: This table displays $p$-values for two-tailed Wald tests applied on

the effort $E$ per subject and game with individual controls and clustered standard errors per subject. 


\section{Independence from Randomness}

Given our design, the willingness to keep control in T2 and T3 could be potentially driven by motives linked to the behavior of the bot, which in our main study determines its effort randomly. In this section, we evaluate the weight on the IV of a desire for independence from randomness:

Motive 4 (IND-R) Aversion to be affected by the decision made by a random device.

We run four additional treatments (T2A, T2B, T2C, and T2D) that differ from $\mathrm{T} 2$ in how the bot makes its choice of effort. ${ }^{30}$ In each treatment, the bot chooses a certain level of effort $\bar{e}$ with probability $\pi$ and any other level between 0 and 100 with probability $1-\pi$ (each level having the same chance of being chosen). In order to test for the potential effect of giving a focal point at $\bar{e}$, we let $\bar{e} \in\{50,60\}$. In T2A and T2B, $\pi$ takes the value of $95 \%$. This is meant to decrease the degree of randomness that the principal faces in case of delegation, but not to the point of certainty in order to keep the elicitation of the principals' minimum effort requirement incentive compatible. In order to control for the potential impact of framing effects, we run two treatments (T2C and T2D) that are identical to T2, but in which the presentation of the decision making of the bot is similar to T2A and T2B. In these treatments $\bar{e}$ is either 50 or 60 and $\pi=1 / 101$, which means that the bot chooses its effort level randomly as in T2. ${ }^{31}$ Table A10 summarizes these additional treatments.

Table A10: Additional treatments

\begin{tabular}{ccc}
\hline \hline Treatment & $\bar{e}$ & $\pi$ \\
$\mathrm{T} 2 \mathrm{~A}$ & 60 & $95 \%$ \\
$\mathrm{~T} 2 \mathrm{~B}$ & 50 & $95 \%$ \\
$\mathrm{~T} 2 \mathrm{C}$ & 60 & $1 / 101$ \\
$\mathrm{~T} 2 \mathrm{D}$ & 50 & $1 / 101$ \\
\hline \hline
\end{tabular}

Assuming that independence from randomness is a motive in $\mathrm{T} 2, \mathrm{~T} 2 \mathrm{C}$ and $\mathrm{T} 2 \mathrm{D}$, but negligible in $\mathrm{T} 2 \mathrm{~A}$ and $\mathrm{T} 2 \mathrm{~B}$, we can estimate the weight of this motive in the intrinsic value of holding control as follows: ${ }^{32}$

\footnotetext{
${ }^{30} \mathrm{As}$ in $\mathrm{T} 2$, the bot chooses project $\mathcal{A}$ and principals are informed about the decision making model of the bot.

${ }^{31}$ The only difference in the instructions of T2C (as compared with T2) read as follows: "The bot chooses a probability of success equal to 60 with 1/101 chance and, with 100/101 chance, the bot chooses a probability of success between 0 and 100 that is different from 60 , with each of these values having the same chance to be selected. There is thus a $1 / 101$ chance that the bot picks a probability of success equal to 0 ; a $1 / 101$ chance that the bot picks a probability of success equal to 1 ; etc.; $1 / 101$ chance that the bot picks a probability of success equal to $59 ; 1 / 101$ chance that the bot picks a probability of success equal to $60 ; 1 / 101$ chance that the bot picks a probability of success equal to 61 ; etc.; $1 / 101$ chance that the bot picks a probability of success equal to $100 . "$ The other additional treatments read similarly with the respective differences in $\bar{e}$ and $\pi$.

${ }^{32}$ We assume that IND-R is negligible in T2A and T2B for the sake of presentation. Our tests of the weight of IND-R are valid as long as the desire for independence from randomness depends monotonically and smoothly on the degree of randomness. Note that the degree of randomness is considerably reduced in $\mathrm{T} 2 \mathrm{~A}$ and $\mathrm{T} 2 \mathrm{~B}$ when compared to T2, T2C, and T2D.
} 


$$
\mathbf{I N D - R}=I V_{T 2 i}-I V_{T 2 j}=(S E L F+I N D-R)-(S E L F)
$$

where $\{i, j\} \in\{\{\emptyset, A\},\{\emptyset, B\},\{C, A\},\{D, B\}\}$. The additional treatments involved 191 subjects in Rennes and Osaka, and our analysis is based on 172 principals due to nationality restrictions. ${ }^{33}$ All experimental procedures were the same as those of the main study.

First, and reassuringly, we find no evidence of effects due to focal points and framing effects in both locations. We cannot reject the null hypotheses that the IV is the same in T2A and T2B, that the IV is the same in T2C and T2D, neither the null hypotheses that the IV is the same in $\mathrm{T} 2$ and $\mathrm{T} 2 \mathrm{C}$ or $\mathrm{T} 2$ and $\mathrm{T} 2 \mathrm{D}$ (based on two-tailed Wald tests from OLS regression reported in column (2) of Table A12, $p>0.1$ for all tests). ${ }^{34}$

We present the measured values of independence from randomness in Table A11. As it can be seen from the table, independence from randomness is not a statistically significant motive in either location. In Rennes, and contrary to the hypothesis that independence from randomness is a motive for the intrinsic value of holding control, the IV is on average lower when randomness increases. While this difference could be interpreted as a desire for randomness, the treatment differences are not significantly different from 0 for 3 out of 4 of our measures of aversion from (desire for) randomness. In Osaka, the IV is on average higher when randomness increases. While this accords with a potential relevance of independence from randomness, the effect is small and not significantly different from 0 for all of our measures of IND-R. Taken together, these results suggest that independence from randomness is not a motive for the intrinsic value of decision rights in $\mathrm{T} 2$ and $\mathrm{T} 3$ of our main study.

Table A11: Independence from randomness (IND-R)

\begin{tabular}{cccc}
\hline \hline & Rennes & Osaka & $H_{0}:$ Rennes = Osaka \\
$I V_{T 2 C}-I V_{T 2 A}$ & -4.591 & 2.271 & -6.862 \\
$I V_{T 2 D}-I V_{T 2 B}$ & -12.348 & 0.345 & -10.076 \\
$I V_{T 2}-I V_{T 2 A}$ & -5.707 & 6.009 & -11.716 \\
$I V_{T 2}-I V_{T 2 B}$ & $-15.201^{* *}$ & 6.726 & $-9.192^{* *}$ \\
\hline \hline
\end{tabular}

Notes: *Significant at $10 \%$ level, **Significant at $5 \%$ level, ***Significant at $1 \%$ level, based on two-tailed Wald tests from OLS regression with clustered standard errors per subject and individual controls reported in column (2) of Table A12.

\footnotetext{
${ }^{33}$ More specifically, the analysis is based on 71 principals in Rennes (17 in T2A, 14 in T2B, 21 in T2C, and 19 in T2D) and 101 principals in Osaka (27 T2A, 24 in T2B, 28 in T2C, and 22 in T2D). The characteristics of the subjects that participated to these additional treatments are similar to the ones of the main study, with the exception of the mean age which is significantly lower in the two locations and the significantly lower number of female subjects and students in Economics and Management in Rennes $(p<0.05$ for all tests). We control for gender and field of study in our regressions.

${ }^{34}$ Due to a technical problem, we do not have data on loss aversion in one session. For that reason, we perform the regression analysis reported in column (2) of Table A12 without integrating this measure. Note however that loss aversion is not significant in any regression that we run.
} 
Table A12: The Intrinsic Value of Decision Rights, IV (Additional Treatments)

\begin{tabular}{|c|c|c|}
\hline & $(1)$ & $(2)$ \\
\hline \multirow[t]{2}{*}{ T1 Rennes } & $46.454^{* * *}$ & $40.014^{* * *}$ \\
\hline & 5.466 & 8.775 \\
\hline \multirow[t]{2}{*}{ T1 Osaka } & $17.430 * * *$ & 10.843 \\
\hline & 6.033 & 8.857 \\
\hline \multirow[t]{2}{*}{ T2 Rennes } & $32.279^{* * *}$ & $26.122^{* * *}$ \\
\hline & 5.631 & 9.726 \\
\hline \multirow[t]{2}{*}{ T2A Rennes } & $38.359^{* * *}$ & $31.829^{* * *}$ \\
\hline & 5.464 & 8.899 \\
\hline \multirow[t]{2}{*}{ T2B Rennes } & $47.393^{* * *}$ & $41.322^{* * *}$ \\
\hline & 4.737 & 8.017 \\
\hline \multirow[t]{2}{*}{ T2C Rennes } & $34.205^{* * *}$ & $27.238^{* * *}$ \\
\hline & 6.557 & 9.419 \\
\hline \multirow[t]{2}{*}{ T2D Rennes } & $34.916^{* * *}$ & $28.974^{* * *}$ \\
\hline & 6.550 & 9.243 \\
\hline \multirow[t]{2}{*}{ T2 Osaka } & $39.311^{* * *}$ & $32.317^{* * *}$ \\
\hline & 4.920 & 8.826 \\
\hline \multirow[t]{2}{*}{ T2A Osaka } & $32.985^{* * *}$ & $26.308^{* * *}$ \\
\hline & 6.467 & 9.511 \\
\hline \multirow[t]{2}{*}{ T2B Osaka } & $32.517^{* * *}$ & $25.591^{* * *}$ \\
\hline & 6.052 & 8.716 \\
\hline \multirow[t]{2}{*}{ T2C Osaka } & $35.493^{* * *}$ & $28.579^{* * *}$ \\
\hline & 5.369 & 9.003 \\
\hline \multirow[t]{2}{*}{ T2D Osaka } & $32.786^{* * *}$ & $25.935^{* * *}$ \\
\hline & 5.942 & 8.469 \\
\hline \multirow[t]{2}{*}{ T3 Rennes } & $41.221^{* * *}$ & $34.905^{* * *}$ \\
\hline & 5.373 & 8.758 \\
\hline \multirow[t]{2}{*}{ T3 Osaka } & $29.762^{* * *}$ & $23.636^{* *}$ \\
\hline & 6.328 & 9.689 \\
\hline \multirow[t]{2}{*}{ Female } & & -0.357 \\
\hline & & 3.291 \\
\hline \multirow[t]{2}{*}{ Raven's Score } & & 0.580 \\
\hline & & 0.595 \\
\hline \multirow[t]{2}{*}{ Econ. \& Management } & & 0.943 \\
\hline & & 3.741 \\
\hline \multirow[t]{2}{*}{ Illusion of Control } & & 0.072 \\
\hline & & 0.232 \\
\hline$R^{2}$ & 0.226 & 0.227 \\
\hline $\mathrm{N}$ & 3310 & 3310 \\
\hline
\end{tabular}

Notes: ${ }^{*}$ Significant at $10 \%$ level, $* *$ Significant at $5 \%$ level, $* * *$ Significant at $1 \%$ level, based on OLS regressions with clustered standard errors per subject. 


\section{Robustness Tests}

Table A13: The Intrinsic Value of Decision Rights, $I V / C E$

\begin{tabular}{|c|c|c|}
\hline & (1) & $(2)$ \\
\hline T1 France & $\begin{array}{c}0.226^{* * *} \\
(0.026)\end{array}$ & $\begin{array}{c}0.250^{* * *} \\
(0.053)\end{array}$ \\
\hline T1 Japan & $\begin{array}{c}0.095^{* * *} \\
(0.024)\end{array}$ & $\begin{array}{c}0.133^{* *} \\
(0.051)\end{array}$ \\
\hline T2 France & $\begin{array}{c}0.205^{* * *} \\
(0.026)\end{array}$ & $\begin{array}{c}0.233^{* * *} \\
(0.057)\end{array}$ \\
\hline T2 Japan & $\begin{array}{c}0.183^{* * *} \\
(0.016)\end{array}$ & $\begin{array}{c}0.223^{* * *} \\
(0.050)\end{array}$ \\
\hline T3 France & $\begin{array}{c}0.201^{* * *} \\
(0.022)\end{array}$ & $\begin{array}{c}0.230^{* * *} \\
(0.048)\end{array}$ \\
\hline T3 Japan & $\begin{array}{c}0.138^{* * *} \\
(0.017)\end{array}$ & $\begin{array}{c}0.174^{* * *} \\
(0.048)\end{array}$ \\
\hline Female & & $\begin{array}{c}0.021 \\
(0.021)\end{array}$ \\
\hline Raven's Score & & $\begin{array}{l}-0.004 \\
(0.004)\end{array}$ \\
\hline Economics \& Management & & $\begin{array}{c}-0.014 \\
(0.023)\end{array}$ \\
\hline Loss Aversion & & $\begin{array}{c}0.002 \\
(0.007)\end{array}$ \\
\hline Illusion of Control & & $\begin{array}{c}0.000 \\
(0.001)\end{array}$ \\
\hline$R^{2}$ & 0.258 & 0.261 \\
\hline $\mathrm{N}$ & 2740 & 2700 \\
\hline
\end{tabular}

Table A14: The Roots of the Intrinsic Value of Decision Rights (Nonparametric Tests)

\begin{tabular}{lccc}
\hline \hline & $\begin{array}{c}\text { INDependence } \\
\left(I V_{T 1}-I V_{T 3}\right)\end{array}$ & $\begin{array}{c}\text { POWer } \\
\left(I V_{T 3}-I V_{T 2}\right)\end{array}$ & $\begin{array}{c}\text { SELF-reliance } \\
\left(I V_{T 2}\right)\end{array}$ \\
\hline France & -0.394 & 5.955 & $36.709^{* * *}$ \\
Japan & $-12.387^{*}$ & $-8.648^{*}$ & $39.967^{* * *}$ \\
\hline \hline Notes: *Significant at 10\% level, **Significant at 5\% level, ***Significant at \\
1\% level, based on Mann-Whitney U tests (IND and POW) and Wilcoxon \\
signed-rank test (SELF) and with average IV by subject.
\end{tabular}


Table A15: Maching Estimators, IV

\begin{tabular}{ccccccccc}
\hline \hline & \multicolumn{2}{c}{ OLS regression } & \multicolumn{3}{c}{ Nearest-neighbor matching } & \multicolumn{2}{c}{ Propensity score } \\
& & & \multicolumn{2}{c}{ Mahalanobis } & \multicolumn{2}{c}{ Euclidean } & matching \\
& $(1)$ & $(2)$ & $(3)$ & $(4)$ & $(5)$ & $(6)$ & $(7)$ & $(8)$ \\
& Coef. & $p$-value & Coef. & $p$-value & Coef. & $p$-value & Coef. & $p$-value \\
T1 (FR - JP) & 21.963 & 0.001 & 20.885 & $<0.001$ & 19.108 & $<0.001$ & 22.348 & $<0.001$ \\
T2 (FR - JP) & -4.384 & 0.481 & -10.133 & 0.067 & -0.984 & 0.848 & -5.006 & 0.544 \\
T3 (FR - JP) & 10.952 & 0.093 & 10.287 & 0.018 & 11.529 & 0.013 & 2.855 & 0.592 \\
\hline \hline
\end{tabular}

Notes: Columns (1)-(2) present the difference in IV between French and Japanese subjects for treatments 1-3 based on the OLS regression controlling for gender, main field of study, illusion of control, and loss aversion [see column (2) in Table 4]. Columns (3)-(8) present the difference in IV between French and Japanese subjects for treatments 1-3 based on matching estimators. The Mahalanobis and Euclidean distance between subjects and the propensity score matching are estimated based on gender, main field of study, illusion of control, and loss aversion.

Table A16: Maching Estimators, INDependence and POWer

\begin{tabular}{|c|c|c|c|c|c|c|c|c|}
\hline & \multirow{2}{*}{\multicolumn{2}{|c|}{ OLS regression }} & \multicolumn{4}{|c|}{ Nearest-neighbor matching } & \multirow{2}{*}{\multicolumn{2}{|c|}{$\begin{array}{c}\text { Propensity score } \\
\text { matching }\end{array}$}} \\
\hline & & & Maha & anobis & Euc & idean & & \\
\hline & $(1)$ & $(2)$ & $(3)$ & $(4)$ & $(5)$ & $(6)$ & $(7)$ & $(8)$ \\
\hline & Coef. & $p$-value & Coef. & $p$-value & Coef. & $p$-value & Coef. & $p$-value \\
\hline \multicolumn{9}{|l|}{ France } \\
\hline $\operatorname{IND}\left(I V_{T 1}-I V_{T 3}\right)$ & -1.079 & 0.868 & -1.081 & 0.829 & -.751 & 0.885 & .376 & 0.950 \\
\hline $\begin{array}{l}\mathrm{POW}\left(I V_{T 3}-I V_{T 2}\right) \\
\text { Japan }\end{array}$ & 5.854 & 0.361 & .915 & 0.840 & -.254 & 0.951 & 3.961 & 0.396 \\
\hline IND $\left(I V_{T 1}-I V_{T 3}\right)$ & -12.090 & 0.054 & -10.179 & 0.041 & -9.677 & 0.040 & -15.95 & 0.003 \\
\hline $\mathrm{POW}\left(I V_{T 3}-I V_{T 2}\right)$ & -9.483 & 0.077 & -7.803 & 0.144 & -9.217 & 0.124 & -3.307 & 0.577 \\
\hline
\end{tabular}

Notes: Columns (1)-(2) present the values for independence and power based on the OLS regression controlling for gender, main field of study, illusion of control, and loss aversion [see column (2) in Table 4]. Columns (3)-(8) present the values for independence and power based on matching estimators. The Mahalanobis and Euclidean distance between subjects and the propensity score matching are estimated based on gender, main field of study, illusion of control, and loss aversion.

\section{Situational Determinants}

The experimental design allows us to test for two situational determinants of the IV and its rationales: (i) stake size and (ii) conflict of interest. In terms of stake size, it is possible to distinguish between "low stakes" games (1-5) and "high stakes" games (6-10) [see Table 2].

Table A17 shows the IV and its motives for the two stake size levels. As it can be seen from the table, the magnitudes of all our estimated absolute values increase with the stake size. In terms of the IV, this is consistent with the findings of Bartling et al. (2014). One can note that this is not surprising since the percentage difference also increases with the stake size. The IV is positive and significantly different between France and Japan for both low and high stake sizes. This is again consistent with our main results. The only difference with respect to our main analysis is that the IV in Japan becomes insignificant for low stakes. But either using percentage difference as the dependent variable or non-parametric tests with average IV by individual the intrinsic value of holding control is highly significant for low stakes also in Japan ( $p=0.019$ based on OLS regression with clustered standard errors per subject and individual 
Table A17: The Effect of Stake Size

\begin{tabular}{ccccc}
\hline \hline & IV & INDependence & POWer \\
& $I V_{T 1}$ & $\left(I V_{T 1}-I V_{T 3}\right)$ & $\left(I V_{T 3}-I V_{T 2}\right)$ & $\begin{array}{c}\text { SELF-reliance } \\
\left(I V_{T 2}\right)\end{array}$ \\
\hline France (Low) & $29.767^{* * *}$ & 1.351 & 2.450 & $25.966^{* * *}$ \\
France (High) & $52.800^{* * *}$ & -3.509 & 9.257 & $47.052^{* * *}$ \\
\hline$H_{0}$ : Low = High & $p=0.001$ & $p=0.565$ & $p=0.395$ & $p=0.001$ \\
\hline Japan (Low) & 11.965 & $-8.166^{*}$ & -4.355 & $24.486^{* *}$ \\
Japan (High) & $26.677^{* *}$ & -16.014 & $-14.610^{*}$ & $57.301^{* * *}$ \\
\hline$H_{0}$ : Low = High & $p=0.026$ & $p=0.395$ & $p=0.240$ & $p<0.001$ \\
\hline$H_{0}:$ FR = JP (Low) & $p<0.001$ & $p=0.141$ & $p=0.272$ & $p=0.769$ \\
$H_{0}:$ FR = JP (High) & $p=0.014$ & $p=0.375$ & $p=0.069$ & $p=0.281$ \\
\hline \hline
\end{tabular}

Notes: *Significant at $10 \%$ level, **Significant at $5 \%$ level, ***Significant at $1 \%$ level, based on OLS regression with clustered standard errors per subject and individual controls.

controls, and $p=0.003$ based on a Wilcoxon signed-rank test respectively). In terms of the roots of the intrinsic value of holding control, our main results are robust to the stake size. In particular, self-reliance continues to be the only positive and significant rationale of the IV. In addition, independence and power continue to be non-significantly valued in France and on average negatively valued (though either not significantly or significantly just at 10\%) in Japan.

In terms of the conflict of interest between the principal and the agent, Bartling et al. (2014) distinguish between "high conflict" games (3, 4, 8 and 9), "low conflict" games (1, 2,6 and 7), and "no conflict" games (5 and 10) [see Table 2]. ${ }^{35}$ However, performing a similar analysis as in Table A17 may lead to misleading inferences given that the stake size is different for different degrees of conflict; in particular, it is not possible to disentangle the two effects resorting to that method. In order to further investigate our results concerning different stake sizes and have a sense of the effect of the degree of conflict between the principal and the agent, we test the marginal effects of stake size and degree of conflict on our IV measure.

Table A18 shows the marginal effect of the stake size and degree of conflict on the IV, per treatment and country. ${ }^{36}$ As seen from the table, and taking all motives into account (i.e., values for T1), while the intrinsic value of holding control increases 0.155 and 0.075 points per additional unit of stake size in France and Japan respectively, it decreases 0.341 and 0.128 points for each additional unit of degree of conflict in France and Japan respectively. In terms of the roots of the IV, the marginal effect of stake size is only significant for self-reliance in France $(p<0.001$, Wald test based on the OLS regression of column $(2)$ of Table A18), and for self-

\footnotetext{
${ }^{35}$ In Bartling et al. (2014) conflict of interest is defined as the principal's relative payoff difference between projects $\mathcal{A}$ and $\mathcal{P}\left[\left(P_{\mathcal{A}}-P_{0}\right) /\left(P_{\mathcal{P}}-P_{0}\right)\right]$.

${ }^{36}$ The principal's payoff of project $A$ in case of success $\left(P_{\mathcal{A}}\right)$ is used as a proxy for the stake size of each game while the difference between the principal's payoff and the agent's payoff of project $A$ in case of success $\left(P_{\mathcal{A}}-A_{\mathcal{A}}\right)$ is used as a proxy for the degree of conflict in each game. We use project $A$ because it determines the high payoff of the delegation lottery for which the principal has not to pay the cost of effort.
} 
Table A18: The Marginal Effect of Stake Size and Conflict of Interest, $I V$

\begin{tabular}{|c|c|c|}
\hline & (1) & $(2)$ \\
\hline \multirow[t]{2}{*}{ T1 France } & 14.153 & 13.393 \\
\hline & $(9.783)$ & $(13.564)$ \\
\hline \multirow[t]{2}{*}{ T1 Japan } & 3.345 & 3.733 \\
\hline & $(7.636)$ & $(11.867)$ \\
\hline \multirow[t]{2}{*}{ T2 France } & 9.848 & 9.649 \\
\hline & $(6.394)$ & $(9.753)$ \\
\hline \multirow[t]{2}{*}{ T2 Japan } & -5.503 & -2.786 \\
\hline & $(6.851)$ & (11.163) \\
\hline \multirow[t]{2}{*}{ T3 France } & $10.462^{*}$ & 10.162 \\
\hline & $(6.002)$ & $(10.504)$ \\
\hline \multirow[t]{2}{*}{ T3 Japan } & -3.026 & -1.044 \\
\hline & $(8.035)$ & (11.668) \\
\hline \multirow[t]{2}{*}{ Stake*T1 France } & $0.156^{* * *}$ & $0.155^{* * *}$ \\
\hline & $(0.034)$ & $(0.035)$ \\
\hline \multirow[t]{2}{*}{ Stake*T2 France } & $0.125^{* * *}$ & $0.125^{* * *}$ \\
\hline & $(0.030)$ & $(0.030)$ \\
\hline \multirow[t]{2}{*}{ Stake*T3 France } & $0.168^{* * *}$ & $0.168^{* * *}$ \\
\hline & $(0.026)$ & $(0.026)$ \\
\hline \multirow[t]{2}{*}{ Stake*T1 Japan } & $0.075^{* *}$ & $0.075^{* *}$ \\
\hline & $(0.036)$ & $(0.036)$ \\
\hline \multirow[t]{2}{*}{ Stake*T2 Japan } & $0.209^{* * *}$ & $0.207^{* * *}$ \\
\hline & $(0.030)$ & $(0.031)$ \\
\hline \multirow[t]{2}{*}{ Stake*T3 Japan } & $0.171^{* * *}$ & $0.171^{* * *}$ \\
\hline & $(0.034)$ & $(0.035)$ \\
\hline \multirow[t]{2}{*}{ Conflict*T1 France } & $-0.344^{* * *}$ & $-0.341^{* * *}$ \\
\hline & $(0.120)$ & $(0.123)$ \\
\hline \multirow[t]{2}{*}{ Conflict*T2 France } & $-0.192^{* *}$ & $-0.192^{* *}$ \\
\hline & $(0.077)$ & $(0.077)$ \\
\hline \multirow[t]{2}{*}{ Conflict*T3 France } & $-0.331^{* * *}$ & $-0.331^{* * *}$ \\
\hline & $(0.092)$ & $(0.092)$ \\
\hline \multirow[t]{2}{*}{ Conflict*T1 Japan } & -0.128 & -0.128 \\
\hline & $(0.121)$ & $(0.121)$ \\
\hline \multirow[t]{2}{*}{ Conflict*T2 Japan } & $-0.309^{* * *}$ & $-0.334^{* * *}$ \\
\hline & $(0.077)$ & $(0.076)$ \\
\hline \multirow[t]{2}{*}{ Conflict*T3 Japan } & $-0.308^{* * *}$ & $-0.342^{* * *}$ \\
\hline & $(0.088)$ & $(0.083)$ \\
\hline \multirow[t]{2}{*}{ Female } & & 0.711 \\
\hline & & $(4.050)$ \\
\hline \multirow[t]{2}{*}{ Raven's Score } & & -0.053 \\
\hline & & $(0.679)$ \\
\hline \multirow[t]{2}{*}{ Economics \& Management } & & -0.049 \\
\hline & & $(4.033)$ \\
\hline \multirow[t]{2}{*}{ Loss Aversion } & & -0.256 \\
\hline & & $(1.162)$ \\
\hline \multirow[t]{2}{*}{ Illusion of Control } & & 0.268 \\
\hline & & $(0.246)$ \\
\hline$R^{2}$ & 0.299 & 0.300 \\
\hline $\mathrm{N}$ & 2740 & 2700 \\
\hline
\end{tabular}


reliance and independence in Japan $(p<0.001$ and $p=0.060$ respectively, Wald tests based on the OLS regression of column (2) of Table A18). As for the marginal effect of degree of conflict, it is only significant for self-reliance in France and Japan $(p=0.013$ and $p<0.001$ respectively, Wald tests based on the OLS regression of column (2) of Table A18). Though it may seem surprising that the degree of conflict has no effect on the value of independence and power, it accords with the result that independence and power are not behind the IV in our setting.

Finally, gender is an important determinant of many differences in behavior, preferences, and beliefs. In our experiment, our main result that self-reliance is the only motive behind the IV, and that it is similarly valued in France and Japan, holds for both genders. The separation by gender brings, nonetheless, some interesting insights into the roots of the IV. In particular, we observe that in Japan the negative value of independence is mainly driven by male subjects, while the negative value of power is driven by female subjects. This aligns with the intuition that women are less likely to seek power. Furthermore, we observe that independence is differently valued for male subjects across countries. This brings an additional suggestion that there may exist cultural differences worth exploring on future research.

Table A19: The Effect of Gender

\begin{tabular}{cccc}
\hline \hline \multicolumn{4}{c}{ INDependence $\left(I V_{T 1}-I V_{T 3}\right)$} \\
Female & France & Japan \\
Male & -8.429 & -5.07 & $p=0.8144$ \\
$H_{0}:$ Fem = Male & 13.008 & $-16.383^{* *}$ & $p=0.012$ \\
& $p=0.0838$ & $p=0.4172$ & \\
& POWer $\left(I V_{T 3}-I V_{T 2}\right)$ & \\
France & Japan & \\
Female & 11.606 & $-16.268^{* *}$ & $p=0.0144$ \\
Male & -5.245 & -4.846 & $p=0.9751$ \\
$H_{0}:$ Fem = Male & $p=0.2005$ & $p=0.2951$ & \\
\multicolumn{4}{c}{} \\
Sem & France & Japan \\
Female & $35.235^{* * *}$ & $43.405^{* * *}$ & $p=0.2212$ \\
Male & $38.225^{* * *}$ & $38.212^{* * *}$ & $p=0.999$ \\
$H_{0}:$ Fem $=$ Male & $p=0.7675$ & $p=0.4133$ \\
\hline \hline Notes: *Significant at 10\% level, **Significant at $5 \%$ level, *** Significant at \\
$1 \%$ level, based on two-tailed Wald tests from OLS regression with clustered \\
standard errors per subject, individual controls, and interaction terms.
\end{tabular}




\section{Other Proxies of Cultural Background}

Since we are interested in the effect of the cultural background, in the main analysis we have excluded subjects that are neither born in France or in Japan and are not of French or Japanese nationality. Our results are robust to other proxies of cultural background, that either "weaken" (proxies 1,2, and 3) or "strengthen" (proxies 4 and 5) the proxy used in the main text. We test for the following proxies:

- Proxy 1: A subject is said to be French/Japanese if she/he was born in France/Japan or one of her/his parents was born in France/Japan.

- Proxy 2: A subject is said to be French/Japanese if she/he is of French/Japanese nationality.

- Proxy 3: Union of Proxy 1 and Proxy 2.

- Proxy 4: Intersection of Proxy 1 and Proxy 2.

- Proxy 5: Intersection of Proxy 1 and Proxy 2 and at least one parent was born in France/Japan.

Table A20 reports the number of subjects for the different proxies. Table A21 presents the summary of the main results in terms of sign and significance, where "Proxy 0" represents the proxy used in the main text.

Table A20: Number of Subjects per Proxy

\begin{tabular}{lccccc}
\hline \hline & \multicolumn{2}{c}{ France } & \multicolumn{2}{c}{ Japan } \\
Proxy $1 \downarrow /$ Proxy $2 \rightarrow$ & French & Not French & Proxy $1 \downarrow /$ Proxy $2 \rightarrow$ & Japanese & Not Japanese \\
French & 133 & 9 & Japanese & 130 & 4 \\
Not French & 8 & 32 & Not Japanese & 0 & 2 \\
\hline
\end{tabular}

For proxy 5 there are 121 subjects in France and 130 subjects in Japan. 
Table A21: Summary of the Results per Proxy

\begin{tabular}{|c|c|c|c|}
\hline & France & Japan & $\mathrm{FR}-\mathrm{JP}$ \\
\hline \multicolumn{4}{|c|}{ INDependence } \\
\hline Proxy 0: & 0 & $-^{*}$ & 0 \\
\hline Proxy 1: & 0 & $-{ }^{*}$ & $+^{*}$ \\
\hline Proxy 2: & 0 & $-{ }^{* *}$ & 0 \\
\hline Proxy 3: & 0 & $-^{*}$ & 0 \\
\hline Proxy 4: & 0 & $-{ }^{* *}$ & $+^{*}$ \\
\hline Proxy 5: & 0 & $-^{* *}$ & $+^{* *}$ \\
\hline \multicolumn{4}{|l|}{ POWer } \\
\hline Proxy 0: & 0 & $-^{*}$ & $+^{*}$ \\
\hline Proxy 1: & 0 & $-^{*}$ & 0 \\
\hline Proxy 2: & 0 & $-^{*}$ & $+^{*}$ \\
\hline Proxy 3: & 0 & $-^{*}$ & 0 \\
\hline Proxy 4: & 0 & $-^{*}$ & $+^{*}$ \\
\hline Proxy 5: & 0 & $-^{*}$ & $+^{*}$ \\
\hline \multicolumn{4}{|c|}{ SELF-reliance } \\
\hline Proxy 0: & $+^{* * *}$ & $+^{* * *}$ & 0 \\
\hline Proxy 1: & $+^{* * *}$ & $+^{* * *}$ & 0 \\
\hline Proxy 2: & $+^{* * *}$ & $+^{* * *}$ & 0 \\
\hline Proxy 3: & $+^{* * *}$ & $+^{* * *}$ & 0 \\
\hline Proxy 4: & $+^{* * *}$ & $+^{* * *}$ & 0 \\
\hline Proxy 5: & $+^{* * *}$ & $+^{* * *}$ & 0 \\
\hline
\end{tabular}




\section{Alternative Explanations}

In this supplementary material we discuss the robustness of the experimental design and our results to alternative explanations. First, one may wonder if the experimental design is robust to effects linked to principals' social and risk preferences. Note, however, that the indifference point between the control and the delegation lotteries is endogenously chosen based on the principals' unobserved social and risk preferences (see also Bartling et al. 2014, p. 2022). These preferences therefore enter similarly into the determination of the certainty equivalents of the two lotteries in Part 2. It follows that the measured IV, since it is based on the difference between the certainty equivalents of the two lotteries, is computed after these preferences are taken into account which cancels bias from social and risk preferences. ${ }^{37}$ This means that even though social preferences are not present in $\mathrm{T} 2$ and may be present in $\mathrm{T} 1$ and $\mathrm{T} 3$, this difference should not bias our results.

Second, one may wonder about the potential effect of principals' beliefs about the agents' or bots' behaviors. For example, the delegation mechanism in the experiment where agents choose an effort could cue principals for more familiar "real-world" setups in which principals expect their agents to shirk after delegation (see also Bartling et al. 2014, fn. 36). This could lead principals to increase the minimum effort requirements beyond their optimal indifference point to avoid that delegation occurs in T1. Another possibility would be that principals could believe that an altruistic agent would choose a higher effort level if the agent would be less constrained from the minimum effort requirement (see Falk and Kosfeld 2006). This could lead principals to decrease the minimum effort requirements below their optimal indifference point to favor altruism from agents in T1. Since these two phenomena go in opposite directions, it seems difficult to test if they are present. Nonetheless, in our data they seem to either cancel each other or not to be present. In France, the average minimum effort requirement $\underline{e}$ per treatment was 62.155 (T1), 65.171 (T2), and 64.878 (T3). We find no statistically significant difference between treatments based on an OLS regression controlling for individual characteristics (see Tables A6 and A7 in OSM III). In Japan, the average minimum effort requirement $\underline{e}$ per treatment was 53.663 (T1), 63.606 (T2), and 56.103 (T3), and we find that the value in $\mathrm{T} 2$ is statistically significantly greater than in $\mathrm{T} 1$ and $\mathrm{T} 3$ and no statistical significantly difference between $\mathrm{T} 1$ and T3 (see again Tables A6 and A7 in OSM III). Contrary to what any of these conjectures would predict, $\underline{e}$ in $\mathrm{T} 1$ was not higher (lower) than in T2 and T3 for either country.

Note, more importantly, that for any of these conjectures to be valid principals should have misunderstood the delegation mechanism. In fact, the principal (taking into account her risk and social preferences) should set the optimal choice of the minimum effort requirement $\underline{e}$ irrespective

\footnotetext{
${ }^{37}$ This is based on the weak assumptions that the principal's utility from a delegation lottery is increasing in the probability of success and that the principal weakly prefers if the agent chooses project $\mathcal{P}$ (see Bartling et al. 2014, pp. 2018-9). See also Bartling et al. (2014, p. 2022) for a discussion of the potential (but unlikely) effect of extreme forms of inequality aversion.
} 
of the agent's or bot's effort choice. Recall that there is no feedback until the end of the experiment and that delegation takes place if and only if $e \geq \underline{e}$, which means that the principal has control over the minimum effort that the agent needs to choose for her to delegate the decision right. The instructions and control questions were designed such that the logic of setting an optimal minimum effort requirement was clearly understood, and the non-significant effect of cognitive ability on the IV brings further support for the rejection of explanations based on the misunderstanding of the instructions. The measured IV should then be independent of principals' beliefs about the agents' or bots' effort choice. Similarly, though principals in Part 1 of T1 are faced with risk and uncertainty, while principals in Part 1 of T2 and T3 are faced only with risk, the independence of beliefs about the agents' and bots' effort choices indicates that this should not be an issue for our treatment comparisons.

In terms of the principals' belief about the agents' chosen project, it could, at least in principle, have an effect on our treatment comparisons. In particular, if principals believed that project $\mathcal{P}$ was chosen by agents with positive probability in $\mathrm{T} 1$, then we would underestimate the intrinsic value of decision rights in T1 with respect to T2 and T3 (see Bartling et al. 2014, pp. 2022-3 on how this could underestimate the IV in T1). In our experiment, the agents' project choices indicate that this would be a reasonable anticipation especially in France (agents chose project $\mathcal{P} 32 \%$ of games in France and $9 \%$ of games in Japan). ${ }^{38}$ If principals anticipated these probabilities correctly, we would underestimate the value of the IV and independence and the differences between France and Japan in these two measures. But if this would be the case, behaviorally it should translate into a lower $\underline{e}$ in T1 as compared to T2 and T3. However, we find no significant differences for $\underline{e}$ between treatments in France and we find that $\underline{e}$ is significantly higher in T2 than in T1 and T3 in Japan (see Table A7 in OSM III). ${ }^{39}$

An alternative explanation for the positive difference between the certainty equivalents of the delegation and the control lotteries would be a changing attitude towards risk between Part 1 and Part 2 of the experiment. Results by Abdellaoui et al. (2011) suggest that risk aversion may depend on the source of ambiguity, and Part 1 (a game) involve different sources of ambiguity than Part 2 (a lottery task) that could be behind such an effect. For example, if subjects in our experiment were risk neutral in the delegation task (Part 1) but risk averse in the lottery task (Part 2), and followed a Constant Relative Risk Aversion (CRRA) utility function [i.e., $\left.u(x)=x^{1-\rho} /(1-\rho)\right]$, then simulations indicate that the difference in certainty equivalents

\footnotetext{
${ }^{38}$ Note that we exclude from these calculations (and from any similar calculations presented below) the data from games 5 and 10, where the payoffs are the same for the two players, as well as the passive (non-incentivized) agents that participated in T3.

${ }^{39} \mathrm{~A}$ post-experimental survey answer suggests that some principals believed that the agents cared about their [the principals'] outcomes: 35\% of principals in France and 51\% of principals in Japan in T1 answered "yes" when asked if they thought "the other player cared about [their] outcomes?" In France the $\underline{e}$ is non-significantly correlated with this belief $(r=-0.069, p=0.154)$, while in Japan it is negatively significantly correlated with it $(r=-0.178, p<0.001)$. This brings further support to the claim that this belief is not driving our results in France. As for Japan, it could in principle underlie the lower $\underline{e}$ in T1 when compared to T2. However, note that such rationale fails to explain the significant difference in the $\underline{e}$ between T2 and T3 as well as the non-significant difference between $\mathrm{T} 1$ and T3.
} 
would be positive for almost all games and for any parameter $\rho>0$. However, in order to explain the average values found in our experiment, $\rho$ would need to take a value equal or higher than 2, a considerably high value when compared with the existing literature. For example, Holt and Laury (2002) found that the decisions made by a majority of subjects over paired lottery choices could be rationalized by a CRRA utility function with $\rho$ between -0.15 and 0.68 . Alternatively, if subjects evaluated lotteries based on Prelec's (1988) specification $w(p) x+(1-w(p)) y$ with $x>y>0$ of the probability weighting function $w(p)=\exp \left(-\beta(-\ln (p))^{\alpha}\right)$, we should find a mean difference in certainty equivalents of 6 points in Japan and 9.5 in France, which is well below our results. ${ }^{40}$ These estimations suggest that this effect, if present, could result in an upward bias of the IV but it could not rationalize the differences in certainty equivalents that we found. In addition, the potential change in risk attitudes across the two parts should not affect our treatment comparisons and estimations of independence and power.

Our results are also robust to alternative explanations based on loss aversion, illusion of control, and bounded rationality discussed in Bartling et al. (2014). Our regressions show that these factors have no significant impact on the IV. Our data is neither consistent with explanations based on reciprocity, preference reversals, and corner solutions (see Bartling et al. 2014 for details). If reciprocity would be behind the measured IV, the differences in the certainty equivalents between the delegation and control lotteries in Part 2 should be higher the lower the minimum effort requirement imposed by the principal in Part 1 . However, our data do not lend support to this trend. In a regression of the percentage difference in certainty equivalents on the minimum effort requirement, controlling for subject and game fixed effects, the percentage difference in the certainty equivalents increases by 3.5 percentage points per 10 point increase in the minimum effort requirement ( $p<0.001$, standard errors clustered at the subject level).

In terms of preference reversals, there exists a large literature showing that people tend to overbid a high-amount lottery in a pricing task (as is Part 2 of our experiment) while preferring a high-probability lottery in a binary choice (e.g. Lichtenstein and Slovic 1971; Grether and Plott 1979; Berg et al. 2010). If success payoffs of delegation lotteries are larger than the ones of control lotteries, subjects will give, according to this explanation, a higher certainty equivalent to delegation lotteries. We thus need to check if delegation lotteries are considered high-amount lotteries, i.e., if $P_{\mathcal{A}}$ is larger than $P_{\mathcal{P}}-C(E)$. We find that control lotteries have a smaller success payoff in $56.1 \%$ of the cases (59.3\% in France, and $52.7 \%$ in Japan), a larger one in $43.7 \%$ of the cases ( $40.6 \%$ in France, and $47 \%$ in Japan) and the payoffs are equal in $0.3 \%$ of the cases ( 2 cases in France, and 7 in Japan). Moreover, our findings indicate that control and delegation lotteries have similar probabilities. The average success probabilities are, respectively, $63.6 \%$ (65.6\% in France and $61.4 \%$ in Japan) and $59.8 \%$ (63.5\% in France and $55.8 \%$ in Japan). In $43.6 \%$ of cases

\footnotetext{
${ }^{40}$ We use L'Haridon and Vieider's (2016) estimated values of $\alpha$ and $\beta$ for French and Japanese subjects for these calculations.
} 
(43.9\% in France and $43.2 \%$ in Japan), the control lottery has a higher probability of success than the delegation lottery. On the contrary, delegation is the high-probability lottery in $36.7 \%$ of cases (39.7\% in France and $33.4 \%$ in Japan). The two lotteries have the same probability of success in $19.7 \%$ of cases (16.3\% in France and $23.4 \%$ in Japan). Taken together, these results suggest that preference reversals are not behind the IV observed in our experiment.

Finally, corner minimum effort requirements, i.e., $\underline{e}=1$ and $\underline{e}=100$, could in principle undermine the elicitation of the principals' point of indifference. However, we observe low percentages of corner solutions for $\underline{e}$. In our sample, principals selected $\underline{e}=1$ in $6.2 \%$ of cases. In total, $75.2 \%$ of subjects have never chosen $\underline{e}=1$ ( $84.5 \%$ in France, and $65.2 \%$ in Japan), $8.8 \%$ of them have chosen $\underline{e}=1$ only once ( $7 \%$ in France, and $10.6 \%$ in Japan), and $8 \%$ twice (7\% in France, and $9.1 \%$ in Japan). It turns out that $\underline{e}=100$ is chosen in $5.29 \%$ of cases, and $81.4 \%$ of subjects have never chosen $\underline{e}=100$ (83.8\% in France, and $78.8 \%$ in Japan), $6.9 \%$ of them have chosen $\underline{e}=100$ only once ( $4.2 \%$ in France, and $9.9 \%$ in Japan), and $5.5 \%$ twice ( $7 \%$ in France, and $3.8 \%$ in Japan). These findings, both for $\underline{e}=1$ and $\underline{e}=100$, are similar for all treatments. ${ }^{41}$ Given its low frequency, and in accordance with the additional control experiment ran by Bartling et al. (2014) to address this issue, we conclude that these choices do not pose a problem for the elicitation of the principals' point of indifference.

\footnotetext{
${ }^{41}$ The higher frequency is for $\mathrm{T} 1$ and $\underline{e}=1$ in Japan, in which $46.5 \%$ of subjects have never chosen $\underline{e}=1$, $18.6 \%$ of them have chosen $\underline{e}=1$ once, and $11.6 \%$ twice.
} 


\section{Instructions}

In this supplementary material we present the English version of the instructions of the experiment that were handed out to subjects in the position of principals in the three treatments, and from which the French and Japanese instructions were translated and back translated. The French and Japanese instructions, as well as the agents' instructions of Part 1 (the remaining instructions are common to principals and agents) are available from the authors upon request.

To be self-contained, we exclude repetitions of the instructions between treatments. The redcolored sentences are specific to different treatments, with [T1] indicating sentences for treatment 1, [T2] sentences for treatment 2, and [T3] sentences for treatment 3. The black-colored sentences are common to all instructions, based on treatment 1 and with the exception (not highlighted) that "Participant B" is substituted by "the bot" in treatment 2 and sometimes in treatment 3 (only in sentences where "Participant B" in the instructions refer to the one that makes decisions or is the potential holder of the decision right). The instructions in the supplementary file are organized as follows:
A. Instructions for Part 1 (Principals)
B. Instructions for Part 2 (All subjects)
C. Instructions for Illusion of Control Task (All subjects)
D. Instructions for Loss Aversion Task (All subjects)
E. Instructions for Cognitive Ability Task (All subjects)
F. Supplementary Cost Sheet (All subjects) 


\section{A. Instructions for Part 1 (Principals)}

\section{Instructions for Participant A}

Welcome to this experiment.

Please carefully read the following instructions. These will provide you with all the information needed to participate in this experiment. If you don't understand something, don't hesitate to raise your hand. We will come and answer your question where you are seated.

You will receive an initial endowment of $\mathbf{5}$ euros at the start of the experiment. You can earn an additional monetary amount during the experiment by earning points. The number of points you will earn depends on both your decisions and those of other participants.

All the points you earn during the course of this experiment will be converted to euros at the end of the experiment. The following exchange rate will be applied:

\section{0 points $=2.50$ euros}

At the end of the experiment, you will receive the money you earned during the experiment as well as the initial sum of 5 euros.

Please note that all communication is strictly forbidden during the entirety of the experiment. We also want to emphasize that you must only use the computer functions that are related to the experiment. We remain at your disposal to answer any questions you might have.

This experiment is composed of $\mathbf{4}$ parts:

1. [T1 and T3] The first part of the experiment is composed of 10 rounds. For each of these 10 rounds, you will be randomly paired with a Participant B. You will be able to implement a project with the Participant B who is randomly paired with you in each round. A detailed explanation of the first part of the experiment is found in the following pages.

1. [T2] The first part of the experiment is composed of 10 rounds. For each of these 10 rounds, you will interact with a "bot". You will be able to implement a project with the bot in each round. A detailed explanation of the first part of the experiment is found in the following pages.

2. In the second part of the experiment, you will be presented with 20 different decisions between a fixed and an unfixed amount. You will receive detailed instructions on the second part of the experiment once the first part is concluded. 
3. The third part of the experiment is very short and you will receive detailed instructions once the second part is concluded.

4. In the fourth part of the experiment, we will ask you to answer a series of questions.

\section{General Instructions for the First Part of the Experiment}

[T1 and T3] There are two types of participants in the first part of the experiment: Participant A and Participant B. You are Participant A.

There are 10 rounds. You will be paired with a different Participant B in each round. A project can be implemented in each round. If the project is a success, Participant A and B will receive positive payments. A successful implementation of the project will lead to a positive payment for participants $\mathrm{A}$ and $\mathrm{B}$.

[T2] There are 10 rounds. You will be paired with a bot for each round. A project can be implemented in each round. If the project is a success, you will receive a positive payment.

\section{The decision right}

In each round, either you or Participant B has the decision right. The participant with the decision right can make two decisions:

\section{Which project - A or B - will be implemented?}

Participant A receives a greater share of the project payment in Project A and Participant B receives a greater share of the project payment in Project B (It is possible that Participant A and Participant B receive the same share in certain rounds).

\section{What is the probability the project will be successful?}

The determination of the probability of success is connected to the costs paid by the participant who has the decision right. The higher the probability of success, the higher the costs.

[T3] Please note that if the bot has the decision right, the bot makes the decisions on behalf of Participant B. To put it another way, Participant B will not make their decisions themselves. This means that the payment of the project and the costs linked to the choice of the probability of success (a choice made by the bot) are automatically assigned to Participant B.

[T2 and T3] The manner in which the bot makes decisions is described later in the instructions. 


\section{Payment of the project}

The payments that result from the implementation of the project vary from one round to another. You will be informed of the payments at the start of each round.

Example: The payments for one project for one round. In the case that Project A is successful, you receive 200 points and Participant $B$ receives 150 points. In the case that Project $B$ is successful, Participant $B$ receives 200 points and you receive 150 points. In the event that the project fails, both participants receive 100 points each.

\begin{tabular}{|l|l|c|c|}
\hline & & Your Payment & $\begin{array}{c}\text { Payment for } \\
\text { Participant B }\end{array}$ \\
\hline \multirow{2}{*}{$\begin{array}{l}\text { In the case } \\
\text { of success }\end{array}$} & Project A & 200 & 150 \\
\cline { 2 - 4 } & Project B & 150 & 200 \\
\hline \multicolumn{2}{|l|}{ In the case of failure } & 100 & 100 \\
\hline
\end{tabular}




\section{The probability of success}

If you have the decision right, then you can determine the probability of success for the chosen project, either A or B.

\section{How is the probability of success determined?}

The probability of success is a number between 0 and 100 that can be chosen freely.

\section{$0 \leq$ probability of success $\leq 100$}

A probability of success of 0 means that the project will never be successful. A probability of success of 100 indicates that the success of the project is guaranteed. A value of 50 indicates that a project has a $50 \%$ chance of success.

\section{The cost of the choice of the probability of success}

The higher the probability of success you choose, the higher the cost. Two information sheets (one blue and one yellow) are at your desk: they both provide a table and a graph outlining the cost schedule for the different probabilities of success. Each round, you will be informed whether the cost schedule from the blue or yellow sheet will be applied. You can also always have the computer show you the costs on the monitor while choosing the probability of success.

\section{The success of the project}

At the end of the experiment, one of the 10 rounds will be randomly selected by the computer. The choices made by you and Participant B in this round will determine your payments for the first part of the experiment.

The success or failure of the project chosen by the participant with the decision right for the randomly selected round will be determined in the following manner.

[T2 and T3] The success or failure of the project chosen by the one with the decision right (either you or the bot) for the randomly selected round will be determined in the following manner.

A number between 1 and 100 will be drawn; all numbers between 1 and 100 have an equal chance of being drawn. The number that is drawn will then be compared to the probability of success that was chosen by the participant with the decision right.

If the number drawn is smaller than or equal to the probability of success that was chosen, the project is a success. If the number drawn is larger, the project is not a success. The greater the probability of success that you have chosen, the greater the chance that the 
number drawn will be smaller than your chosen probability. To put it another way, there is a greater chance your project will be successful.

\section{Examples:}

1. Example 1: You have chosen a probability of success of 15, that is to say $15 \%$.

This means:

- If the number drawn at random is between 1 and 15 (= 15 chances out of 100 ), the project is successful.

- If the number drawn is larger than 15 (= 85 chances out of 100$)$, the project is not a success.

2. Example 2: You have chosen a probability of success of $\mathbf{8 0}$, that is to say $80 \%$.

This means:

- If the number drawn at random is between 1 and 80 (= 80 chances out of 100$)$, the project is successful.

- If the number drawn is larger than 80 (= 20 chances out of 100$)$, the project is not a success.

\section{Suppose that the number chosen at random is 93.}

In this case, the project is not a success in either example (the randomly drawn number is larger than the chosen probability of success in both examples).

\section{Suppose that the number chosen at random is 54 .}

In this case, the project in Example 1 would not have been successful (the randomly drawn number is larger than 15) but the project in Example 2 would have been a success (the randomly drawn number is less than 80 ).

\section{Suppose that the number chosen at random is 3 .}

In this case, the project would have been a success in both examples (the randomly drawn number is lower than the chosen probability of success in both examples). 


\section{The income}

The incomes for Participant A and Participant B are made up of two elements:

- The payment from the chosen project in the event the project is successful. In the case the project fails, the two participants receive a lower payment that is independent of the project chosen.

- The costs linked to the chosen probability of success are deducted from the payment of the participant who has the decision right.

This results in the following four possibilities for you:

1. You have the decision right and the project is successful:

Income = Payment from the project that you chose minus the costs linked to the choice of the probability of success

2. You have the decision right and the project is a not a success:

Income = Payment in case of failure minus the costs linked to the choice of the probability of success

3. You do not have the decision right and the project is successful:

Income $=$ Payment from the project chosen by Participant B

[T2] Income = Payment from the project chosen by the bot

[T3] Income = Payment from the project that the bot chose on behalf of Participant B

4. You do not have the decision right and the project is a not a success:

Income $=$ Payment in case of failure

[T2] Please note that the bot's payments are hypothetical. Nobody in the room will receive the points earned by the bot during the first part of the experiment.

[T3] Please note that Participant B makes no decisions. Thus, they have no influence on your income. But the decisions that the bot makes in their place as well as your decisions will affect the income of Participant B. 


\section{Detailed Procedure of One Round on the Computer}

\section{[T1] $1^{\text {st }}$ Stage: Participant B's decision}

In each round, you as participant A first have the decision right. You can also opt to delegate the decision right to Participant B. Before deciding if you want to delegate the decision to Participant B, Participant B must make a definite choice of a project and a probability of success in the event that you delegate the decision right.

If you end up delegating the decision right to Participant B, then the decisions participant B makes in the first stage will be realized.

You will not yet learn which decisions participant B makes in the first stage.

[T2] $1^{\text {st }}$ Stage: Bot's decision

In each round, you as participant A first have the decision right. You can also opt to delegate the decision right to the bot. Before deciding if you want to delegate the decision to the bot, the bot must make a definite choice of a project and a probability of success in the event that you delegate the decision right.

\section{How does the bot make its decisions?}

1. The bot always chooses the project that earns itself the most points.

1. The bot chooses a probability of success between 0 and 100 at random. There is thus a $1 / 101$ chance that the bot picks a probability of success equal to 0 ; a $1 / 101$ chance that the bot picks a probability of success equal to 1; etc.; and a 1/101 chance that the bot picks a probability of success equal to 100 .

If you end up delegating the decision right to the bot, then the decisions the bot makes in the first stage will be realized.

You will not yet learn which decisions the bot makes in the first stage.

\section{[T3] $1^{\text {st }}$ Stage: Bot's decision on behalf of Participant B}

In each round, you as participant A first have the decision right. You can also opt to delegate the decision right to the bot. Before deciding if you want to delegate the decision to the bot, the bot must make a definite choice of a project and a probability of success (on behalf of Participant B) in the event that you delegate the decision right.

\section{How does the bot make its decisions?}

1. The bot always chooses the project that earns Participant B the most points.

2. The bot chooses a probability of success between 0 and 100 at random. There is thus a $1 / 101$ chance that the bot picks a probability of success equal to 0 ; a $1 / 101$ chance that 
the bot picks a probability of success equal to 1; etc.; and a 1/101 chance that the bot picks a probability of success equal to 100 .

If you end up delegating the decision right to the bot, then the decisions the bot makes in the first stage will be realized.

You will not yet learn which decisions the bot makes in the first stage.

\section{$2^{\text {nd }}$ Stage: Choice of project}

At this stage of the experiment, you have not yet made the final decision on whether or not you will delegate the decision right. For this reason, you must select the project that you would like to implement in case you opt to keep the decision right. The choice of project will be made on this type of screen:

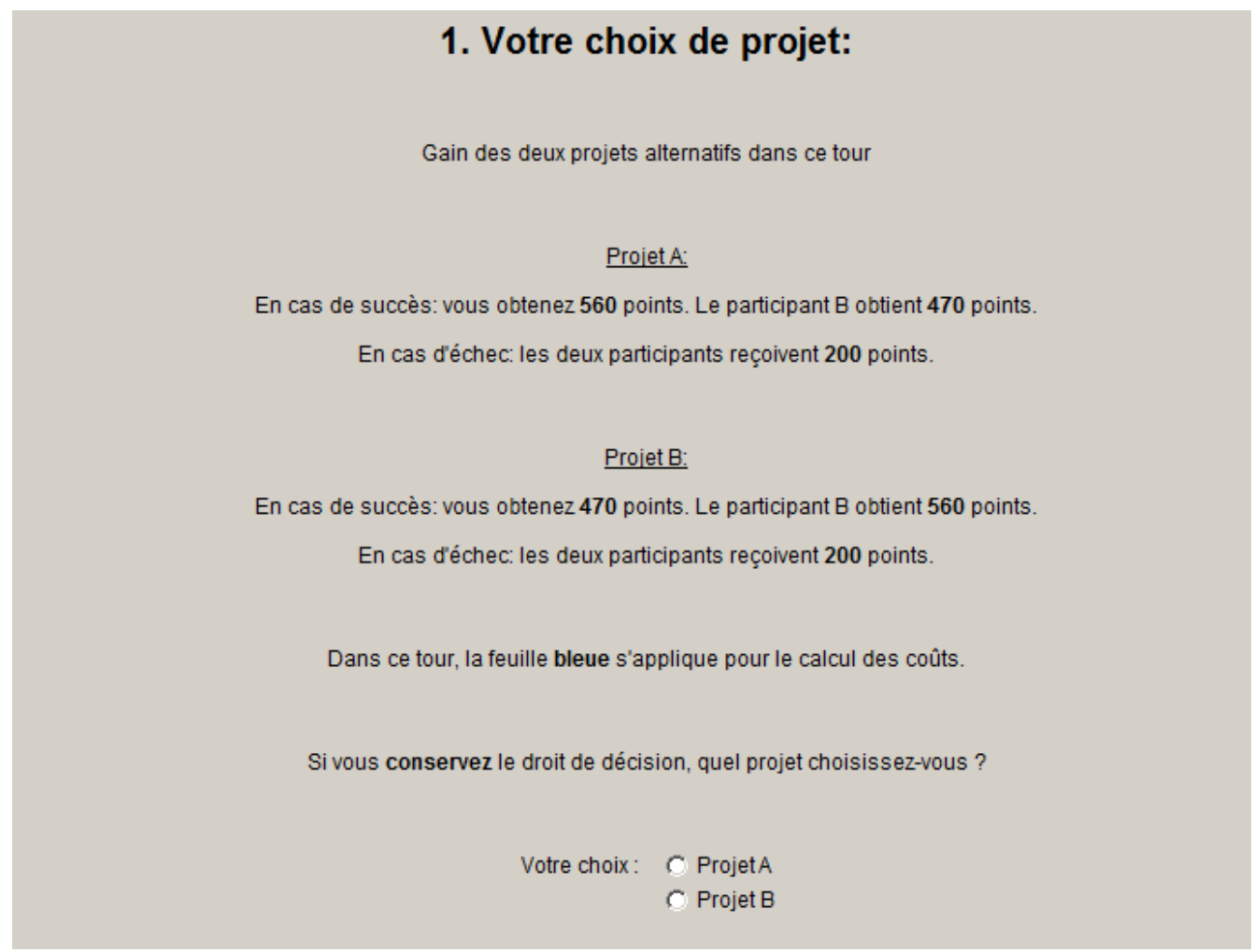

After having chosen a project, please click on the "OK" button.

\section{$3^{\text {rd }}$ Stage: Choice of probability of success}

When selecting the probability of success, you still have not made a definite choice of whether or not to delegate the decision right. After having chosen a project, you must select the probability of success for this choice in case you keep the decision right. The cost of the probability of success will only be applied if you ultimately keep the decision right. 
You make your choice of the probability of success on this type of screen:

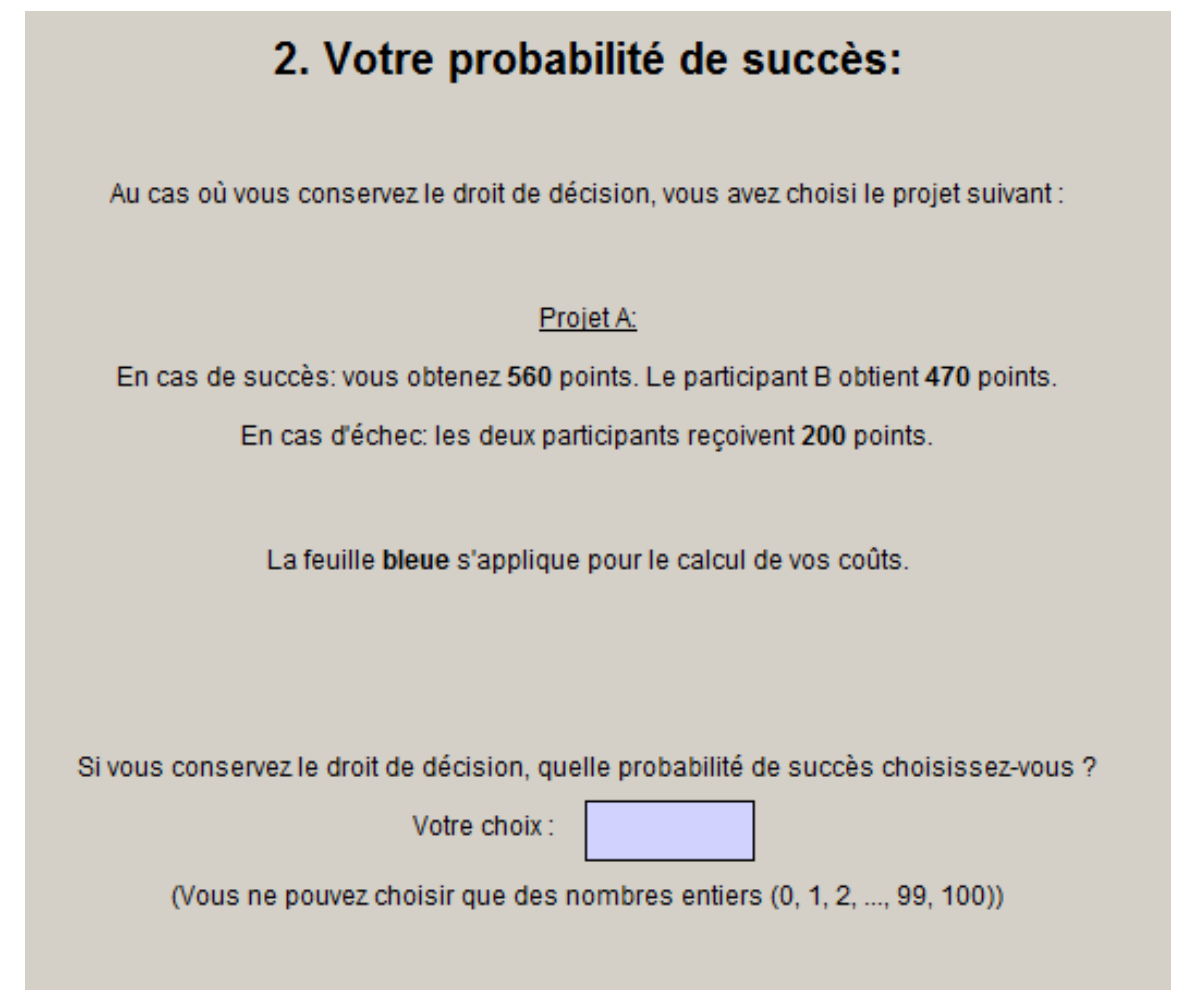

After having selected the probability of success, click on the button "Display costs". This will then show you the exact costs of the probability of success that you chose. You can modify your probability of success if you wish. By clicking on "Confirm", you make your definitive selection.

\section{$4^{\text {th }}$ Stage: Who has the decision right?}

You can decide in each round - after participant B has made his decisions - whether you would like to delegate the decision right to participant B or if he would like to retain this for yourself. In this case, you do not make the decision directly, but by determining a minimum requirement:

[T3] You can decide in each round - after the bot has made his decisions on behalf of Participant B - whether you would like to delegate the decision right to the bot or if he would like to retain this for yourself. In this case, you do not make the decision directly, but by determining a minimum requirement:

In each round, you determine the minimum probability of success that Participant B must have chosen in order for you to be willing to delegate the decision right to them. You can choose any minimum requirement between 1 and 100. 
Participant B has already chosen their probability of success at the moment when you determine a minimum requirement. Thus there is no possibility you will influence the choice made by Participant B.

Please note that you do not know the probability of success chosen by Participant B when you determine your minimum requirement.

[T3] Please also note that Participant B will make no decisions.

If the probability of success chosen by Participant $B$ is equal to or higher than the minimum requirement you have determine, you will delegate the decision right. If the probability of success chosen by Participant $B$ is lower than the minimum requirement you determine, you will keep the decision right.

The graph seen below will clarify the link between the minimum requirement you have determine, the probability of success chosen by Participant B, and the question of who will have the decision right.

If, for example, you chose a minimum requirement of 45, this means that you wish to delegate the decision right to Participant B if they have selected a probability of success of 45 or more.
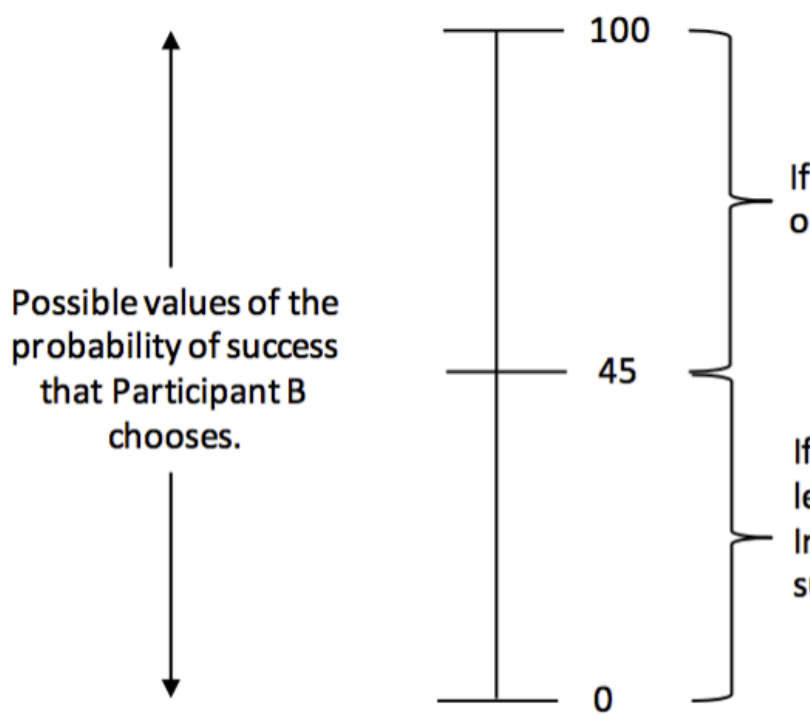

If Participant B selects a probability of success of 45 or higher, you will delegate the decision right.

If Participant B selects a probability of success of less than 45 , you will retain the decision right. In this case, you will determine the probability of success.

When considering what minimum requirement to determine, you should ask the following question:

- Do I want to delegate the decision right if Participant B selects a probability of success of 1 ? If the answer is no, you should ask the question:

- Do I want to delegate the decision right if Participant B selects a probability of success of 2? If the answer is no, you should ask the question: 
- Do I want to delegate the decision right if Participant B selects a probability of success of 3? And so on.

Do this until you reach a level of probability of success chosen by Participant B above which you would delegate the decision right. This level should be your minimum requirement.

- In the above example, the value is 45 . This means that you would just be willing to delegate the decision right if Participant B chooses a probability of success of 45 but that you would prefer retaining this right at all values of 44 or less.

\section{Other examples:}

1. You select a minimum requirement of $\mathbf{7 8 .}$

This means:

- If during Stage 1, Participant B selects a probability of success between 0 and 77, you do not delegate the decision right.

- If during Stage 1, Participant B selects a probability of success between 78 and 100 , you delegate the decision right to them.

\section{You select a minimum requirement of 4 .}

This means:

- If during Stage 1, Participant B selects a probability of success between 0 and 3, you do not delegate the decision right.

- If during Stage 1, Participant B selects a probability of success between 4 and 100 , you delegate the decision right to them.

You make your decision on the minimum requirement for participant B on a screen like the one shown below:

The upper part of the screen informs you of the payments in the two project alternatives as well as the payment in case of lack of success in the round in question. You will also be informed whether the cost schedule on the blue or yellow sheet will be applied for the round in question. You can indicate your choice of a minimum requirement for delegating the decision right in the lower part of the screen. Here is an example: 


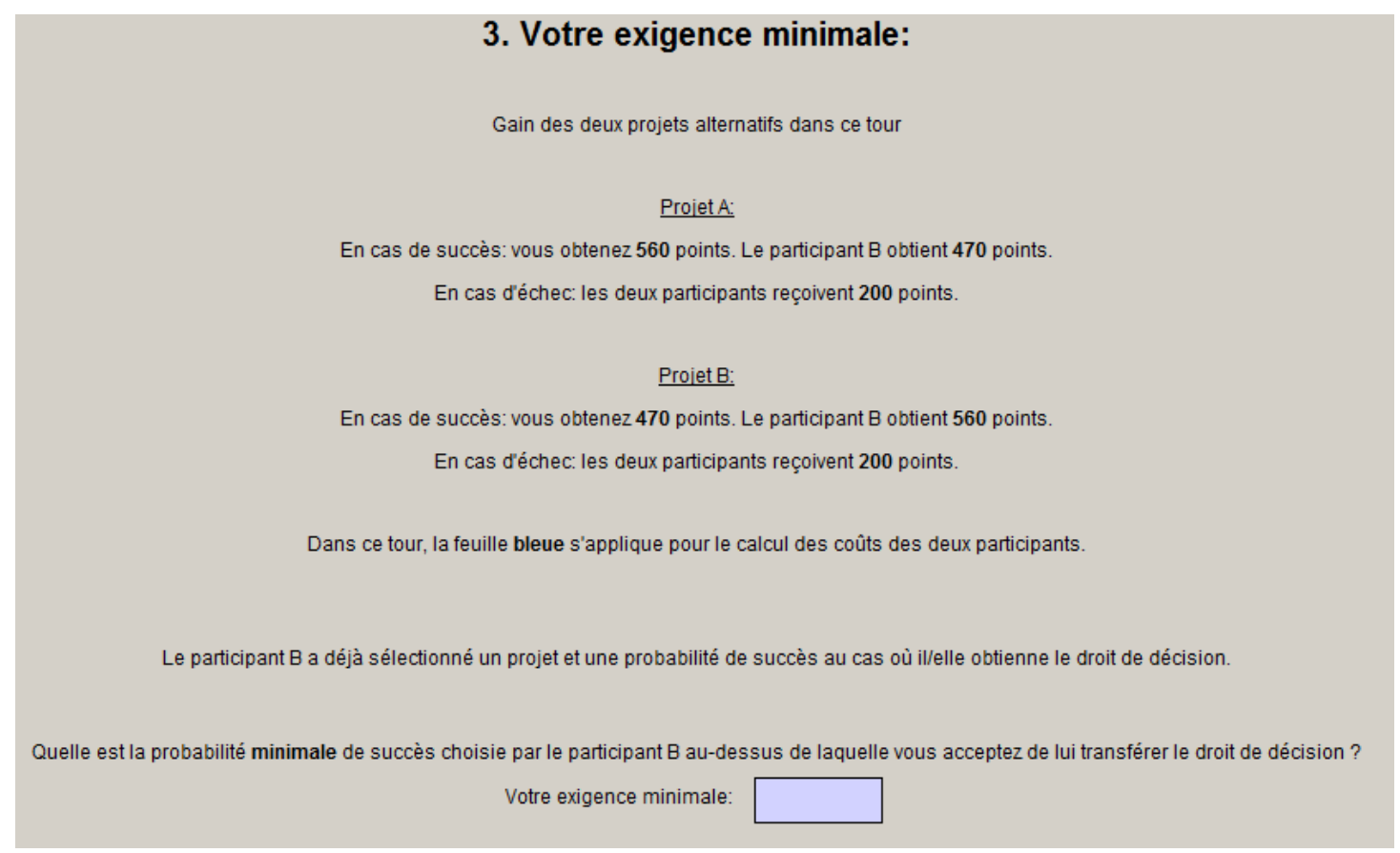

After having indicated your minimum requirement, please click on the "OK" button. A new round will then begin.

\section{How the success of the project is determined}

At the end of the experiment, the computer will randomly select one of the 10 rounds and the payments for you and Participant B for this part of the experiment will be determined on the basis of the decisions made by you and Participant B in that round. As you will not know which round will be randomly selected by the computer, you should make careful decisions every round.

a) The computer will first randomly determine which round will be selected for payment.

b) The computer then assesses whether the Participant B you had been randomly paired with for that round chose a probability of success that was at least equal to your minimum requirement.

- If the minimal requirement is lower than or equal to the probability of success chosen by Participant B, you will delegate the decision right.

- If the minimal requirement is greater than the probability of success chosen by Participant B, you will retain the decision right.

If you keep the decision right, the success of the project you chose during the randomlyselected round is determined by a pair of electronic dice that will randomly pick a number between 1 and 100. This number is then compared to the probability of success you have chosen.

More precisely, the participant who holds the decision right will see the following on their screen: 


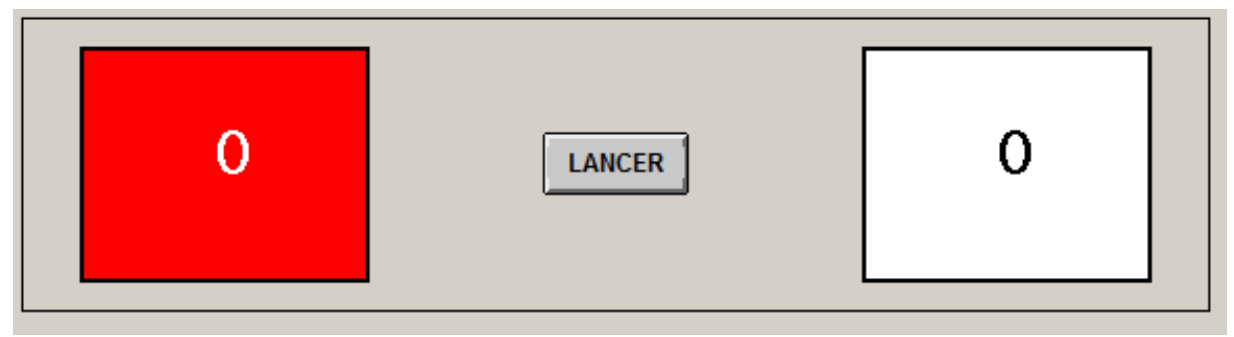

The number on the red background represents the tens column and the number on the white background represents the ones column.

Please then click on the "THROW" button. You will see numbers on the dice change quickly in a random manner. You can stop the numbers by clicking on the button "STOP".

As you will see, the numbers change too quickly to be able to choose which numbers to stop on.

After having clicked on "STOP", the two numbers that appear on the screen will give you a number between 1 and 100 (two zeroes represent 100).

If the number is less than or equal to the probability of success chosen by the participant who had the decision right, the project is then a success. On the contrary, if the number is greater than the probability of success chosen by the participant who had the decision right, the project is then a failure.

[T2 and T3] If you did not have the decision right, a number between 1 and 100 will be chosen at random by the computer. If this number is less than or equal to the probability of success chosen by the bot at random, the project is then a success. On the contrary, if the number is greater than the probability of success chosen by the bot, the project is then a failure. 


\section{Summary of the First Part of the Experiment}

These are the stages of one round:

$1^{\text {st }}$ Stage: Participant B chooses a project and a probability of success in the event that you delegate the decision right to them.

$2^{\text {nd }}$ Stage: You choose a project in the event you keep the decision right.

$3^{\text {rd }}$ Stage: You choose a probability of success in the event you keep the decision right.

$4^{\text {rd }}$ Stage: You choose the minimum requirement for the probability of success for the project that Participant B must choose in order for you to agree to delegate the decision right to them.

At the end of the experiment, one of the 10 rounds will be drawn at random. The decisions that you and Participant B made during that round will determine the monetary income for the first part of the experiment. This will be added to your initial payment of 5 euros and the payments you obtain in the rest of the experiment.

Do you have any questions regarding this experiment? Please raise you hand if you have one. We will come answer you where you are seated.

You will find questions to test your understanding of the experiment on the following pages. 


\section{Comprehension Questions}

Please answer the following comprehension questions. Please signal the experiment supervisor if you have any questions.

1. Consider the case where you have selected a minimum requirement of 85 .

a) If Participant B selected a probability of success of 80 , who has the decision right in this round? ......

b) If Participant B selected a probability of success of 90, who has the decision right in this round? ......

2. Consider the case where you have selected a minimum requirement of 55 .

a) If Participant B selected a probability of success of 50, who has the decision right in this round? ......

b) If Participant B selected a probability of success of 60, who has the decision right in this round? ......

3. Consider the case where Participant B chose a probability of success of 3 .

a) If you chose a minimum requirement of 1 , who has the decision right in this round?

b) What is the probability that the project will be successful? ......

c) If you chose a minimum requirement of 4 , who has the decision right in this round?

d) What is the probability that the project will be a successful? ......

4. Consider the case where Participant B chose a probability of success of 90.

a) If you chose a minimum requirement of 85 , who has the decision right in this round? ......

b) What is the probability that the project will be successful? ......

c) If you chose a minimum requirement of 95 , who has the decision right in this round? ......

d) What is the probability that the project will be successful? ...... 
5. Consider the case where you keep the decision right and you have chosen a probability of success of 54 . The cost schedule from the yellow information sheet applies in this round. Assume further that you obtain 8 as your number on the red background and 2 as your number on the white background.

a) What are your costs? ......

b) Will the project be successful? ......

The following payments are applied for this project:

\begin{tabular}{|l|l|c|c|}
\hline & & Your Payment & $\begin{array}{c}\text { Payment for } \\
\text { Participant B }\end{array}$ \\
\hline \multirow{2}{*}{$\begin{array}{l}\text { In case of } \\
\text { success }\end{array}$} & Project A & 200 & 150 \\
\cline { 2 - 4 } & Project B & 150 & 200 \\
\hline \multicolumn{2}{|l|}{ In case of failure } & 100 & 100 \\
\hline
\end{tabular}

Consider the case that you have chosen Project A.

c) What will be your payment? ......

d) What will be the payment for Participant B?

Now consider the case where you have chosen a probability of success of 24 . Also, you now have the number 1 on the red background and the number 5 on the white background. The cost schedule from the yellow paper is applied for this round. You have again chosen Project A.

e) What are your costs? ......

f) Will the project be successful? ......

g) What will be your payment? ......

h) What will be the payment for Participant B? ......

6. Consider the case where you have delegated the decision right. Participant B selected Project B and chose a probability of success of 48. The cost schedule from the blue paper is applied for this round. 
The following payments are applicable to the project:

\begin{tabular}{|l|l|c|c|}
\hline & & Your Payment & $\begin{array}{c}\text { Payment for } \\
\text { Participant B }\end{array}$ \\
\hline \multirow{2}{*}{$\begin{array}{l}\text { In case of } \\
\text { success }\end{array}$} & Project A & 180 & 150 \\
\cline { 2 - 4 } & Project B & 150 & 180 \\
\hline \multicolumn{2}{|l|}{ In case of failure } & 100 & 100 \\
\hline
\end{tabular}

Consider the case where Participant B obtains the number 5 on the red background and the number 7 on the white background.

a) Will the project be successful? ......

b) What will your payment be? ......

c) What will be the payment of Participant B? ......

Consider the case where Participant B obtains the number 3 on the red background and the number 9 on the white background.

d) Will the project be successful? ......

e) What will your payment be? ......

f) What will be the payment of Participant B? ...... 


\section{Comprehension Questions: Answers}

Please answer the following comprehension questions. Please signal the manager of the experiment if you have any questions.

1. Consider the case where you have selected a minimum requirement of 85.

a) If Participant B selected a probability of success of 80 , who has the decision right in this round? $\underline{\text { You }}$

b) If Participant B selected a probability of success of 90, who has the decision right in this round? Participant $\mathrm{B}$

2. Consider the case where you have selected a minimum requirement of 55 .

a) If Participant B selected a probability of success of 50, who has the decision right in this round? You

b) If Participant B selected a probability of success of 60 , who has the decision right in this round? Participant B

3. Consider the case where Participant B chose a probability of success of 3.

a) If you chose a minimum requirement of 1 , who has the decision right in this round? Participant B

b) What is the probability that the project will be successful? $\underline{\mathbf{3 \%}}$

c) If you chose a minimum requirement of 4, who has the decision right in this round? You

d) What is the probability that the project will be a success? According to your choice

4. Consider the case where Participant B chose a probability of success of 90.

a) If you chose a minimum requirement of 85 , who has the decision right in this round? Participant B

b) What is the probability that the project will be successful? $\underline{\mathbf{9 0 \%}}$

c) If you chose a minimum requirement of 95 , who has the decision right in this round? $\underline{\text { You }}$ 
d) What is the probability that the project will be successful? According to your choice

5. Consider the case where you keep the decision right and you have chosen a probability of success of 54. The cost schedule from the yellow information sheet applies in this round. Assume further that you obtain 8 as your number on the red background and 2 as your number on the white background.

a) What are your costs? $\underline{29.2 \text { points }}$

b) Will the project be successful? No

The following payments are applied for this project:

\begin{tabular}{|l|l|c|c|}
\hline & & Your Payment & $\begin{array}{c}\text { Payment for } \\
\text { Participant B }\end{array}$ \\
\hline \multirow{2}{*}{$\begin{array}{l}\text { In case of } \\
\text { success }\end{array}$} & Project A & 200 & 150 \\
\cline { 2 - 4 } & Project B & 150 & 200 \\
\hline \multicolumn{2}{|l|}{ In case of failure } & 100 & 100 \\
\hline
\end{tabular}

Consider the case that you have chosen Project A.

c) What will be your payment? $\underline{100-29.2=70.8}$

d) What will be the payment for Participant B? $\underline{\mathbf{1 0 0}}$

Now consider the case where you have chosen a probability of success of 24 . Also, you now have the number 1 on the red background and the number 5 on the white background. The cost schedule from the yellow paper is applied for this round.

You have again chosen Project A.

e) What are your costs? $\underline{\mathbf{5 . 8}}$

f) Will the project be successful? $\underline{\text { Yes }}$

g) What will be your payment? $\underline{200-5.8=194.2}$

h) What will be the payment for Participant B? $\underline{\mathbf{1 5 0}}$

6. Consider the case where you have delegated the decision right. Participant B selected Project B and chose a probability of success of 48. The cost schedule from the blue paper is applied for this round. 
The following payments are applicable to the project:

\begin{tabular}{|l|l|c|c|}
\hline & & Your Payment & $\begin{array}{c}\text { Payment for } \\
\text { Participant B }\end{array}$ \\
\hline \multirow{2}{*}{$\begin{array}{l}\text { In case of } \\
\text { success }\end{array}$} & Project A & 180 & 150 \\
\cline { 2 - 4 } & Project B & 150 & 180 \\
\hline \multicolumn{2}{|l|}{ In case of failure } & 100 & 100 \\
\hline
\end{tabular}

Consider the case where Participant B obtains the number 5 on the red background and the number 7 on the white background.

a) Will the project be successful? No

b) What will your payment be? $\underline{\mathbf{1 0 0}}$

c) What will be the payment of Participant B? $\underline{\mathbf{1 0 0}-\mathbf{4 6 . 1}=\mathbf{5 3 . 9}}$

Consider the case where Participant B obtains the number 3 on the red background and the number 9 on the white background.

d) Will the project be successful? Yes

e) What will your payment be? $\underline{\mathbf{1 5 0}}$

f) What will be the payment of Participant B? $\underline{\mathbf{1 8 0}-\mathbf{4 6 . 1}=133.9}$ 


\section{B. Instructions for Part 2 (All subjects)}

\section{Second Part of the Experiment}

The second part of the experiment is made up of 20 rounds. You will be randomly paired with another participant for every round. The exchange rate of 2.50 euros for 100 points is still applicable.

In each round, you must choose between a guaranteed payment and an uncertain payment. Your choice will also affect the payment of the other participant with whom you have been randomly paired.

Here's an example:

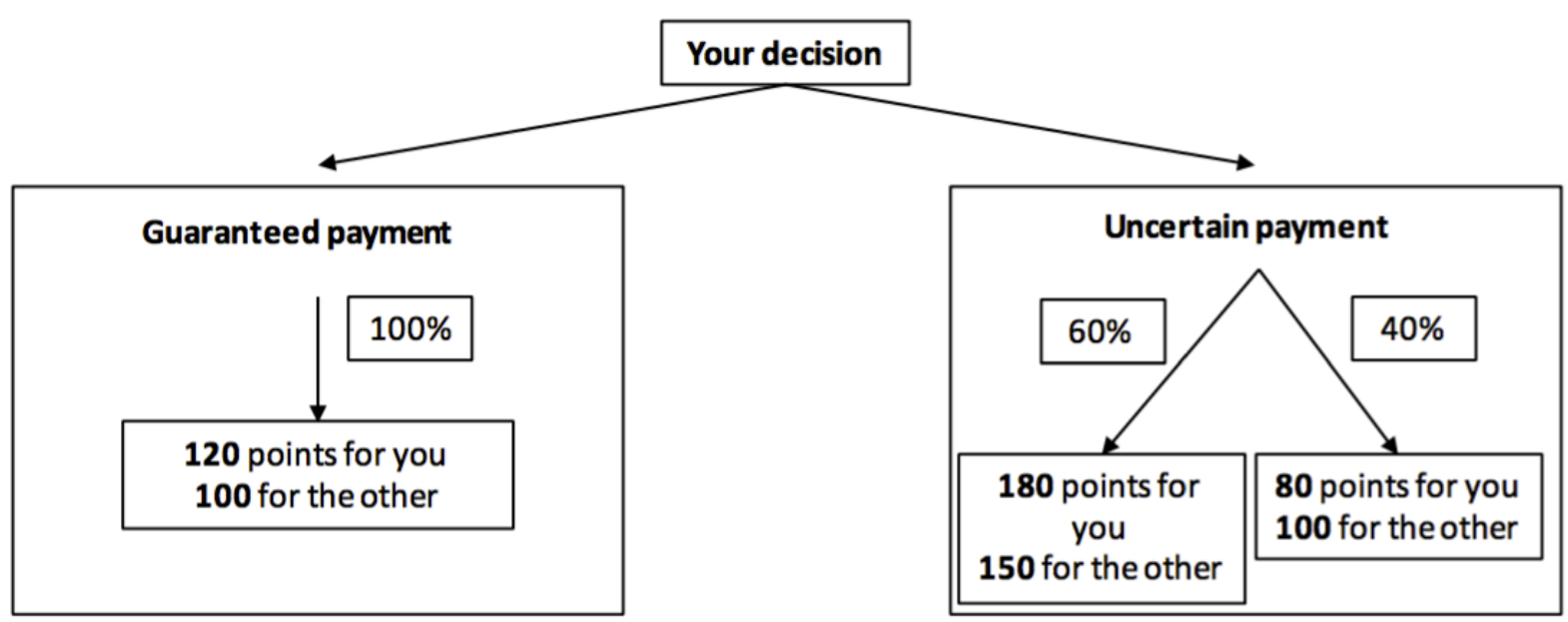

If, in the example above, you decide for the guaranteed payment, you will receive 120 points and the participant you have been randomly associated will receive 100 points.

If you opt for the uncertain payment, there is a $60 \%$ probability that you will receive 180 points and the other participant will receive 150 points. There is a $40 \%$ probability you will receive 80 points and the other participant will receive 100 points.

In each of the 20 rounds, you choose between a guaranteed payment and an uncertain payment. The amount of the payments and the probabilities change each round. 
How do you choose between guaranteed payment and uncertain payment in each round?

When you make your choice between the guaranteed payment and the uncertain payment, you don't yet know the amount of the guaranteed payment. Thus, you can't directly choose between the guaranteed payment and the uncertain payment. Instead, you must indicate the minimum payment for which you prefer to choose the guaranteed payment than the uncertain payment.

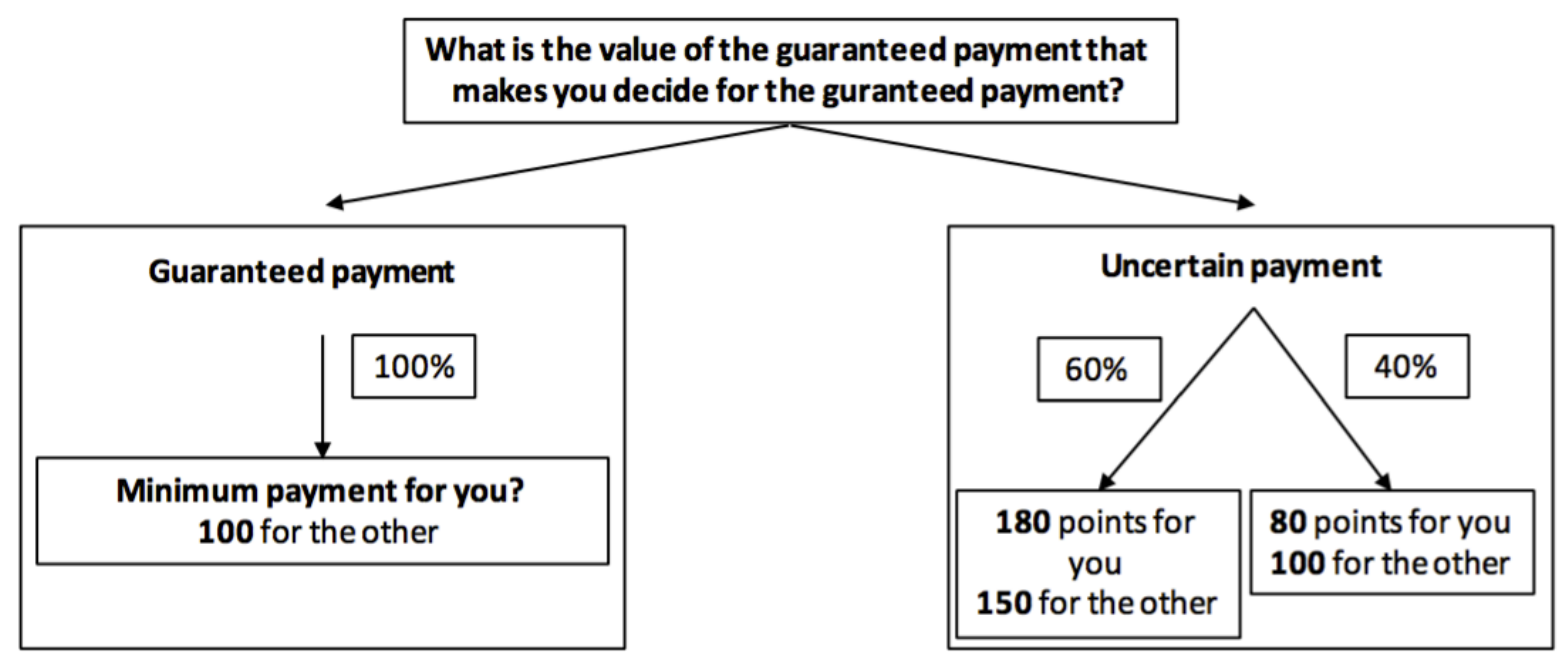

In each round, you will be informed of the guaranteed payment for the other participant, the uncertain payment available to you and the other participant, and the probabilities associated with the uncertain payment in each round.

After having indicated the minimum payment that would make you choose the guaranteed payment in a round, you will be informed of your actual guaranteed payment for that round. The choice between the guaranteed payment and the uncertain payment is made in the following manner:

- If the guaranteed payment is less than the minimum payment that you have chosen, the uncertain payment determines your income and that of the other participant.

- If the guaranteed payment is equal to or greater than the minimum payment you have chosen, you will receive the actual guaranteed payment and the other participant will receive the guaranteed payment shown on the screen (100 points in the above example).

The possible values of your guaranteed payment lie between both of your uncertain payments (in the above example, between 80 and 180 points). Every amount in this range $(80,81, \ldots$, 180 ) is possible and has the same probability of occurring. The minimum guaranteed payment you choose can be any integer value between the two possibilities for your uncertain payment. 
The following graph clarifies the relationship between the minimum payment you choose, the amount of the actual guaranteed payment, and your choice between the guaranteed payment and the uncertain payment.

If, for example, you choose a minimum payment of 127, this means that you prefer any guaranteed payment between 127 and 180 points to the uncertain payment.

You will only learn the exact value of your actual guaranteed payment after you have chosen your minimum payment.

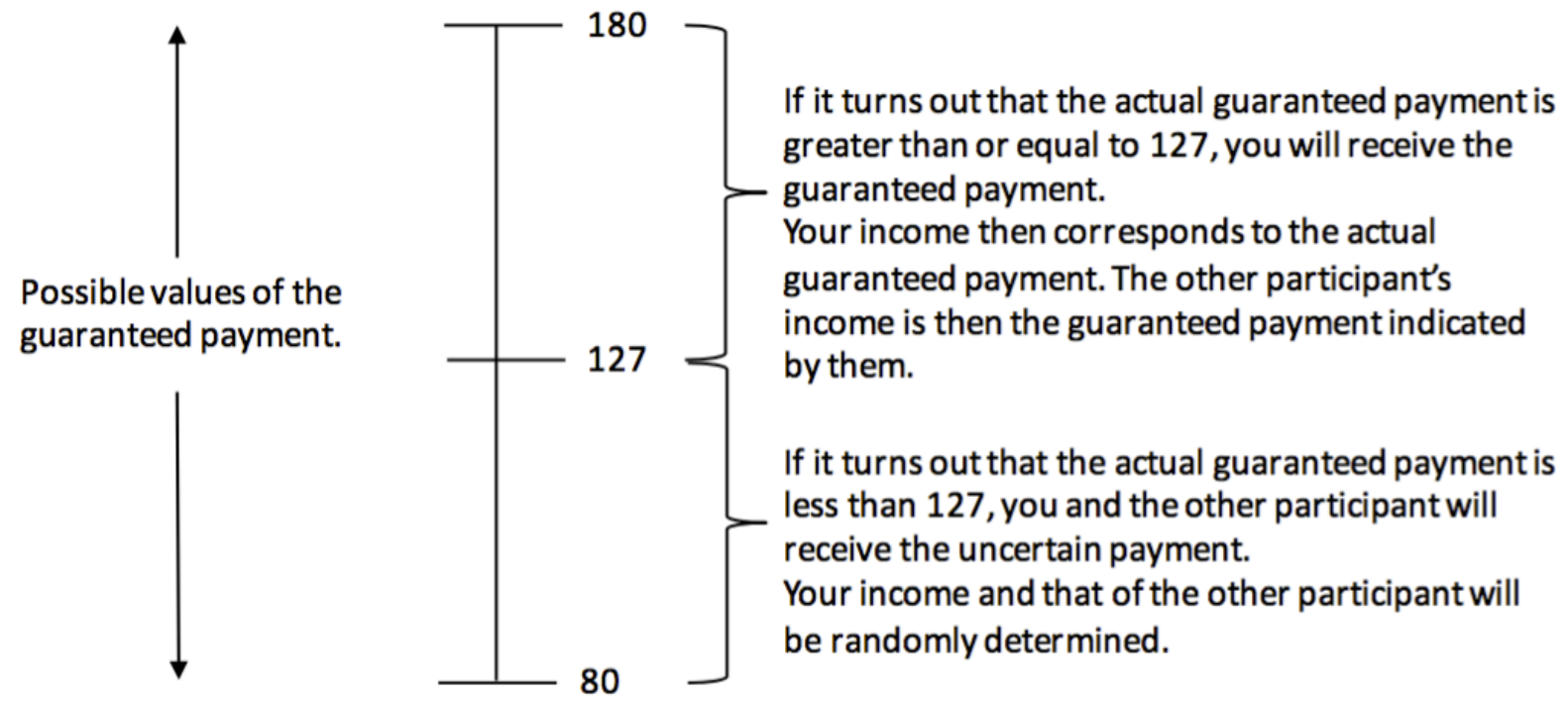

When you consider your minimum payment, then you should (assuming the numbers from the example above) ask the following questions:

- Would I prefer a guaranteed payment of 180 points to the uncertain payment? If yes, you then should ask:

- Would I prefer a guaranteed payment of 179 points to the uncertain payment? If yes, you then should ask:

- Would I prefer a guaranteed payment of 178 points to the uncertain payment? Etc.

Continue until you reach a value for the guaranteed payment where you just prefer the guaranteed payment to the uncertain payment. You should then choose this value as your minimum payment.

In the above example, this value is 127 . This means you have a slight preference for the guaranteed payment of 127 over the uncertain payment but you prefer the uncertain payment over the guaranteed payment of 126 (or any guaranteed payment less than 126). 
The income:

If the actual guaranteed payment is at least as high as the minimum payment you selected:

You will receive the actual guaranteed payment.

The other participant will receive the guaranteed payment assigned for them.

If the actual guaranteed payment is less than the minimum payment you selected:

One of the two possible uncertain payments will be selected randomly according to the indicated probabilities.

At the end of the experiment, the computer will pick 2 of the 20 rounds at random.

For each of the randomly selected rounds, the minimum payment you have chosen will be compared to the actual guaranteed payment. If the actual guaranteed payment is equal to or greater than the minimum payment you have chosen, you will receive the guaranteed payment. If the actual guaranteed payment is less than the minimum payment you have chosen, a random draw will determine which of the uncertain payments you and the other participant each receive.

As you don't know which rounds will be randomly drawn by the computer, it is in your interest to make careful decisions every round. 


\section{Procedure on the Computer}

For each round, you will choose the guaranteed payment that you must receive as a minimum in order to make you prefer the guaranteed payment over the uncertain payment. This decision will be made each round on this type of screen:

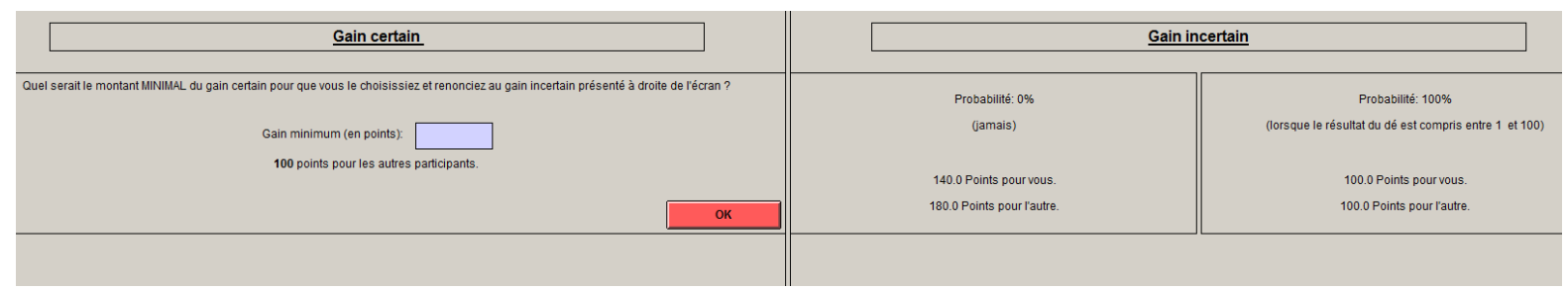

On the right of the screen you can see the possible values for your uncertain payments and the uncertain payments for the other participant who has been paired with you in a random manner. You will also see the probability of receiving each of the possible payments. This information changes for each of the 20 rounds.

You indicate the minimum payment on the left of the screen. This minimum payment indicates what value the guaranteed payment must be for you to prefer the guaranteed payment to the uncertain payment. Once you have entered your choice, please click on the "OK" button. You can modify the number you enter up until the point you click on the "OK" button.

At the end of the experiment, two rounds will be drawn randomly. If the actual guaranteed payment is less than the minimum payment you have chosen in one of these two rounds, a number between 1 and 100 will be selected randomly by a pair of electronic dice. More precisely, you will see the following image on your screen:

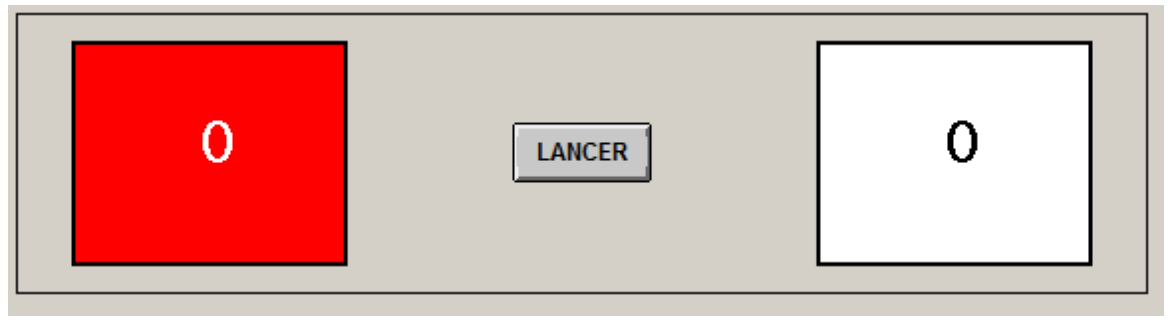

The number on the red background represents tens and the number on the white background represents ones (two zeros indicate 100).

Please then click on the "THROW" button. You will see numbers on the dice change quickly in a random manner. You can stop the numbers by clicking on the "STOP" button.

As you will see, the numbers change too quickly to be able to choose which numbers to stop on.

After having clicked on "STOP", the two numbers that appear on the screen will give you a number between 1 and 100 (two zeros represent 100). 
The number on the screen will then determine which of the uncertain payments you and the other participant (who you have been randomly paired with for this part of the experiment) will receive.

For example, consider the scenario with the following uncertain payments:

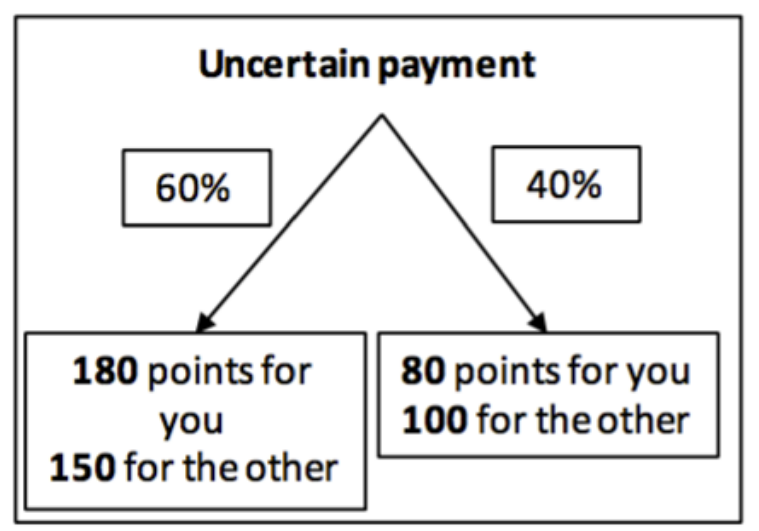

If you ended up with an uncertain payment rather than a guaranteed payment, a number between 1 and 100 will be selected at random using the electronic dice.

- If the number is between 1 and 60, then you will receive 180 points and the other participant will receive 150 points.

- If the number is between 61 and 100, then you will receive 80 points and the other participant will receive 100 points.

Do you have any questions regarding the second part of the experiment? If so, please raise your hand. We will come to your seat to give you an answer.

You will find questions to test your understanding of the experiment on the following pages. 


\section{Comprehension Questions}

Consider a scenario with the following sums and probabilities:
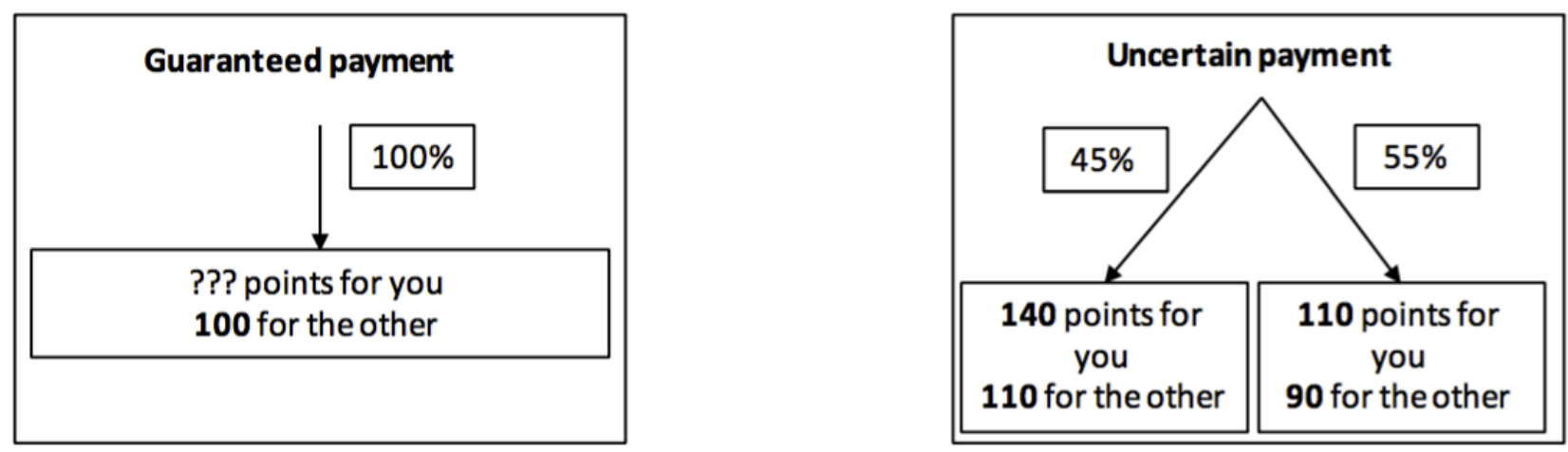

1. In the case that you chose a minimum payment of 120:

(b) If the actual guaranteed payment is 128 :

What will your payment be for this round? ......

What will the payment be for the other participant in this round? ......

(b) If the actual guaranteed payment is 117:

What will your payment be for this round?

What will the payment be for the other participant in this round? ......

2. In the case that you chose a minimum payment of 135:

(a) In the case the actual guaranteed payment is 128:

What will your payment be for this round? ......

What will the payment be for the other participant in this round? ......

(b) In the case the actual guaranteed payment is 113:

What will your payment be for this round? ......

What will the payment be for the other participant in this round?

3. In the case that you chose a minimum payment of 115:

(a) In the case the actual guaranteed payment is 128:

What will your payment be for this round? ......

What will the payment be for the other participant in this round?......

(b) In the case the actual guaranteed payment is 135:

What will your payment be for this round? ......

What will the payment be for the other participant in this round?......

If you have a question, please raise your hand. We will come answer you where you are seated. 


\section{Comprehension Questions: Answers}

Consider a scenario with the following sums and probabilities:
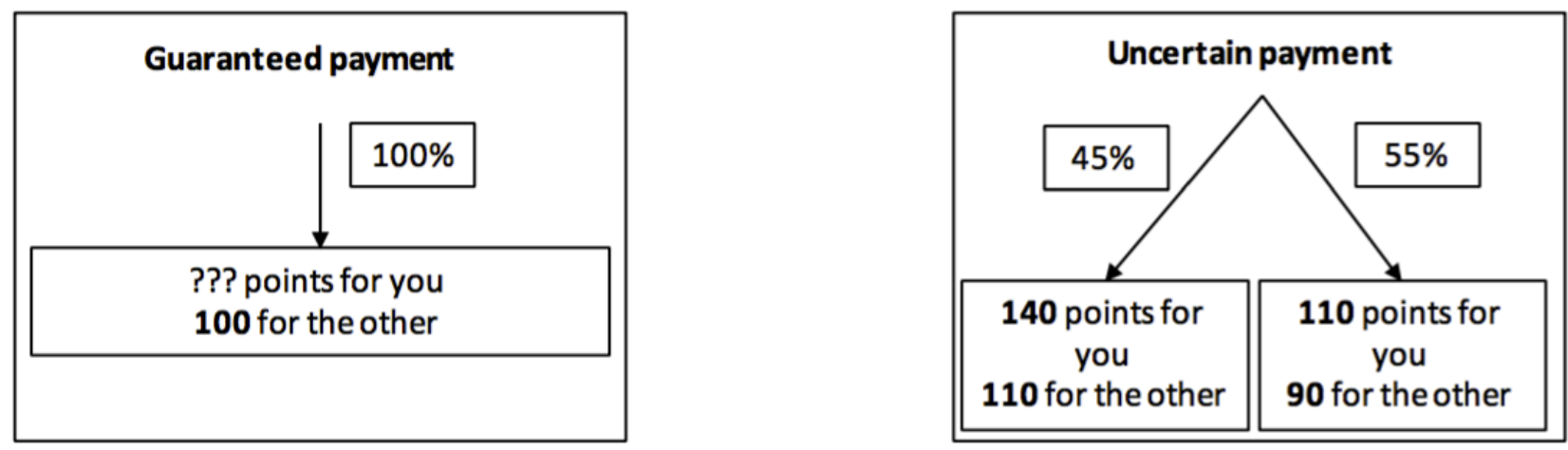

A. In the case that you chose a minimum payment of 120:

(b) In the case the actual guaranteed payment is 128:

What will your payment be for this round? $\underline{\mathbf{1 2 8}}$

What will the payment be for the other participant in this round? $\underline{\mathbf{1 0 0}}$

(b) In the case the actual guaranteed payment is 117:

What will your payment be for this round? 140 or 110

What will the payment be for the other participant in this round? 110 or 90

B. In the case that you chose a minimum payment of 135 :

(a) In the case the actual guaranteed payment is 128 :

What will your payment be for this round? 140 or 110

What will the payment be for the other participant in this round? 110 or $\mathbf{9 0}$

(b) In the case the actual guaranteed payment is 113:

What will your payment be for this round? 140 or 110

What will the payment be for the other participant in this round? 110 or $\mathbf{9 0}$

C. In the case that you chose a minimum payment of 115:

(a) In the case the actual guaranteed payment is 128:

What will your payment be for this round? $\underline{\mathbf{1 2 8}}$

What will the payment be for the other participant in this round? $\underline{\mathbf{1 0 0}}$.

(b) In the case the actual guaranteed payment is 135:

What will your payment be for this round? 135

What will the payment be for the other participant in this round? $\underline{\mathbf{1 0 0}}$

If you have a question, please raise your hand. We will come answer you where you are seated. 


\section{Instructions for Illusion of Control Task (All subjects)}

\section{Additional Information}

The computer will select a round at random to use as the basis to calculate your payments for the first part of the experiment. If you have the right to decide for the chosen round, you will be able to stop the electronic dice yourself.

We would like to know how important it is to you to be able to stop the electronic dice yourself and not leave it to the computer to stop them. (It's just a matter of stopping the dice and not the possibility of selecting the probability of success or the project).

Thus, you will receive 30 new points. You can use a part or the totality of these points to purchase the right "to stop the electronic dice yourself". If you don't purchase this right, the dice are stopped in a random manner by the computer. If you do purchase this right, you will do the stopping yourself.

We are asking the following question:

Do you wish to pay to have the ability to stop the electronic dice yourself ?

If you click on "Yes", we will ask you to then indicate the maximum number of points you are ready to pay to have the ability to stop the electronic dice yourself (in the event that you have the right to decide).

When you are answering this question, have in mind the following process: you can purchase the right to stop the electronic dice yourself by indicating your maximum willingness to pay for this right - this must lie between 1 and 30. Then, a price between 1 and 30 will be drawn at random. If the price is less than or equal to your willingness to pay, you will pay the price and stop the electronic dice yourself. If the price is greater, you keep the 30 points and the electronic dice are stopped randomly. With this procedure, it is best to honestly indicate how much you value the right to stop the electronic dice.

Example 1: You are willing to pay a maximum of 5 points to have the ability to stop the electronic dice yourself (your readiness to pay is 5 points). The price that is randomly drawn is 18 points. As your readiness to pay is less than the price, you don't pay the price. You keep the whole 30 points and the electronic dice are stopped randomly.

Example 2: You are prepared to pay a maximum of 25 points to have the ability to stop the electronic dice yourself (your readiness to pay is 25 points). The price that is randomly drawn is 7 points. As your readiness to pay is greater than the price, you pay the price of 7 points. You keep 23 of the 30 points and stop the electronic dice yourself.

If you are ready to pay for the ability to stop the electronic dice, we ask that you indicate your exact readiness to pay.

At this moment in the experiment, you do not yet know which rounds will be drawn at random by the computer.

If you delegated the right to decide or did not have the right to decide in the round that was drawn randomly, you will not pay for the right to stop the electronic dice. 
As well, if you chose the guaranteed payment in the two rounds drawn randomly from the second part of the experiment, you will not pay for the right to stop the electronic dice.

Please raise your hand if you have any questions about these instructions. We will come answer you at your seat. If not, click on the "CONTINUE" button. 


\section{Instructions for Loss Aversion Task (All subjects)}

You now have the possibility to play in a series of lotteries. The potential earnings will be added to your total income, the potential losses will be subtracted from your total income.

You will soon be presented with a series of lottery decisions. For each lottery, please decide whether you accept or reject this lottery. At the end, one of the lotteries will be chosen at random.

If you accepted that lottery, a random process will determine whether you have won or lost the lottery.

If you rejected the lottery, nothing will happen and your total income will remain unchanged.

For each of the following lotteries, please choose whether to accept or reject the lottery:

1. With a probability of 50\%, you win 5 euros; with a probability of $50 \%$, you lose 1 euro.

2. With a probability of $50 \%$, you win 5 euros; with a probability of $50 \%$, you lose 2 euros.

3. With a probability of $50 \%$, you win 5 euros; with a probability of $50 \%$, you lose 3 euros.

4. With a probability of $50 \%$, you win 5 euros; with a probability of $50 \%$, you lose 4 euros.

5. With a probability of $50 \%$, you win 5 euros; with a probability of $50 \%$, you lose 5 euros.

6. With a probability of $50 \%$, you win 5 euros; with a probability of $50 \%$, you lose 6 euros. 


\section{E. Instructions for Cognitive Ability Task (All subjects) \\ (Raven's Progressive Matrices Test) \\ Information regarding the fourth part of the experiment}

Please answer this last questionnaire, following the next instructions:

1. For each question, choose, among the 8 options shown on the bottom of the screen, the image most adapted to fill the black space in the picture above. In order to register your choice, click on the corresponding number in the right part of the screen, then click on the "OK" button.

2. There are 16 questions in total. Try to answer correctly to the most possible questions within a time limit of 10 minutes.

3. If you wish to reach one question directly, you can enter its number (1-16) and click on the "Go" button on the left part of the screen.

4. You can equally go to the preceding (next) question by clicking on the "Preceding" ("Next") buttons on the left low corner of the screen. 


\section{F. Supplementary Cost Sheet (All subjects)}

(The figure and the table display all possible effort levels and their associated costs. This was distributed to all subjects to aid the determination of the intended effort level in Part 1 of the experiment. This is the "yellow" sheet with the cost parameter $\mathrm{k}=0.01$.

The "blue" sheet was equivalent with the respective costs with $\mathrm{k}=0.02$ )

Supplementary sheet with cost schedule YELLOW SHEET

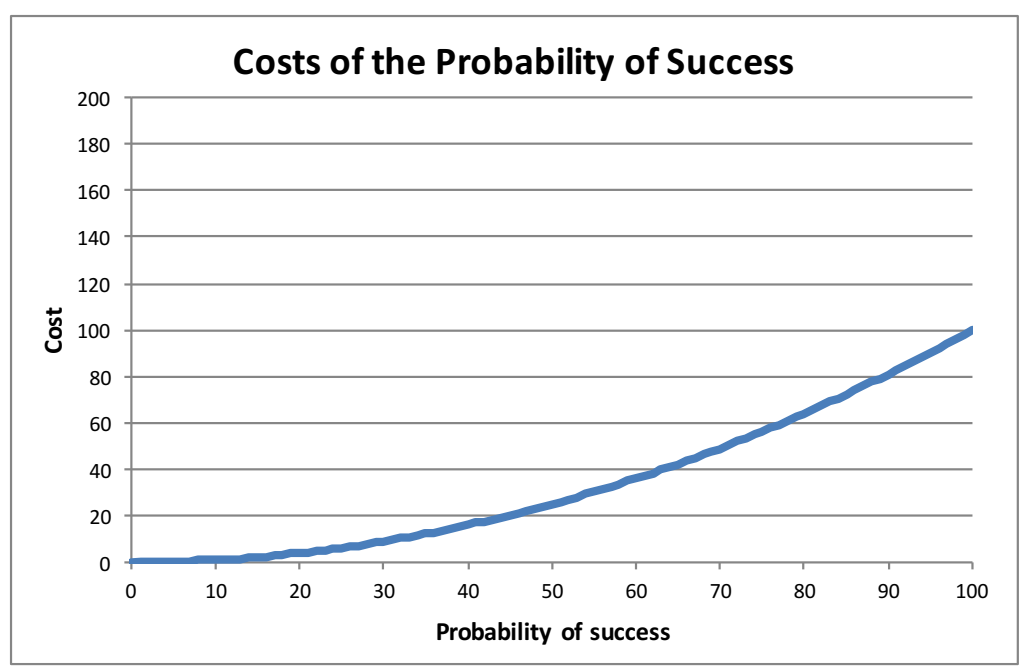

\begin{tabular}{|c|c|}
\hline $\begin{array}{l}\text { Probability } \\
\text { of Success }\end{array}$ & Cost \\
\hline 0 & 0 \\
\hline 1 & 0,1 \\
\hline 2 & 0,2 \\
\hline 3 & 0,3 \\
\hline 4 & 0,4 \\
\hline 5 & 0,5 \\
\hline 6 & 0,6 \\
\hline 7 & 0,7 \\
\hline 8 & 0,8 \\
\hline 9 & 0,9 \\
\hline 10 & 1 \\
\hline 11 & 1,3 \\
\hline 12 & 1,5 \\
\hline 13 & 1,7 \\
\hline 14 & 2 \\
\hline 15 & 2,3 \\
\hline 16 & 2,6 \\
\hline 17 & 2,9 \\
\hline 18 & 3,3 \\
\hline 19 & 3,7 \\
\hline 20 & 4 \\
\hline 21 & 4,5 \\
\hline 22 & 4,9 \\
\hline 23 & 5,3 \\
\hline 24 & 5,8 \\
\hline 25 & 6,3 \\
\hline
\end{tabular}

\begin{tabular}{|c|c|}
\hline $\begin{array}{l}\text { Probability } \\
\text { of Success }\end{array}$ & Cost \\
\hline 26 & 6,8 \\
\hline 27 & 7,3 \\
\hline 28 & 7,9 \\
\hline 29 & 8,5 \\
\hline 30 & 9 \\
\hline 31 & 9,7 \\
\hline 32 & 10,3 \\
\hline 33 & 10,9 \\
\hline 34 & 11,6 \\
\hline 35 & 12,3 \\
\hline 36 & 13 \\
\hline 37 & 13,7 \\
\hline 38 & 14,5 \\
\hline 39 & 15,3 \\
\hline 40 & 16 \\
\hline 41 & 16,9 \\
\hline 42 & 17,7 \\
\hline 43 & 18,5 \\
\hline 44 & 19,4 \\
\hline 45 & 20,3 \\
\hline 46 & 21,2 \\
\hline 47 & 22,1 \\
\hline 48 & 23,1 \\
\hline 49 & 24,1 \\
\hline 50 & 25 \\
\hline
\end{tabular}

\begin{tabular}{|c|c|}
\hline $\begin{array}{l}\text { Probability } \\
\text { of Success }\end{array}$ & Cost \\
\hline 51 & 26,1 \\
\hline 52 & 27,1 \\
\hline 53 & 28,1 \\
\hline 54 & 29,2 \\
\hline 55 & 30,3 \\
\hline 56 & 31,4 \\
\hline 57 & 32,5 \\
\hline 58 & 33,7 \\
\hline 59 & 34,9 \\
\hline 60 & 36 \\
\hline 61 & 37,3 \\
\hline 62 & 38,5 \\
\hline 63 & 39,7 \\
\hline 64 & 41 \\
\hline 65 & 42,3 \\
\hline 66 & 43,6 \\
\hline 67 & 44,9 \\
\hline 68 & 46,3 \\
\hline 69 & 47,7 \\
\hline 70 & 49 \\
\hline 71 & 50,5 \\
\hline 72 & 51,9 \\
\hline 73 & 53,3 \\
\hline 74 & 54,8 \\
\hline 75 & 56,3 \\
\hline
\end{tabular}

\begin{tabular}{|c|c|}
\hline $\begin{array}{r}\text { Probability } \\
\text { of Success }\end{array}$ & Cost \\
\hline 76 & 57,8 \\
\hline 77 & 59,3 \\
\hline 78 & 60,9 \\
\hline 79 & 62,5 \\
\hline 80 & 64 \\
\hline 81 & 65,7 \\
\hline 82 & 67,3 \\
\hline 83 & 68,9 \\
\hline 84 & 70,6 \\
\hline 85 & 72,3 \\
\hline 86 & 74 \\
\hline 87 & 75,7 \\
\hline 88 & 77,5 \\
\hline 89 & 79,3 \\
\hline 90 & 81 \\
\hline 91 & 82,9 \\
\hline 92 & 84,7 \\
\hline 93 & 86,5 \\
\hline 94 & 88,4 \\
\hline 95 & 90,3 \\
\hline 96 & 92,2 \\
\hline 97 & 94,1 \\
\hline 98 & 96,1 \\
\hline 99 & 98,1 \\
\hline 100 & 100 \\
\hline
\end{tabular}

